Illinois State University

ISU ReD: Research and eData

Theses and Dissertations

3-20-2021

\title{
Turning The Page: Using Foucauldian Rhetorical Criticism To Evaluate Literacy Center Communication
}

Sarah Monsma

Illinois State University, inkandletters9@gmail.com

Follow this and additional works at: https://ir.library.illinoisstate.edu/etd

Part of the Communication Commons

\section{Recommended Citation}

Monsma, Sarah, "Turning The Page: Using Foucauldian Rhetorical Criticism To Evaluate Literacy Center Communication" (2021). Theses and Dissertations. 1394.

https://ir.library.illinoisstate.edu/etd/1394

This Thesis is brought to you for free and open access by ISU ReD: Research and eData. It has been accepted for inclusion in Theses and Dissertations by an authorized administrator of ISU ReD: Research and eData. For more information, please contact ISUReD@ilstu.edu. 


\section{TURNING THE PAGE: USING FOUCAULDIAN RHETORICAL CRITICISM TO EVALUATE LITERACY CENTER COMMUNICATION}

\section{SARAH M. MONSMA}

\section{Pages}

Literacy, or the ability to read at or above a determined level, is an important and necessary skill. Many adult education programs exist to provide adults with specific educational resources. Literacy centers and programs contribute a vital resource to their respective communities, in helping adults who struggle with reading obtain their goals. In this thesis, I focused on the one such organization in particular, the Literacy Center of West Michigan. This organization utilizes regularly updated forms of online communication, including a News \& Blog site on its website with 165 articles pertaining to the experiences of learners, background of staff and volunteers, events, and other information necessary for understanding how these organizations communicate with their intended audiences. Using Michel Foucault as a theoretical orientation, in addition to principles drawn from literacy research and Foucauldian public relations, I conducted a rhetorical criticism of the center's online News \& Blog. This rhetorical criticism aims to fill a gap in the literature assessing literacy center communication, with the ultimate goal of improving such efforts. My analysis evaluates the effectiveness of News \& Blog, while detailing how this case is emblematic of the episteme of adult literacy center communication.

KEYWORDS: literacy, adult literacy centers, Foucauldian public relations 


\title{
TURNING THE PAGE: USING FOUCAULDIAN RHETORICAL CRITICISM TO EVALUATE LITERACY CENTER COMMUNICATION
}

\author{
SARAH M. MONSMA
}

\author{
A Thesis Submitted in Partial \\ Fulfillment of the Requirements \\ for the Degree of \\ MASTER OF SCIENCE \\ School of Communication \\ ILLINOIS STATE UNIVERSITY
}


(C) 2021 Sarah M. Monsma 


\title{
TURNING THE PAGE: USING FOUCAULDIAN RHETORICAL CRITICISM TO EVALUATE LITERACY CENTER COMMUNICATION
}

\author{
SARAH M. MONSMA
}

COMMITTEE MEMBERS:

Pete Smudde, Chair

Phil Chidester

Mary Beth Deline 


\section{ACKNOWLEDGMENTS}

First, I want to thank my chair, Dr. Smudde, for his dedication, guidance, and support. Thank you so much for your help, time, feedback, brainstorming sessions, and pushing me to be a better writer. I am grateful for Dr. Chidester and Dr. Deline for their insights and ideas that helped me navigate this process.

Next, I want to express my sincere gratitude for my parents, Michael and Sieglinde Aten. I would not have achieved this milestone without your support. I am incredibly grateful to have such amazing parents who always supported me and shaped me into the person I am today. I always felt like you both were right alongside me the entire time I was at Illinois State. I have such fond memories showing you around campus. Showing Mom the classroom I taught in and her pretending to be one of my students is a particular favorite of mine. This is as much my achievement as it is yours. Vielen Dank.

To my husband, Jon, thank you for believing in me, supporting me, and never failing to make me laugh. There's no way I could have done this without you.

Far too many amazing people at ISU have inspired me to work hard, get through this program, or provided motivation, to list, but I will do my best: Anjali Patel, Kelly Murphy, Sarah Engstrom, Becky Fletcher, MJ Mason, Maddi Loiselle, Jenny Stewart, Beverly Beyer and everyone at the Stevenson Center (would not have gotten here without you), Courtney Cox. Thank you Hannah and Kim for being such sweet and supportive family members.

S. M. M. 


\section{CONTENTS}

Page

ACKNOWLEDGMENTS

TABLES

CHAPTER I: INTRODUCTION 1

CHAPTER II: LITERATURE REVIEW 26

$\begin{array}{ll}\text { Literacy } & 6\end{array}$

History of Adult Education in the U.S. 6

$\begin{array}{ll}\text { What Literacy Is } & 10\end{array}$

Definitions of Literacy 11

$\begin{array}{ll}\text { Literacy in Practice } & 14\end{array}$

$\begin{array}{ll}\text { Immigrants and Literacy } & 17\end{array}$

$\begin{array}{ll}\text { The Role of Literacy in Forming Identity } & 19\end{array}$

$\begin{array}{ll}\text { Why Literacy Matters } & 20\end{array}$

$\begin{array}{ll}\text { Literacy Centers and Programs } & 21\end{array}$

$\begin{array}{ll}\text { Impact on Learners } & 21\end{array}$

$\begin{array}{ll}\text { Literacy Providers and Teachers } & 24\end{array}$

$\begin{array}{ll}\text { International Literacy Efforts } & 26\end{array}$

$\begin{array}{ll}\text { Measuring Effectiveness of Literacy Programs } & 27\end{array}$

$\begin{array}{ll}\text { Promoting Literacy Centers } & 29\end{array}$

Nonprofit Organizations $\quad 31$

$\begin{array}{ll}\text { Message-Design } & 33\end{array}$

Public Relations Discourse and Power 36 
$\begin{array}{ll}\text { Conclusion } & 40\end{array}$

CHAPTER III: METHODOLOGY

$\begin{array}{ll}\text { Rhetorical Criticism } & 41\end{array}$

Description $\quad 43$

$\begin{array}{ll}\text { Interpretation } & 44\end{array}$

$\begin{array}{ll}\text { Evaluation } & 45\end{array}$

Foucauldian Rhetorical Criticism $\quad 46$

Foucauldian View of Discourse and Discursive Formations 46

$\begin{array}{ll}\text { Power/Knowledge } & 48\end{array}$

$\begin{array}{ll}\text { Case Example } & 50\end{array}$

Literacy Center of West Michigan $\quad 51$

$\begin{array}{ll}\text { Texts } & 52\end{array}$

Methodological Unity $\quad 54$

$\begin{array}{ll}\text { Conclusion } & 55\end{array}$

CHAPTER IV: ANALYSIS OF THE CASE

$\begin{array}{ll}\text { Description } & 56\end{array}$

$\begin{array}{ll}\text { Overview of the Case } & 57\end{array}$

Collection of the Case's Texts $\quad 58$

$\begin{array}{ll}\text { Description Summary } & 67\end{array}$

$\begin{array}{ll}\text { Interpretation } & 67\end{array}$

$\begin{array}{ll}\text { Foucauldian Power/Knowledge } & 68\end{array}$

$\begin{array}{ll}\text { Literacy Communication } & 75\end{array}$

Foucauldian Public Relations $\quad 84$ 
$\begin{array}{ll}\text { Interpretation Summary } & 92\end{array}$

$\begin{array}{ll}\text { Evaluation } & 93\end{array}$

$\begin{array}{ll}\text { Foucauldian Power/Knowledge } & 95\end{array}$

$\begin{array}{ll}\text { Literacy } & 97\end{array}$

$\begin{array}{lr}\text { Foucauldian Public Relations } & 100\end{array}$

$\begin{array}{ll}\text { Evaluation Summary } & 103\end{array}$

$\begin{array}{ll}\text { Conclusion } & 104\end{array}$

$\begin{array}{ll}\text { CHAPTER V: CONCLUSION } & 107\end{array}$

Overview and Key Findings 107

$\begin{array}{ll}\text { Suggestions } & 111\end{array}$

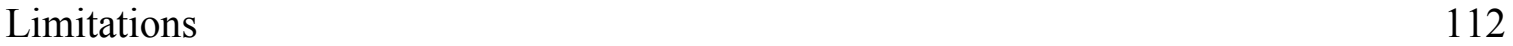

$\begin{array}{ll}\text { Future Research } & 114\end{array}$

$\begin{array}{ll}\text { Importance } & 115\end{array}$

$\begin{array}{ll}\text { REFERENCES } & 117\end{array}$

APPENDIX A: LEARNER STORIES 130

APPENDIX B: ADVOCATE SPOTLIGHTS 134

$\begin{array}{ll}\text { APPENDIX C: TUTORS } & 137\end{array}$

$\begin{array}{ll}\text { APPENDIX D: COMMUNITY } & 140\end{array}$

APPENDIX E: UNCATEGORIZED 142 


\section{TABLES}

Table $\quad$ Page

1. Number of Articles in News \& Blog 53

2. Criteria for Effectiveness 94 


\section{CHAPTER I: INTRODUCTION}

Literacy is often associated with opportunity (Neuman, Caperelli, \& Kee, 1998) and literacy programs and centers offer resources to improve this necessary skill. A significant portion of adults in the U.S. struggle with literacy (Kirsch, Jungeblut, Jenkins, \& Kolstad, 2002), indicating a need to examine literacy-based organizations and programs. Research into literacy center communication benefits the longevity of such organizations, and by extension, the literacy services provided. These programs and organizations assist diverse populations that struggle with literacy, and this thesis seeks to investigate one specific literacy center's communicative patterns as a case example. Two exclusively national surveys, conducted in 1992 and 2003, provide a foundation for understanding adult literacy rates in the U.S. and are frequently cited in literature pertaining to literacy. International surveys including the U.S. supply up-to-date numbers on adult literacy rates from the past decade. The National Adult Literacy Survey (NALS) conducted in 1992 provides a comprehensive report of adult literacy in the U.S. In-depth interviews with a sample population of 26,000 resulted in a thorough picture of literacy skills across five levels: Level 1 represents the lowest literacy capabilities and Level 5 the highest (Kirsch, et al., 2002). Literacy is a complicated issue and cannot be reduced to labeling individuals as either literate or illiterate, "thereby treating literacy as a condition that individuals do or do not have" (Kirsch et al., 2002, p. xv).

The 1992 NALS found that between 40 to 44 million adults in the U.S. fall within Level 1, or have the lowest literacy levels. Even within this category, there is variation. Some participants could find a meeting location on document, while many did not possess the literacy skills needed to complete that function; "some had such limited skills that they were unable to respond to much of the survey" (Kirsch, et al., 2002, p. xvi). The NALS notes important aspects 
of their findings. U.S. adults born in the country tended to perform better than immigrants. Higher levels of education were connected with higher levels of literacy. Those with high literacy skills "were more likely to be employed, work more weeks in a year, and earn higher wages than individuals demonstrating lower proficiencies" (Kirsch, et al., 2002, p. xix). International surveys that include the U.S. provide more up-to-date data on adult literacy rates. Estimations from the 2012, 2014, and 2017 Program for the International Assessment of Adult Competencies (PIACC) run by the Organisation for Economic Co-operation and Development (OECD) reveal that 52 million U.S. adults have low literacy skills (National Center for Education Statistics, n.d.). The literature review will go in-depth into available data on adult literacy rates in the U.S., as well as how literacy can be defined. The above findings present reasons to be concerned about the prospects of adults in the U.S. who possess rudimentary literacy skills, "not only to preserve our economic vitality but also to ensure that every individual has a full range of opportunities for personal fulfillment and participation in society" (Kirsch et al., 2002, p. xii). This thesis seeks to better understand literacy organizations to address this problem.

There are a wide variety of adult literacy programs and centers that exist in the U.S., which are a subset of adult education programs, and provide instruction, classes, and similar services with the overall goal of improving literacy skills. This thesis seeks to fill a gap in the literature addressing the difficulty in literacy organizations using written materials to connect with an audience already struggling with literacy. Past research explored low-literate audiences from a healthcare perspective, offering practical suggestions in the construction of patient materials (Aldridge, 2004; C. Doak, L. Doak, \& Root, 1996). However, little research has 
examined current literacy center communication practices and the research done has indicated their ineffectiveness (Jae, 2014).

In Michigan, eight percent of the 7,629,134 residents do not possess basic prose literacy skills (National Center for Education Statistics, 2003). In comparison to other states, 10 states have lower rates of illiteracy, while 36 states and D.C. have higher rates of illiteracy, and three states have the same rate (National Center for Education Statistics, 2003). Thus, Michigan, while still having a sizable portion of adults struggling with literacy skills, nationally has lower rates of illiteracy than the majority of states. While rates of literacy are due to a myriad of factors and are impossible to pinpoint to a single cause, this suggests that adult literacy services in the state are considerable but have ample room to grow. The Literacy Center of West Michigan, located in Grand Rapids, like many such centers, provides a local area with one-on-one adult tutoring, English classes, family literacy services, and business and workplace services. In this case, this center serves the Grand Rapids area of Michigan, which includes surrounding communities in western Michigan. The center is particularly special and worthy of study due to the thorough News \& Blog section on its website with 165 categorized articles published between June 5, 2015 and the cut-off date I selected, January 29, 2021. These articles cover the perspective of learners, tutors, donors, and community-members. Some of the articles are written by learners themselves. In this center, as in others, the center itself represents literacy and demonstrates its role in learners' acquisition of literacy skills that matter in learners' lives. Other Michigan-based adult literacy programs and centers I have encountered have more rudimentary websites providing necessary information to connect tutors and learners, but convey little else, particularly in terms of what improved literacy skills enable individuals to do. Because of the Literacy Center of West 
Michigan's substantial collection of articles, research into this organization can be used to inform similar organizations' efforts to construct public relations materials.

The central idea for this thesis is that, although literacy centers engage in very pragmatic messaging approaches, those centers must engage in greater analysis of and planning for their messages' rhetorical dynamics about themselves and literacy or risk losing support and clients. Accordingly, this thesis examines the messages and digital and online/website communication channels that are used to promote the center through rhetorical criticism. Literacy encompasses people's needs to learn to read and perform similar skills. Literacy also concerns people who have never learned to read to those who are immigrants with established careers in their home country. Literacy learners' backgrounds can be diverse (e.g., in age, gender, race, ethnicity, immigration status, prior literacy skill, career), so this research will shed light on these areas of relevant experience, especially immigrants. The analysis will not be restricted to immigrant learner experiences, however, but will also draw on native English-speaking learners and tutors' experiences.

Because this project's focus is particular texts and their effectiveness, rhetorical criticism will be the dominant methodological and analytical approach. In particular, I aim to gain a deeper understanding about literacy conceptualization in the Center's News \& Blog, by using Michel Foucault's perspective of power/knowledge. Given that the News \& Blog so thoroughly addresses a multitude of audiences that are essential for the success of the organization, this rhetorical-analytical project will serve a practical purpose. Since literacy skills are important to functioning in twenty-first century life, the research presented in this thesis is significant in improving literacy center communications. This problem intersects with public relations, because literacy centers must create and share promotional and communicative materials to their 
audiences. Using Foucauldian rhetorical criticism to examine the center's News \& Blog as a case example, this research yields insights into literacy conceptualization that can be used by literacy organizations as they seek to engage with diverse audiences ranging from clients to donors. 


\section{CHAPTER II: LITERATURE REVIEW}

This literature review brings together several distinct areas of research relevant to this thesis. First, I examine literacy from different perspectives, ranging from the history of adult education in the U.S. to identifying a concise definition of the term, while presenting research on how literacy relates to identity. Then research on literacy centers and programs is provided, including the role of public relations for those centers and nonprofit organizations. This literature review draws its overall argument from these research areas to assert that it is necessary to fill a gap in the communication literature assessing the effectiveness of literacy center public relations, which is essential to both securing support for them so they continue operating and providing services to the people who need them. Having highlighted the crucial nature of literacy skills and the current lack of research, particularly recent literature, on these programs from a communication perspective, this literature review establishes the importance of this research.

\section{Literacy}

Adult education has a long history and notable moments, such as the passing of the 1964 Economic Opportunity Act, which recognized illiteracy as a significant issue that warranted federal funding to support the importance of adult education programs (Department of Education, 2013; Eyre, 2013). As national and international surveys indicate, tens of millions of adults in the U.S. struggle to read, and further research shows the detrimental impact this has on people's lives. Literacy is a term associated with varied connotations, as the ability to read is situationally positioned differently in people's lives.

\section{History of Adult Education in the U.S.}

Adult literacy centers and programs falls under the larger conceptual umbrella of adult basic education $(\mathrm{ABE})$, which provides adults with fundamental learning opportunities for living 
and prospering in society. Pinpointing a precise definition to adult basic education is difficult, as programs tend to be varied in the services offered, overall purpose and mission, and clients (Merriam \& Brockett, 2007; Department of Education, 2013). Indeed, the unique aspect of learners having divergent backgrounds and experiences "is the most significant distinguishing characteristic of ABE classes” (Mezirow, Darkenwald, \& Knox, 1975, p. 11). Adult education programs "are systemic, organized events intended to bring about learning" (Merriam \& Brockett, 2007, p. 6). The Michigan Department of Labor and Economic Opportunity (n.d.) identifies over 100 adult education programs in Michigan, which is the state relevant to the research in this thesis, categorized to include specific goals, but all seek to educate adult learners at little to no cost. Adult basic education programs address rudimentary literacy and numbers skills, which adult secondary education programs target learners who want to obtain high school equivalency education (Department of Labor and Economic Opportunity, n.d.). English as a Second Language, Integrated English Literacy, and Civics Education programs are designed for learners to strengthen English language proficiency. Integrated education and training, in addition to workplace literacy programs, focus on necessary skills in a particular work environment. Family literacy programs improve parent literacy "to support their children's learning needs and to help improve the family's economic situation" (Department of Labor and Economic Opportunity, n.d., para. 15). While there may be different variations of adult education programs, they share the common goal of providing targeted instruction for adults.

Adult education programs have a long and diverse history in the U.S. Since its inception, the U.S. has seen different versions of these programs, which sought to improve the lives of adults (Eyre, 2013). A lack of consensus over what constituted basic education contributed to problems in locating adult education programs throughout history (Department of Education, 
2013). Adult education programs running in the 1700s and beyond are supported by state histories (Department of Education, 2013). Job growth and immigration in the beginning of the 1900s resulted in evening adult English language classes to assist with cultural assimilation. Conceptualized as "night schools" for a time, adult basic education programs vastly changed in the 1960s as the government expanded adult education (Department of Education, 2013; Eyre, 2013). Greater funding and attention to the problem in the 1960 s was due in part to a recession and a burgeoning desire to stem inequality in all forms as the civil rights movement grew (Department of Education, 2013).

President Johnson signed the Economic Opportunity Act of 1964 (Eyre, 2013), which impacted the course of adult basic education. Considered a consequential moment in federal involvement in adult basic education, the Economic Opportunity Act exemplified President Johnson's desire to end poverty (Department of Education, 2013; Eyre, 2013; Matthews, 2014; Levitan, 1969 as cited by Bailey \& Duquette, 2014). As detailed in his 1964 State of the Union address, Johnson vowed "all-out war on human poverty and unemployment" (para. 4). Johnson notes that "our failure to give our fellow citizens a fair chance to develop their own capacities, in a lack of education and training" (1964, para. 25) is the root of poverty. Illiteracy, here, is framed as an economic issue. Part B of the Economic Opportunity Act of 1964 lays out directives to fund and develop adult basic education programs across the U.S.

Sec. 212. It is the purpose of this part to initiate programs of instruction for individuals who have attained age eighteen and whose inability to read and write the English language constitutes a substantial impairment of their ability to get or retain employment commensurate with their real ability, so as to help eliminate such inability and raise the level of education of such individuals with a view to making them less likely to become 
dependent on others, improving their ability to benefit from occupational training and otherwise increasing their opportunities for more productive and profitable employment, and making them better able to meet their adult responsibilities. (p. 520)

This act explicitly ties literacy to individualistic opportunity and the ability to obtain and maintain employment. The 1966 Adult Education Act, which amended sections of the 1964 Act pertaining to adult education, further legitimized the government's vested interest in funding and growing adult basic education (Rose, 1992). The Adult Education Act was amended five times from 1968 to 1978 that "continued to forge a firm legislative foundation for adult basic education" (Department of Education, 2013, p. 13). The 1991 National Literacy Act supplied legislation dedicated to improving literacy levels nationwide for the first time (Eyre, 2013). The 1992 NALS and 2003 NAAL, to be discussed further, were two national initiatives to track and gauge literacy rates throughout the U.S., both discovering that tens of millions of adults in the U.S. fall in the lowest levels of literacy and are unable to complete basic reading tasks (Kirsch et al., 2002; Kutner, Greenberg, Jin, Boyle, Hsu, \& Dunleavy, 2007).

It is necessary to examine the history of adult education programs in order to understand where adult literacy instruction is situated. Adult literacy programs, centers, and affiliated organizations seek to address one specific area of adult education. Across the U.S., these programs take shape in different ways that will be discussed later in this literature review, in a subsection devoted to literacy centers and programs. However, all of these organizations and programs share the same common goal: to improve literacy skills and capabilities in adult populations. 


\section{What Literacy Is}

Literacy is a crucial skill needed for navigating different areas of life. People regularly encounter written information that is imperative to functioning in society, such as obtaining a driver's license, completing voter registration forms, renting or buying a home, reading instructions on prescription medication, filling out field trip permission forms for children, and reviewing Social Security and Medicare information are several examples of this (Kutner et al., 2007). To evaluate the effectiveness of public relations materials produced by literacy centers, it is essential to provide background information on literacy; namely, what it actually is. Literacy is a multifaceted subject that has been researched from a variety of academic and governmental perspectives. In this section, I will explore credible definitions of literacy to first determine what the term encompasses. I then will provide research from significant national and international surveys on adult literacy rates to illustrate the problem in the U.S., and I will assess the dearth of literature, especially more-recent literature available, about literacy.

To establish a foundation on literacy, I use research frequently cited in more recent literacy-related literature, such as national surveys from 1992 and 2003. I found both surveys cited in articles and websites pertaining to literacy and sought out the surveys themselves as a starting point for exploring the issue. Their inclusion in this literature review is done, in part, to trace the trajectory of literacy as it was studied. However, large-scale national surveys of literacy rates are not frequently done and 2003 was the last specifically national survey completed. Research from the last decade on literacy use these surveys to describe the problem. For example, Jae's (2014) article assessing the promotional materials used by an adult literacy center cites the 2003 survey when illustrating the prevalence of adult literacy difficulties. Henry (2013) presents the 1992 and 2003 surveys as evidence of the issue when detailing adult education 
providers. While this research provides a comprehensive background on assessing literacy in the U.S., it doesn't yield a complete picture of the situation currently. As such, I draw from international surveys on literacy that include the U.S. and provide more up-to-date information on the situation. Additionally, in this section, I will examine the impact that literacy or lack thereof has on an individual's life.

\section{Definitions of Literacy}

There are disparate definitions associated with literacy, which can be simplified as the ability to read written text. The Organisation for Economic Co-operation and Development (OECD) collects data internationally on adult skills, including literacy, which makes the OECD an authoritative source for understanding this skill. The OECD uses its results to offer a global comparison of different adult skills. Although many definitions of literacy exist, the OECD presents a comprehensive and clear definition as the basis for its 2013 international survey on adult skills:

Literacy is defined as the ability to understand, evaluate, use and engage with written texts to participate in society, to achieve one's goals, and to develop one's knowledge and potential. Literacy encompasses a range of skills from the decoding of written words and sentences to the comprehension, interpretation, and evaluation of complex texts. (OECD, 2013, p. 59)

The OECD does not include writing as a measure of literacy, given the challenges of accurately measuring and comparing writing proficiency internationally (OECD, 2013). Here, literacy is not restricted to reading proficiency but is connected to the larger societal accomplishments that it enables for people. Industrial-based economies are making way for information-based economies, which are highly digitized and require readers to judge and 
evaluate the uncensored plethora of digital text available (OECD, 2009). The OECD notes that "literacy and numeracy skills constitute a foundation for developing higher-order cognitive skills" which are needed "for gaining access to and understanding specific domains of knowledge" (OECD, 2013, p. 56). These skills are needed to interact with digital platforms and an inability to utilize emerging technology may be detrimental (OECD, 2013). As the internet has become a primary means of global communication, this forces us to reevaluate how people use written language to communicate. Therefore, digital texts are "an integral part of literacy measured" (OECD, 2013, p. 61).

The Department of Education was directed by Congress to facilitate an adult literacy survey on a national scale (Kirsch et al., 2002). This resulted in the National Adult Literacy Survey (NALS) in 1992, which yielded important information on adult literacy rates across the U.S. The National Assessment of Adult Literacy (NAAL) in 2003 provided more up-to-date information on adult literacy to evaluate any changes from the 1992 data (Department of Education, 2005). The 2003 survey was the last national effort to determine literacy rates, however the U.S. has administered surveys for international research on literacy. The results of these international and more recent surveys will be explored in-depth later. Both the 1992 and 2003 surveys provide data on adults 16 and older. Literacy is a complicated issue and cannot be reduced to labeling individuals as either literate or illiterate, "thereby treating literacy as a condition that individuals do or do not have" (Kirsch et al., 2002, p. xv). The 1992 NALS and 2003 NAAL included three types of literacy, encompassing the diversity and context of the topic: prose literacy, document literacy, and quantitative literacy.

- Prose literacy — the knowledge and skills needed to understand and use information from texts that include editorials, news stories, poems, and fiction; for example, 
finding a piece of information in a newspaper article, interpreting instructions from a warranty, inferring a theme from a poem, or contrasting views expressed in an editorial.

- Document literacy — the knowledge and skills required to locate and use information contained in materials that include job applications, payroll forms, transportation schedules, maps, tables, and graphs; for example, locating a particular intersection on a street map, using a schedule to choose the appropriate bus, or entering information on an application form.

- Quantitative literacy — the knowledge and skills required to apply arithmetic operations, either alone or sequentially, using numbers embedded in printed materials; for example, balancing a checkbook, figuring out a tip, completing an order form, or determining the amount of interest from a loan advertisement. (Kirsch et al., 2002, p. 2-3)

These three categories exemplify that literacy, in practice, is a contextual process that hinges on important subtle differences. C. Doak, L. Doak, and Root (1996) provide relevant information on engaging with adults who struggle with literacy from a healthcare perspective. Their work contributes valuable insights into how adults with low literacy skills deal with written texts and how to make the process easier. As such, literacy centers, programs, and scholars can learn important information on creating written material that can be understood by audiences with low literacy levels. I found their work cited in Aldridge (2004) and Bastable (2011), whose research includes literacy work. While C. Doak, L. Doak, and Root's (1996) book was published twenty five years ago, it is a valuable and foundational source for those seeking to understand 
adult illiteracy; particularly in how adults who lack sufficient literacy skills engage with written materials.

While grade level used to be the main determinant in literacy and text readability, a more nuanced scale of skill has been utilized (C. Doak, L. Doak, \& Root, 1996). Functional competency levels "measures the ability of people to perform literacy tasks over a range of difficulty levels" (p. 2), with Level 1 representing the lowest literacy capabilities and Level 5 representing the highest literacy abilities (C. Doak, L. Doak, \& Root, 1996). The 1992 NALS also uses this approach, breaking down an individual's literacy capabilities into one of five categories (Kirsch et al., 2002).

\section{Literacy in Practice}

Literacy cannot be evaluated unless through the examination of individuals using written material to demonstrate their reading comprehension skills. Previously viewed as an individual issue, literacy has been recognized as having a larger societal impact (Kirsch et al., 2007). As such, "the human costs of limited literacy have, in a sense, been overshadowed by concerns about the economic and social costs" (Kirsch et al., 2002, p. xii). The 1992 NALS points out that "there is widespread agreement that we as a nation must respond to the literacy challenge" for economic prospects, but further "to ensure that every individual has a full range of opportunities for personal fulfillment and participation in society" (Kirsch et al., 2002, p. xii). Therefore, a commitment to literacy is a commitment to the opportunity of every individual.

There are many reasons why the issue of illiteracy is underestimated. Illiteracy has a powerful social stigma, which causes individuals to hide their inability to read (C. Doak, L. Doak, \& Root, 1996). People will feign tired eyes or "use ruses such as 'I forgot my glasses' or 'I'll have to take this home for my husband (wife) to see it first'” (C. Doak, L. Doak, \& Root, 
1996, p. 6). Illiteracy is not an issue of intelligence, but of economic situation (C. Doak, L. Doak, \& Root, 1996). Given this and the invisibility of the problem, literacy difficulties can be overlooked. However, research suggests that illiteracy is a persistent and serious problem with negative impacts. One in five adult Americans face literacy difficulties (C. Doak, L. Doak, \& Root, 1996). The 1992 NALS found that between 40 to 44 million U.S. adults were in the lowest literacy levels and while some within the category could complete simple tasks, others "had such limited skills that they were unable to respond to much of the survey" (Kirsch et al., 2002, p. xvi). The 1992 NALS and the 2003 NAAL are the two national surveys on adult literacy in the U.S., offering a comparison to show how rates changed throughout the decade (National Center for Education Statistics, n.d.; Kirsch et al., 2002; Department of Education, 2005).

Overall, literacy rates between 1992 and 2003 remained consistent. While there was an increase in quantitative literacy scores, prose and document literacy scores did not significantly change (Department of Education, 2005). The 2003 NAAL appraised how employment status and opportunities connected to literacy skills. Adults with higher literacy levels had more advantages in employment as "a higher percentage of adults with higher literacy levels were employed full-time and a lower percentage were out of the labor force than adults with lower literacy levels" (Kutner et al., 2007, p. 60). The 2003 NAAL ascertained that individuals scoring lower on literacy scales tend to make less money. Literacy levels of parents can affect the home and education environment of children; "parents with higher literacy did more literacy-related activities with their children and had more educational resources in their home" (Kutner et al., 2007, p. 70). Across all prose literacy levels, the majority of parents assisted children completing homework; "however, the percentage of parents who never helped or never worked on homework with their children declined with each increasing prose literacy level" (Kutner et al., 
2007, p. 71). Therefore, the literacy proficiency of parents can affect their involvement in the athome education of children. Other areas of life necessitate competent literacy skills. Voting is an important civic engagement opportunity, and literacy precludes the ability to read and fill out voter registration forms and cast ballots. The 2003 NAAL found that "the percentage of adults who voted in the 2000 presidential election was higher in each prose and document literacy level than in the next lower level" (Kutner et al., 2007, p. 78).

International surveys on literacy skills also offer a picture of the issue. The OECD facilitated the Program for the International Assessment of Adult Competencies (PIAAC), which globally compares skills pertinent to social and economic success, including literacy (National Center for Education Statistics, n.d.). In the U.S., participants could supply background information in either English or Spanish, however the evaluation was administered in English. PIAAC research from 2012, 2014, and 2017 estimate that 52 million U.S. adults have low literacy skills (National Center for Education Statistics, n.d.). Data from PIAAC in 2012 and 2014 estimate that 43 million U.S. working-age adults have low literacy skills (National Center for Education Statistics, n.d.). The PIAAC offers the most recent picture of literacy rates within the U.S., and this information may be the reason the U.S. has not completed a more recent national survey of literacy since 2003 - the 1992 and 2003 surveys already establish the problem, while the PIAAC provides data on current U.S. rates within the last ten years.

Lack of literacy skills manifests itself in different ways. Difficulty in interacting with healthcare professionals and following important directions written on brochures or drugs is a serious problem. Healthcare-related writings "are at readability levels that are 'over the heads" (p. 3) of many patients (C. Doak, L. Doak, \& Root, 1996). Inability to read and comprehend vital patient instructions can have considerable effects on the quality of life of those struggling with 
literacy (C. Doak, L. Doak, \& Root, 1996). The complexity of healthcare forms and the subsequent inability to read and understand them is an obstacle when acquiring health insurance (Saunders, 2006), again demonstrating how literacy is connected to quality of life.

\section{Immigrants and Literacy}

Many literacy programs include English-language and citizenship classes, which makes it necessary to explore the relationship between immigrants in the U.S. and literacy. The use of symbols such as "pictograms, syllabaries, alphabets, and other forms of coded language" to relay information has developed over time (Thomas, 1989, p. 4). The ability to read is the result of different processes coming together. This requires a knowledge of an oral language, as reading "involves a merging of both language and thinking skills" (C. Doak, L. Doak, \& Root, 1996, p. 29). Decoding is the result of speech transitioning into print, while comprehension is the ability to understand a text (C. Doak, L. Doak, \& Root, 1996). Thus, an inability to speak English impacts the ability to read in English. Globally, many people "become functional illiterates in adulthood" after completing school, while others "were never exposed to the experience of a symbolic written representation" (Castro-Caldas, Reis, \& Guerreiro, 1997, p. 328). While there is a distinction among levels of literacy, there is also a distinction between people never before learning written communication in any capacity and those with some levels of schooling that result in rudimentary reading skills, that may be insufficient in daily modern life. The international survey performed by the OECD in 2013 yields information on immigrant literacy rates. Literacy rates are lower among immigrants with a foreign-language background, even among those who resided in their new country for more time, indicating that motivations "to learn the language of the host country are not strong, or that policies encouraging learning the language of that country are not particularly effective" (OECD, 2013, p. 138). When combined 
with low educational attainment, the socioeconomic prospects of these immigrants are all the more challenging (OECD, 2013).

As "language preceded literacy" (Thomas, 1989, p. 4), it is important to note that immigrants in the U.S. may possess sufficient literacy skills in their native language, but do not have the same capabilities in English. Therefore, they are deemed to struggle with literacy, when in fact the issue lies with English language proficiency, which is a separate issue altogether. However, many immigrants arriving in the U.S. may have difficulty reading in their native language, differentiating them from populations who are able to read well in languages other than English. For example, refugees may struggle with literacy in their native language as a result of fleeing mass violence restricting access to formal education (Montero, 2018). Nonetheless, the inability to read in English does not necessarily mean a person struggles with literacy (only literacy in English), but this point is another complex facet of literacy that is difficult to gauge. The 2003 NAAL partly acknowledged this issue. Participants were deemed nonliterate in English if "they were unable to complete a minimum number of simple literacy questions or if they were unable to communicate in English or Spanish" (Kutner et al., 2007, p. 3). If participants lacked the language proficiency to provide demographic background information, they were omitted from the results report. The 2003 NAAL found that 7 million adults in the U.S. are nonliterate in English; however, an additional 4 million adults in the U.S. lacked the necessary English or Spanish speaking skills to provide demographic background information and subsequently were not in the results report (Kutner et al., 2007). The 2003 NAAL concluded that " 5 percent of the adult population of the United States (11 million adults) is estimated to be nonliterate in English" (p. 13). Therefore, immigrant populations in the U.S. 
have disparate experiences when it comes to literacy proficiency, and the help that literacy centers could provide for them is vital.

\section{The Role of Literacy in Forming Identity}

Literacy plays an important role in people's identity formation. Indeed, obtaining a label that identifies an individual as a "struggling reader" can be damaging (Brooks \& Frankel, 2018). Much research has covered the impact of reading in Kindergarten through high school, as students begin the acquisition of language skills at different rates and start to negotiate their identities in relation to reading. In one study, L. Hall (2012) notes that a middle schooler acknowledged his current "bad reader" identity, hoping to become "a good reader." L. Hall (2012) rejects this notion of literacy and encourages a rewriting of identity so "students find their voices and engage with texts in ways that are meaningful to them" (p. 370). Rather than following definitions prescribed by educators, students should reflect on how they want reading to be situated in their own life, while using educators' experience to help them achieve that goal (L. Hall, 2012). Approaching reading from this perspective meant that students understood their "primary role in their development as readers" (L. Hall, 2012, p. 373).

Literacy relates closely to identity, because identity is "social, cultural, historical, institutional, and political", indicating "that identity has material effects related to lived realities in the form of resources, goods, and emotional well-being" (Lewis \& del Valle, 2008, p. 308). A written text is intertwined with its political economy or the way it is disseminated and utilized (Lewis \& del Valle, 2008). Texts are interpreted in different ways and used to fulfill or complete tasks pertinent to an individual's identity based on contextual factors, such as personal characteristics or social and historical position. For example, U.S. citizens complete paperwork to register to vote, identify a polling station or request an absentee or mail-in ballot, and then cast 
a ballot. This act—which necessitates certain literacy skills in reading instructions and identifying candidates - of carrying out an important right and having a say in the governance of the nation is closely tied to the identity of the individual as a U.S. citizen.

As literacy is "a social and cultural achievement centered in social and cultural practices," literacy research should include perspectives "not just cognitive, but social, cultural, historical, and institutional, as well" (Gee, 2015, p. 35). This is an important component of literacy research relevant to this thesis, as adult literacy center learners are heterogeneous populations. Literacy enables learners in unique ways as they belong to different cultures and use literacy in unique ways to function in their life. Religious texts are engaged with in separate ways than legal texts or popular culture media (Gee, 2015). Gee (2015) denotes literacy as literacies, encompassing the "many different social, historical, and cultural practices which incorporate literacy" (p. 36). Engaging with a text is "always integrally and inextricably integrated with ways of talking, thinking, believing, knowing, acting, interacting, valuing, and feeling" (Gee, 2001, p. 30). How those written texts fit into a person's life is deeply individualistic.

\section{Why Literacy Matters}

The above research delineates that many U.S. adults struggle with literacy, an essential skill for interacting with and prospering in society. International and national surveys (Kirsch et al., 2002; Kutner et al., 2007; National Center for Education Statistics, n.d.) establish that tens of millions of adults in the U.S. face literacy difficulties. This inability to process written information can affect individuals in a variety of ways, but greatly diminishes the capability to rely on written instruction imperative to function well in society. The definitions presented from the OECD and the 1992 NALS reinforce the idea that literacy is more than just being able to 
read; literacy involves comprehension of written text and the capability to do something with that text (OECD, 2013). The three categories used to measure literacy in the 1992 NALS and 2003 NAAL further underscore that texts are used in different ways; whether looking through the warranty information on a product, reading job applications, or balancing a checkbook (Kirsch et al, 2002). Lack of literacy skills in adults is a significant problem in the U.S.

\section{Literacy Centers and Programs}

As detailed earlier, literacy centers and programs lie under the larger conceptual umbrella of adult education. Adult education programs are varied, and this variety applies to literacy centers and programs. On the Michigan Department of Labor and Economic Opportunity (n.d.) website, a search engine allows users to locate a myriad of adult education services and programs across the state, taking place at adult education centers, community colleges, employers, community centers, or designated literacy centers. Given this variety, it is difficult to identify a precise number of literacy centers and programs, but the Michigan Department of Labor and Economic Opportunity (n.d.) assert that over 100 such programs exist within the state. Adult education exists as a result of partnerships between federal, state, and local agencies (Department of Education, 2013). In this section, I will explore research on adult literacy programs and centers. Additionally, I will examine research from the perspectives of adult literacy learners, including their motivations and experiences in these programs, to better recognize the role these centers play in society.

\section{Impact on Learners}

Research into literacy centers reveals the potential benefits their programs have on learners. Neuman, Caperelli, and Kee (1998) pull findings directly from participants in family literacy programs funded by the Barbara Bush Foundation for Family Literacy. Family literacy 
programs provide services for parents and can involve children in classes or activities. The Foundation sponsored literacy programs at an array of sites including prisons, homeless shelters, libraries, and housing projects (Neuman, Caperelli, \& Kee, 1998). Many of these participants wanted to use literacy as a way to grow personally. Retention in family literacy programs was tied to meeting specific goals. Programs that supply additional social services can remove obstacles parents face in attending. Integration of social services, such as illness-prevention courses, childcare, and transit tokens, can help participants take part in programs (Neuman, Caperelli, \& Kee, 1998). Family literacy centers are sites of engagement and interaction that have benefits in and of themselves, allowing families to spend time together (Neuman, Caperelli, \& Kee, 1998).

Perceptions of literacy, literacy centers, and programs have also been studied. Malicky and Norman (1995) found many job-related reasons for learners to enroll in literacy programs, positioning literacy as a necessary skill for employment. There are many factors that motivate individuals to seek literacy education, and there are some commonalities among populations. At a Canadian literacy center, immigrants were primarily concerned with "the traditional areas and skills of language arts" while the Canadian-born learners "were more concerned with interpersonal dimensions of literacy instruction" such as overall self-improvement (Malicky \& Norman, 1995, p. 81). This reinforces the idea that adult learners are heterogenous populations, with different reasons for enrolling in such programs.

Student retention in literacy programs is important. African-American student retention in adult education and literacy (AEL) programs is a research area needing more development (Goodwyn, 2019). Texas AEL programs tend to mimic community college models "in order to provide a more seamless transition from AEL into programs at the college" (Goodwyn, 2019, p. 
33). Aiming to assess a link connecting AEL characteristics of instruction to the rate of persistence in African American students, Goodwyn (2019) examined multiple factors that influence retention. Integrated Education and Training (IET) programs combine elements of postsecondary education with job-specific training to best equip students to succeed in their careers (Goodwyn, 2019; Texas Higher Education Coordinating Board, 2016 as cited by Goodwyn, 2019; Wachen et al., 2010 as cited as Goodwyn, 2019). Unmatched expectations between students and teachers can lead to African American students dropping out of school; thus, they are an important group to consider in relation to adult education success (Goodwyn, 2019). Employment again is viewed as a driving force towards adult education, as "traditional AEL academic instruction is combined with work skills instruction, the motivation to learn stems from a desire to enter the workforce or make gains in the workforce" (Goodwyn, 2019, p. 42). However, intrinsic motivation is not the only factor in keeping students enrolled. Characteristics of teachers and the way they run their classroom can influence student retention. Studentcentered teachers "had a higher percentage (80\%) of their African American [sic] students complete 40 hours of attendance" (Goodwyn, 2019, p. 42). This also bolsters the idea that adult learners want to use education as a means of obtaining employment.

Many interpersonal relationships are cultivated within the education environment. Human relationships proved to be a powerful factor in adult literacy programs (Terry, 2006). Certain types of relationships are prominent in the adult education sphere in Canadian adult literacy programs. The instructor-student relationship is important, as are developing connections between students. Classroom climate and the overall learning experience were influenced by strong interpersonal relationships (Terry, 2006). Terry (2006) found that "the adult nature of these instructor-learner relationships was a critical factor of their success" (p. 34). Learners and 
staff of the programs were on first-name terms with each other and took lunch breaks together (Terry, 2006). This sense of community forged strong bonds between staff and learners. Higgins, Long, and Flower (2006) assert that community literacy fosters space for negotiating personal and public issues. This idea builds off of the idea of literacy as being more than just simply reading, but as the springboard for entering into other domains. Community literacy is "this whole family of literate and social practices that draw their strength from different theoretical frameworks - from progressive pedagogy, to community organizing and action research, to discourse analysis, cultural critique, and theories of organizational change" (Higgins, Long, \& Flower, 2006, p. 10).

\section{Literacy Providers and Teachers}

Adult literacy research also considers the qualifications of teachers. Australia and New Zealand do not have equivalent qualifications for adult literacy teachers as customary teachers, or the term the researchers use for teachers in other areas of education (McHardy \& Chapman, 2019). McHardy and Chapman (2019) argue that adult learners in literacy programs "have reading difficulties; otherwise, they would have acquired reading skills as children" (p. 132). As such, they assert customary teachers, while trained and educated on the reading process, might be unable to handle the unique reading difficulties of adult populations (McHardy \& Chapman, 2019). While this view neglects to consider that circumstances may have forced individuals out of education at an early age, this does demonstrate that individuals may be unable to read proficiently because of reading difficulties. This challenges adult literacy centers and programs to adapt to a highly diverse clientele, from immigrants seeking to improve English language capabilities to native-English speakers who left school early or have reading difficulties. Therefore, it is necessary to understand how adult-reading teachers are, or are not, impacting the 
problem of adult illiteracy. McHardy and Chapman (2019) find that "effective instruction that is targeted to learner needs is essential" (p. 131). While wanting to help those struggling with literacy is an important quality in adult literacy teachers, they also need to be equipped to handle complex issues pertinent to adult reading instruction (McHardy \& Chapman, 2019). This study underscores that the diverse clientele of literacy programs may include adults with learning difficulties, and thus, literacy centers are positioned to offer a unique service.

Henry (2013) examined U.S. adult education providers to ascertain their literacy knowledge. In addition to noting areas of improvement in adult education, this research also yielded information about programs. Adult education providers surveyed primarily taught or were involved in GED/Adult Secondary Education, followed by Adult Basic Education. While the predominant amount of time was spent in mathematics instruction, reading was recognized as the next most prominent subject taught (Henry, 2013). Method of instruction among adult education providers differed. Individual one-on-one instruction accounted for most of the time spent teaching, however group instruction was also utilized (Henry, 2013). Adult education providers presented numerous goals that learners sought to meet including developing self-worth and becoming good role models for children (Henry, 2013). Henry (2013) found that adult education providers tend to be overwhelmingly white females over the age of 40 . Roughly $60 \%$ of adult education providers surveyed lacked a teaching certification supplied by the state and that "only two individuals hold certification specific to adult education" (Henry, 2013, p. 41). Henry (2013) concluded that specific professional development "should be available to adult education providers to ensure they possess the necessary knowledge and skills for effective literacy instruction for their service population" (p. 46). Henry (2013) noted that such professional development should also take into consideration "the wide range of ability levels in 
one classroom" (p. 46). This study provides information on adult education providers, which is not an extensive area of research currently.

\section{International Literacy Efforts}

Many studies examine adult literacy programs, centers, and campaigns internationally. One study found that in Ethiopia, adult literacy facilitators (ALFs) had a strong commitment to education, having been through difficult circumstances in order to attain their own schooling (Warkineh, Rogers, \& Danki, 2018). A noteworthy aspect of this research is that in this developmental context, ALFs main drive was to earn a steady income, not "altruism or high ideals about education" (Warkineh, Rogers, \& Danki, p. 17). This is interesting when contextualized with adult literacy programs in developed countries, like the U.S., which may have volunteers. Public primary schools were a common location for these adult literacy classes, conducted after school hours in the evening, demonstrating that many adult education programs don't have designated spaces for classes and are run out of other buildings when not in use (Warkineh, Rogers, \& Danki, 2018). The adult education providers in this study received minimal training to teach adults, indicating that lack of specialty education in adult education teachers may not strictly be a problem in the U.S., however more research in this area is undoubtedly needed. One limitation of this study is that it relied on the perspectives of five ALFs, and the authors caution that wide sweeping generalizations should not be drawn from the research, encouraging more study into adult literacy facilitators to best support programs (Warkineh, Rogers, \& Danki, 2018).

The Literacy for Life Foundation targeted Aboriginal communities in New South Wales, Australia (Durnan \& Boughton, 2018). Of the over 2,000 Aboriginal adults in the communities, 300 who struggled with literacy participated; over half of them successfully graduated the 
program. Durnan and Boughton (2018) examined what happens in the post-literacy phase, once rudimentary skills in literacy have been instilled, which features twelve weeks of activities revolved around literacy “to consolidate participants' literacy competence, extend their language confidence, and build their citizenship and work skills" (p. 12). The post-literacy phase can prove a challenge, as low-literate individuals find themselves shunned from places requiring literacy skills by that time. Institutions such as the legal system can be "a major source of oppression and stress" for those struggling with literacy (Durnan \& Boughton, 2018, p. 12). The primary element to ensuring success in the Literacy for Life Foundation was the inclusion of Aboriginal people "on the front line, coordinating and facilitating the lessons, with professional educators in the background" (Durnan \& Boughton, 2018), leading to a sense of community conducive to effective learning.

\section{Measuring Effectiveness of Literacy Programs}

As the goal of adult education is to improve learner's acquisition of specific skills, it is necessary to examine research pertinent to the subsequent measured impact of these programs on literacy skill and ability. Wolf and Jenkins (2014) underscore that while certificates indicating the completion of an adult education program may be given with the best of intentions, it should not be confused with genuine educational improvement. In one workplace literacy program for British adults, no statistically significant improvement was found for native English speakers. While improvement was found in learners learning English, the "subjects' longer exposure to an English-speaking environment" led the researchers unable to determine if the program was indeed the causal factor for this improvement (Wolf \& Jenkins, 2014, p. 585). It is noted that this study, rather than asserting that literacy instruction is a financial waste for funders, that there is 
an assumption "about how quickly complex skills can be learned" (Wolf \& Jenkins, 2014, p. $605)$.

This study was a rarity in that it directly addressed the impact of adult literacy programs on literacy skill. While much research in the field of adult literacy focuses on learner motivations, teacher characteristics and training, and descriptive information about particular programs and centers, there is a gap in the literature assessing the effectiveness of adult literacy programs as a whole in terms of measurable success. This likely is due to the varied nature of programs and learners, and the difficulty in drawing generalizations from one center or program to another. As detailed earlier, adult education learners come from all backgrounds with differing levels of familiarity and skill with a particular area, like literacy. Adult literacy programs are equally varied: for example, some learners are native English speakers seeking to improve their reading ability, while others are approaching English as a second language and are aiming to achieve a stronger grasp of the language. Wolf and Jenkins (2014) postulate that fundamental characteristics may differ in native-language speakers and second language speakers, which could shed insights into why the non-native English speakers improved over the native-English speakers. A 2011 Turkish study also looked at impact on skill. Reading fluency is supposed to result at the conclusion of the program, but the study found that just $15.8 \%$ of learners achieved this goal, signifying that the goals of the program are not being met (Yildiz, 2011). The cultural landscape and societal norms of Turkey could generate differences that would impact access to education that makes a generalization or comparison to U.S.-based adult literacy courses difficult. 


\section{Promoting Literacy Centers}

While this area is a significant gap in the literature, some research studies exist that assess how a literacy center or program promotes itself through public relations or communicative materials. Jae (2014) noted that low-literate adults are rarely considered in instructional marketing materials. As such, “adult literacy organizations are confronted by unique communication challenges in tailoring their recruitment and retention efforts to appeal to their target audience" (Jae, 2014, p. 51). This underscores the paradox faced when constructing communicative materials for a low-literate audience: if the target public is unable to read or clearly understand the written text advertising a service, how are they able to take advantage of such a service? This paradox is all the more apparent when considering adult literacy programs and centers whose very goal is to recruit individuals struggling to read and provide them a means to improve and develop the necessary skills required for reading. One consideration that Jae (2014) acknowledges is the multiple audiences that an adult literacy center has. Like any organization, adult literacy centers have more than one target audience. While it is essential for literacy centers to communicate with clientele, other audiences are necessary for the survival of the organization.

Jae (2014) examined the communication used by the Virginia-based READ Center. The goal of the community-based center was "to develop promotional materials that will encourage low-literate adults to enroll in literacy programs" (p. 51). Learners from the center provided their insights on these materials. Jae (2014) found that the "one-size-fits-all" (p. 52) brochure was ineffective at speaking to the multiple audiences encompassing not only learners but volunteers, employees, and donors. Learners concluded that the brochure was aimed at recruiting tutors and 
donors. Design elements such as the cluttered text that detracted from the message were also discussed (Jae, 2014).

Higgins (2010) reviewed Colorado State University's Community Literacy Center's website, offering judgements about the different sections and the role they played. More emphasis was given to the website being informative rather than creating an engaging platform for users to interact with. Partnership links were displayed, in addition to the center's mission statement. The center did have a blog, except, similar to other sections of the website, it was not recently updated. Similar to Jae (2014), Higgins (2010) considered the audiences of this website and how effective the communication was at meeting their needs. Webpages pertaining to projects "do not appear to target potential volunteers or participants; no sign-up forms, contact information, or events calendars are featured" (Higgins, 2010, p. 200). While interviews of literacy-interested professors and professionals are featured, participants of the center's programs and projects are not included. Higgins (2010) recommended that serious literacy researchers and professionals pass on this website as a means of instructional information and "keep on clicking" (p. 201).

As detailed above, the current limited research assessing the effectiveness of adult literacy centers indicates a further need to explore this area. Given the relative ineffectiveness of communication materials represented by these two studies, more support is needed for literacy centers when creating these materials. Smith (1996) offered insights into marketing an adult literacy program, incorporating marketing techniques with the unique mission and clientele of adult literacy programs. However, given the dated nature of this information, more current research is needed. 
More research into adult literacy programs overall is needed and this thesis attempts to address a significant gap in the literature on the communication efforts and practices of adult literacy centers. Adult literacy programs and centers have been explored from a variety of perspectives, but few studies explore the ways these centers communicate with their publics. Given that adult learners tend to be diverse in background, skill level, and motivations for undertaking adult education, they constitute an interesting public for centers to communicate with.

\section{Nonprofit Organizations}

While many adult literacy programs and centers run through community colleges or similar institutions, many function independently as nonprofit organizations. The literacy center examined in this thesis is a nonprofit organization, and as such, I find it pertinent to review literature regarding nonprofit organizations, including public relations research. Many adult literacy centers are nonprofit organizations. More research has been done on nonprofit public relations than specifically adult literacy center public relations. Additionally, as the literacy center this thesis focuses on is a nonprofit organization, it is pertinent to provide background information on nonprofit public relations research. Frumkin (2002) notes three unique features that differentiate nonprofit organizations from other businesses:

- Participation is not pressured

- Stakeholders do not receive profits

- Ownership and accountability guidelines differ

The most foundational aspect is the non-coercive nature of nonprofit organizations that rely on “a large reservoir of good will” (Frumkin, 2002, p. 3). Nonprofit organizations exist in a vast variety that supply needs-based services that are not covered by other for-profit or government 
agencies (Frumkin, 2002). Examples of needs-based nonprofit organizations include affordable housing programs, summer science programs, food pantries, and job training programs. Nonprofit organizations run on a combination of earned income, private donation, and government grants (Frumkin, 2002). Nonprofit research has grown in recent years, and given its interdisciplinary nature, it has been approached from different academic perspectives (Frumkin, 200). Comprehension of "nonprofit organizations has benefited from the attention of economists, political scientists, sociologists, psychologists, historians, and management scholars" (Frumkin, 2002, p. v). If a nonprofit's communication is ineffective at reaching its target audiences, this result can have an adverse effect on the organization's survival and in its effort to provide services to the community.

Dyer, Buell, Harrison, and Weber (2002) examined nonprofit public relations efforts from the perspective of employees. They also need more comprehensive information on implementing effective public relations, and communication is an understaffed area within organizations (Dyer et al., 2002). With organizational performance and fundraising as important subjects for nonprofit organizations, many nonprofit organizations have incorporated social media into their communications plan (Curtis, Edwards, Fraser, Gudelsky, Holmquist, Thornton, $\&$ Sweester, 2010). The existence of a public relations department increased the likelihood of social media usage by nonprofits (Curtis et al, 2010). Nonprofit public relations has also been explored from the perspective of crisis response and management (Fussell Sisco, Collins, \& Zoch, 2010). Much of the existing literature on nonprofit communication focuses on the senders of messages, particularly in terms of what nonprofit organizations are doing, rather than how and why they are doing it. A rhetorical approach to message construction in nonprofit organizations will contribute new insights into the field. 


\section{Message-Design}

Because this thesis examines the effectiveness of a literacy center's digital messages, I will explore research that is pertinent to message design. Message design, construction, and dissemination are important factors in an effective public relations campaign. These messages can be examined from the perspective of the source, message content itself, and the reaction elicited among audiences. Effective messages are part of two-way communication, in which publics and organizations mutually exchange information (Kelleher, 2018). Two important aspects of messages are the attitude-formation potential and a means of evaluating campaign effectiveness (Gregory, 2000). Words, visuals, and forms are principle elements of message design (Pettersson, 2012). Message construction is made up of diverse academic disciplines, including communication, language, art and aesthetics, business and law, behavior and cognitive fields. Academic fields pertaining to society and the individual are also relevant to message design (Pettersson, 2012).

Various design theories have been applied to message construction. One communication system views communication as "the creation and negotiation of social selves and situations" (O’Keefe, 1988, p. 87), which creates proactive goal-driven messages. Rhetorical messages are thus contextual and instead of reactionary to a "taken-for-granted feature of the world" they are linked to goals (O'Keefe, 1988, p. 88). O'Keefe's (1988) research into message design logic reveals that although "messages are designed to serve goals" more than just goals are needed to create messages. Organizations must have propositions guiding effective message design (O’Keefe, 1998). O'Keefe (1998) has been used by other scholars as providing foundational knowledge on message design. Barbour, Jacocks, and Wesner (2013) build off of O'Keefe's (1988) work in their study on message design and organizational change. Messages about 
changes within an organizational are influenced by belief intensity (Barbour, Jacocks, \& Wesner, 2013). Amounts of clarity, disclosure, and accuracy in messages influence perceptions of organizational transparency (Holland, Krause, Provencher, \& Seltzer, 2018).

Public relations research has explored components of social media messages. Dodd and Collins (2017) performed a content analysis of Western and Central-Eastern European embassy Twitter accounts. Information sharing was the main message strategy employed by both embassies (Dodd \& Collins, 2017). Advocacy was the overlying theme of Western embassy tweets, while the Central-Eastern European embassy tweets highlighted cultural diplomacy. The authors suggested that this is, in all probability, consistent with current cultural patterns (Dodd \& Collins, 2017). Discovering a link connecting diplomatic approaches and public relations strategies, this research "demonstrates a relationship between disciplines of global importance that have been separated in scholarship" (Dodd \& Collins, 2017, p. 424).

Message source is another key component for public relations. In literature about message design for public relations, all PR discourse promotes and is representative of an organization even though there are many different authors who wrote the discourse. There is usually an inherent collaborative nature to public relations discourse because of the range of people, from subject-matter experts to corporate authorities, that are involved in a text's creation (Smudde \& Courtright, 2012). As the message source varies, it is important to consider how that affects the message itself and how it is received by audiences. In a hypothetical scenario of either a CEO or individual real estate agent posting an inappropriate tweet and subsequently providing a reason for how the erroneous tweet came to be disseminated, insights on message source were gained (Roh, 2017). Participants were more critical of the CEO as they "would have more means 
to prevent such mistakes" (p. 594) over employees not having equivalent organizational power, like an individual real estate agent (Roh, 2017).

Message testing is the process of gauging others' reactions to content prior to formally disseminating it (Kelleher, 2018). Informal ways to message test can be as simple as having a colleague review a message briskly, while more formal approaches could involve focus groups (Kelleher, 2018). Public relations messages can take a variety of forms within corporate settings, including press releases, newsletters, blogs, press kits, or employee handbooks (Courtright \& Smudde, 2009). While organizations play a major role in the construction of these messages, genre conventions also guide message development (Courtright \& Smudde, 2009). These genre conventions are born out of relevant publics communications with one another (Courtright \& Smudde, 2009). Inverted pyramid style is utilized for news releases (Courtright \& Smudde, 2009), mirroring journalistic conventions of putting the most important information first, with additional details following in descending order of importance.

Message framing can affect how the information is received by an audience. Health communication is one area of research that explores the impact of message framing on behavior and attitude (Cho, Chun, \& Lee, 2018). One study seeking to understand how messages encouraging exercise are influenced, in part, by message framing. Messages that utilized a gainframe, over a loss-frame, lead to "higher campaign attitude and behavioral intention" (Cho, Chun, \& Lee, 2018, p. 829). This means that the gain-frame resulted in a greater impact, as "people's willingness to participate in an event to exercise increased when they perceived benefits of physical exercise presented in a gain-framed message" (Cho, Chun, \& Lee, 2018, p. 830). 


\section{Public Relations Discourse and Power}

Public relations is a process of communicating with publics on behalf of an organization or cause. As this thesis examines a sample of an organization's public relations efforts, it is necessary to present research connecting the discipline to critical approaches studying power, and what public relations discourse does once it is out in society. The work of philosopher Michel Foucault is referenced here in relation to the public relations research presented, however an in-depth look at his principles that will guide this thesis will be explored in the methodology. Foucauldian principles and other critical approaches have been applied within different organizational discourse and public relations contexts, revealing ways in which power operates through the use of discourse.

The Public Relations Society of America (PRSA) defines public relations as "strategic communication process that builds mutually beneficial relationships between organizations and their publics" (PRSA, n.d., para. 4). As such, public relations practitioners use communication to "inspire intended audiences to behave in desired ways" (Epley, 2007, p. vii). These behaviors can range from purchasing products to developing favorable attitudes towards an organization. Epley (2007) argues that public relations is, then, "an instrument of power" (p. vii), and that this ability to engender change or action is what differentiates the profession from other areas of communication, such as journalism. It is important to examine how public relations is influencing the world around us to behave in particular ways, and how that power might be used, to better understand the role of public relations within society. Public opinion is the bedrock of successful public relations, as public opinion can sway crucial government influence, which in turn affects how organizations may operate. Smudde (2001) identifies corporate communications as "the measured and ethical use of language and symbols to inspire cooperation between an 
organization and its publics" (p. 36). A keyword in this definition explicitly tied to power is "ethical," as this implies subjective judgement on the part of the public relations practitioner or organization based on particular standards of ethics for communication.

Within the field of public relations, ethics is a prominent topic, as situations may appear where a moral course of action is not clear. Kelleher (2018) defines ethics as "moral principles that govern a person's or group's behavior" (p. 414). Transparency is an important element to public relations professional organizations internationally (Stanić, 2019). When conflicts of interest appear, research suggests that public relations ethics codes recommend they be handled in the same manner; the public relations practitioner speaks to the client explaining the situation, leaving it up to the client to choose how to proceed (Stanić, 2019). Organizations tend to have code of ethics that convey professional standards (Kelleher, 2018).

Organizations can go through a variety of experiences, changes, and crises that result in different reactions among audiences. Rhetorician Kenneth Burke generated the theory of dramatism, which explores how language molds our conceptualization of reality (McGeough \& King, 2016). It is by using language that "we orient ourselves in the world and call others to see the world and act as we do" (McGeough \& King, 2016, p. 148). Studying public relations messages from a dramatistic standpoint "reveals public relations officials' use of language to structure public's thinking about issues and inspire cooperation" (Smudde, 2004, p. 429). Pentadic criticism offers a means to reveal the ways language works in society. The key elements of pentadic criticism are act, scene, agent, agency, and purpose. The act refers to the action or occurrences taking place, while the scene is the circumstances or surroundings of the act (McGeough \& King, 2016). The agent is the primary instigator of the actions, while agency is the method or means used by the agent. The purpose is the overall point of the message 
(McGeough \& King, 2016). Pentadic criticism can be applied when evaluating public relations messages. For example, a press release offers insights into public relations discourse. The agent could be the officials quoted in the piece, while the act is the announcement itself (Smudde, 2004). The scene is particular the situation specified in the press release, and the press release is the agency, or means, of producing the act. The purpose of a press release is to report news relevant to the organization (Smudde, 2004). Dramatism is one way to examine public relations discourse from a critical perspective.

The Foucauldian notion of power will be explored further in the methodology section, but I want to note that power, when examined from a Foucauldian perspective, is not the typical topdown approach, but rather is embedded "in the relationships between persons or groups" (Jerome, Moffitt, \& Knudsen, 2007, p. 92). Individuals confer power to others based on social conventions, such as teachers having power over students or a government having power over citizens (Jerome, Moffitt, \& Knudsen, 2007). Connecting this to public relations, power and knowledge unite through discourse (Foucault 1977/1980, as cited by Courtright \& Smudde, 2007). Motion and Leitch (2007) argue that Foucauldian principles are well-suited to examining public relations, as they underscore "some of the deeply problematic, contradictory and even questionable aspects of this complex profession by placing meaning production, power effects, truth claims and knowledge systems at the centre of our thinking and investigations" (p. 263). Taking a critical approach to public relations research, then, means uncovering ways that organizational discourse shapes society, "as a power effect that produces and circulates certain kinds of truths" (Motion \& Leitch, 2007, p. 268).

One example of this is analyzing Martha Stewart's public reaction to the 2001 insider trading scandal—or lack of a response (Jerome, Moffitt, \& Knudsen, 2007). Stewart's image was 
damaged and she later served time in prison for her involvement. Stewart initially chose nonresponse as a means of handling the conflict, which had consequences on her public image. Erroneously viewed as a simplistic deed, nonresponse actually "functions as a complicated rhetorical process" and "implies meanings when employed in a public, mass setting" (Jerome, Moffitt, \& Knudsen, 2007, p. 93). Stewart's accusers and media received power from Stewart in her nonresponse, signifying that, although she "had the power to tell her story, she did not exercise it" (p. 92), thus relinquishing her ability to control the narrative. While Stewart and her attorneys engaged in other image repair strategies later, Jerome, Moffitt, and Knudsen (2007) argue that many of these subsequent efforts were "too little too late" (p. 98).

Smudde (2007) applies Foucauldian principles of power, knowledge, discourse, and ethics to changes in a software company's organizational discourse. Corporate destiny is, in part, the result of public relations discursive power, and using Foucauldian ideas to understand this relationship reveals how discourse functions (Smudde, 2007). Public relations benefits from this shift to considering future discourse rather than remaining rooted in only critiquing the past, the result being discourse that is increasingly effective. This application can have practical benefits in public relations crises, and Smudde (2007) suggests that possibly "the most important thing that a Foucauldian public relations plan can do is to map power-knowledge relationships so that any discursive action can be properly and effectively focused" (p. 229).

Berger (2005) argues that rather than an abstract concept, power is entrenched in every organizational mechanism. It "is not something 'out there' beyond the practice but instead constitutive of practice in shifting relation of power that both constrain and create opportunities for choices and actions". Organizational workings necessitate decision making. "As the executives indicated, power ebbs and flows and move through various venues and moments of 
decision making so that practice seems inevitably bound up in relations of power" (p.23). Berger (2005) calls for the importance of awareness of all variables invested in public relations, including relevant pressures, "the group, organizational, and social contexts of practice as well as the professional background and orientation of the practitioner" (Berger, 2005, p. 23). Other areas of organizational research, such as human resources, using Foucauldian principles to show "how HRM employs disciplinary practices to create knowledge and power" (Townley, 1993, p. 541).

\section{Conclusion}

This chapter reviewed literature pertinent to the different topics that will be explored further in this thesis. Literacy itself is a broad issue that has been studied from many perspectives. In discussing the history of adult education in the U.S., I provided context to the overall field in which adult literacy education exists. I explored different definitions of literacy, including what the ability to read well enables individuals to do. Research on literacy centers and programs were presented, in addition to the slim existing literature on literacy center communication, to support my argument that there exists a gap in the literature assessing the effectiveness of literacy center public relations. I then incorporated key studies related to nonprofit communication, message-design, and public relations, particularly public relations from the critical perspective I am taking, to provide a solid background of information for my topic. Next, I will discuss the methodology for this thesis. 


\section{CHAPTER III: METHODOLOGY}

This chapter is composed of three main parts: rhetorical criticism as the general method, Michel Foucault as the specific theoretical orientation used in the rhetorical criticism, and a case example as the focus for applying the Foucauldian rhetorical criticism to particular artifacts. Rhetorical criticism is a method used to reveal deeper patterns of meaning in a text. The French philosopher, Michel Foucault, studied the role of knowledge production in society and was particularly concerned with the discursive relationship between power and knowledge (S. Foss, K. Foss, \& Trapp, 2002). Case examples focus research on one organization with the purpose of analyzing a specific aspect of it that can be applied to other organizations. This chapter will also provide information about the organization in question, the Literacy Center of West Michigan (LCWM), and of the texts to be analyzed. This chapter concludes with a brief presentation of the guiding principles for interpreting the case, which also will be relevant to establishing the criteria to be used in the evaluation of the case and future planning for cases in general.

\section{Rhetorical Criticism}

There are many methods available for researchers to use when studying communication. While social-scientific methods strive for objectivity by "removing" the researcher from the research, criticism demands the opposite in that it "actively involves the personality of the researcher" (Kuypers, 2016b, p. 22). It is the critic's personality, perspective, and unique characteristics that decide the object of study "and how and why to study a rhetorical artifact" (Kuypers, 2016b, p. 22). Rhetorical criticism is used to engage with texts as a means of revealing dynamics in, of, and about a text, including uncovering hidden meaning not otherwise apparent. Meaning is the action of "words, images, objects, actions, and messages" forming "thoughts, feelings, and associations" (Brummett, 2019, p. 5). Rhetoric is goal-driven communication 
(Kuypers \& King, 2016), while criticism is “analyzing and interpreting” (Kuypers, 2016a, p. 1) rhetorical components. Keith and Lundberg (2008) argue that rhetoric is "the study of producing discourses and interpreting how, when, and why discourses are persuasive" (p. 4). Rhetorical criticism is the process of both analyzing and interpreting communicative persuasive characteristics. A humanizing undertaking, rhetorical criticism creates knowledge. Rhetorical criticism involves a description of the text or artifact in context, interpretation of that artifact based on a theoretical orientation of rhetoric, and evaluation of the artifact based on clear criteria that rely on a particular orientation (Kuypers, 2016b).

A critic is the individual who analyzes a text. Objectivity and subjectivity in criticism is a debated issue, as some advocate for more or less distance to the rhetorical artifact on the part of the researcher (Kuypers, 2016b). Kuypers (2016) advocates for objective criticism in using "a detached curiosity" (p. 34) when examining a text, characterized by a sense of openness. Social justice, or the desire to identify and root out inequality, is often a motivation to become a critic (Brummett, 2019). This motive is born out of "an understanding that power differences in any society are text-based" (Brummett, 2019, p. 18). A critic may consider how a text is organized or presented. For example, a website requires thought about the different sections, ordering of information, and how to draw the audience's attention to certain areas (Keith \& Lundberg, 2008). This consideration is important and relevant to the criticism in this thesis, as it examines articles on an organization's online news and blog section. There are elements specific to internet communication, such as layout and typography, to acknowledge in a critique that may not apply to print materials.

It is almost important to consider the role of the audience, or "the people to whom the symbol, speech, or message is directed" (Keith \& Lundberg, 2008, p. 11). There are various 
parties and components necessary for communication to occur, including an audience, or receiver. Keith and Lundberg (2008) differentiate rhetoric from other forms of communication in that rhetoric is both contingent (i.e. based on the reaction elicited by the audience) and strategic (i.e. done to achieve positive response with defined audiences at particular times). There are a variety of characteristics that impact a given situation: situation context, demographics, ideology, homogeneity/heterogeneity, occasion, need, and genre (Keith \& Lundberg, 2008). A critic can consider the role of any of these elements when analyzing the construction of the rhetorical artifact. As Keith and Lundberg (2008) summarize, a "speaker wants something from the audience: their attention, their patience, their openness, a change of mind, a change of action" (p. 19). A rhetor creates a text to persuade their audience, thus it is essential for a critic to consider the audience.

Kuypers (2016b) acknowledges that ascertaining what to include or exclude in a criticism is vital. The three categories for organizing a rhetorical analysis are: description, interpretation, and evaluation (Kuypers, 2016b). The analysis presented in this thesis about the Literacy Center of West Michigan's (LCWM) blog articles applies these three parts to the method of rhetorical criticism by (1) describing the organization and its discourse in context as a single case example, (2) analyzing the case and its discourse through the lenses of Foucault and public relations, and finally (3) evaluating the case and discourse for effectiveness in terms of Foucauldian public relations for literacy centers.

\section{Description}

The description part of a rhetorical criticism only provides an illustration of the case and its artifacts/texts, but it also presents information pertaining to the relevant theoretical framework that will be used in the criticism (Kuypers, 2016b). Description section takes into account the 
audience, because the "way you describe the artifact may well be the only exposure they have to it" (Kuypers, 2016b, p. 29). This approach necessitates judicious thought on the part of the critic to effectively provide a complete visualization of the case and its texts (Kuypers, 2016b). This description is provided with context given charting where and when the text exists. The case's and texts' significance needs to be underscored in this section, to provide a reason for this criticism to be undertaken (Kuypers, 2016b). However, conveying the importance of the criticism needs to be supplied throughout the criticism, particularly in the introduction, to give your audience a reason to take the time to digest the work (Kuypers, 2016b).

\section{Interpretation}

The second part of a rhetorical criticism involves both analysis and interpretation, which typically takes the majority of space used (Kuypers, 2016b). Analysis refers to finding "what is in a rhetorical artifact," while interpretation concerns "determining what a rhetorical artifact means" (Kuypers, 2016b, p. 30). The analysis and, notably, the interpretation specifically apply principles from selected theoretical orientations (see item 5 in the "Methodological Unit" section later in this chapter), which directs attention to what matters and what does not—what makes sense and what does not. This part will present analysis based on elements of public relations and Foucault to provide a comprehensive exploration of the texts.

Vital to this interpretive analysis is observing the case's texts for patterns that are relevant to the case and this project's thesis. To examine the 165 articles, I created data sheets, provided in the Appendix, organizing the articles. First, in the data sheet, and in this section, I divided the articles into each of the four categories that the LCWM provided: Learner Stories, Advocate Spotlights, Tutors, Community. There are three articles not belonging to a category, so I created 
an "Uncategorized" category for these articles. For the purposes of the interpretation, I will present characteristics of each category as is represented by the organization.

I went through each article and selected primary, secondary, and, if relevant, tertiary topics from each one. Description is provided for the rationale behind topic selection. Given the subjective nature of rhetorical criticism, the allocation of topics is based on my own judgement of the topics that best glean the main idea or ideas from each article. I offer examples of articles and how I determined their topics. The Appendix contains datasheets categorizing each article, date published, author (if provided), and the topics assigned. The LCWM News \& Blog is available online at https://literacycenterwm.org/news-blog.

\section{Evaluation}

The evaluation is the concluding section of the criticism, in which the critic uses the chosen theoretical orientation to appraise, pass judgement on a text or a case and its texts, as is the point for this thesis (Kuypers, 2016b). The judgements a critic makes about a text are far more complex than merely assigning "like" or "dislike" (p. 32), where particular criteria for passing judgement are based on the interpretive principles used in the preceding part of the analysis. The judgements involve comparing textual elements to particular criteria that come from the theoretical orientation that has governed the critic's work, providing an analysis of how the text works or not, how effective the text is or not (Kuypers, 2016b). The evaluative criteria will be presented in that part of the rhetorical analysis in the next chapter (see item 6 in "Methodological Unit" section below). For the evaluation to be effective, the critic must have provided a "fair-minded description of the inner working of the rhetorical artifact" and that "the standards of judgement used by the critic are provided for all to see" (Kuypers, 2016b, p. 32). In this way, then, a critic passes judgement on the artifact and the lens through which it was viewed, 
which is evident in the description and interpretation parts of the analysis. The critic needs to clearly explain how they arrive at a particular judgement about a text, using the evaluative criteria.

\section{Foucauldian Rhetorical Criticism}

Michel Foucault was a French philosopher, born in 1926, who examined the ways discourse influences society (S. Foss, K. Foss, \& Trapp, 2002). At the Paris École Normale Supérieure, Foucault obtained a philosophy degree in 1948 and a psychology degree in 1949 (S.

Foss, K. Foss, \& Trapp, 2002). This was followed by a psychiatry diploma course (S. Foss, K. Foss, \& Trapp, 2002). Foucault's early research concentrated on conceptions of madness, including how the idea is born out of the assumption of mental normalcy (S. Foss, K. Foss, \& Trapp, 2002). Foucault asserts that "once reason was established as supreme in Western culture," then "anything that constituted a threat to it was disregarded and excluded from the culture, including the notion of madness" (S. Foss, K. Foss, \& Trapp, 2002 p. 341-342). Foucault's work evolved to consider "the understanding of illness and the very concept of disease" through examination of empirical medical research by way of disease classification (S. Foss, K. Foss, \& Trapp, 2002). Foucault's research and teachings feature diverse interests including literature, political activism, the history of sexuality, ethics, and the role of power and knowledge (S. Foss, K. Foss, \& Trapp, 2002). Many of Foucault's ideas constitute a framework for assessing rhetorical validity in a text.

\section{Foucauldian View of Discourse and Discursive Formations}

Discourse is a crucial term in rhetoric because it is used to denote the variety of texts that can be created using language and symbols (visual, verbal, and nonverbal), and it is necessary to understand Foucault's view of the term. Foucauldian thought involves shedding commonplace 
assumptions about subjects in order to better understand how they operate (Foucault, 1972). For example, tradition is a deeply entrenched value in society that is not often explored further. Tradition "is intended to give a special temporal status to a group of phenomena that are both successive and identical" (Foucault, 1972, p. 21). Investigating this term allows for greater depth in what this term uncovers, as "tradition enables us to isolate the new against a background of permanence, and to transfer its merit to originality, to genius, to the decisions proper to individuals" (Foucault, 1972, p. 21). In this instance, Foucauldian thought probes the idea of tradition to offer insights into how tradition can function in society, particularly when juxtaposed with newness.

This deeper thought process about terms applies to understanding discourse, as well. Keith and Lundberg (2008) define discourse as "any speech, written or spoken, as well as the exchange of symbols or meanings in any context" (p. 4). This is a broad definition encompassing any kind of communication, which can then be examined rhetorically. For Foucault, discourse is equivalent to plural statements, with a statement "a set of signs or symbols to which a status of knowledge can be ascribed" (S. Foss, K. Foss, \& Trapp, 2002, p. 347). Discourse "is understood to be true in a culture" if "it follows particular rules" (S. Foss, K. Foss, \& Trapp, 2002, p. 347). Foucault (1972) delves into the idea of knowledge creation, particularly in how genre rules govern discourse categories in writing, such as fiction, history, science, or literature. A focal point of this perspective is that human reality is established again and again through discourse. Individuals become adjusted to this process and neglect to recognize the structures that are in place, through discourse, that control societal norms (Smudde 2007, citing Foucault 1969/1972). Discursive formations, or epistemes, are an important concept in Foucauldian rhetorical criticism. Also understood as "a world-view, a slice of history common to all branches of 
knowledge", discursive formations are "the total set of relations that unite, at a given period, the discursive practices that give rise to epistemological figures, sciences, and possibly formalized systems" (Foucault, 1972, p. 191). Discursive formations offer a means of understanding conventional governing rules in a system (S. Foss, K. Foss, \& Trapp, 2002). Described as "a cultural code, characteristic system, structure network, ground of thought, or style of organization that governs the language, perceptions, values, and practices of a system, a community, or historical period" (p. 348), discursive formations reveal how particular standards, conventions, or ways of thinking influence the creation of discourse (S. Foss, K. Foss, \& Trapp, 2002). Discontinuity is one means of revealing particular discursive formation, as exclusively "one discursive formation can dominate at any one time because the structure governing the discursive formation is so fundamental that...to think by means of another is extremely difficult" (S. Foss, K. Foss, \& Trapp, 2002, p. 348). It is through this discursive change that differences are made apparent.

\section{Power/Knowledge}

One of Foucault's key concepts is power/knowledge. Power can be difficult enough to define, but Foucault's notion of power requires even greater description to convey the meaning of the term. For Foucault, power is "the regulation of social conduct" through knowledge (S. Hall, 2001, p. 75). Foucault (1982) noted that "power relations are rooted deep in the social nexus, not reconstituted 'above' society as a supplementary structure who radical effacement one could perhaps dream of' (p. 791). This is important to note, as Foucauldian power exists in relationships. Similarly, Foucault did not view power as inherently detrimental, but as constructive (Foucault, 1980 as cited by Motion \& Leitch, 2007; Motion \& Leitch 2007). While frequently characterized as dominating, oppressive, or vindictive, Foucault finds power as a 
source of productive good use to society, because power is conferred through relationships among people (Foucault, 1980 as cited by Motion \& Leitch, 2007). For Foucault, power/knowledge reaches every part of society, with academic knowledge "the least harmful institutional site of the power/knowledge relationship" (Motion \& Leitch, 2007, p. 265). As Lee and Blood (2016) note, power may "often be exercised without any tinge of corruption" (p. 217). Foucault asserted that power "not only offered positive benefits to individuals and society but underlay all aspects of human existence" (Motion \& Leitch, 2007, p. 265). Therefore, power functions in an organization's apparatus and technologies, or techniques (S. Hall, 2001). Foucault does not find knowledge and power to be the same but, rather, inseparable symbiotic concepts (Foucault, 1980 as cited by Motion \& Leitch, 2007).

Knowledge is "inextricably enmeshed in relations of power" as it is used as a means of social control that hinges on discourse (S. Hall, 2001, p. 75). Motion and Leitch (2007) find Foucauldian ideas particularly relevant to the field of public relations, as power/knowledge relations are formed by public relations practitioners through the discourse they produce. A Foucauldian rhetorical approach "takes what has been accepted as the "natural way of doing things' and illustrates the manner in which what is seen as 'natural' is merely conventional" (McKerrow, 2011, p. 262). Foucault's notion of power/knowledge offers the opportunity to evaluate the discursive nature of literacy as represented by the LCWM. Discourse shapes the existence of what constitutes knowledge (S. Foss, K. Foss, \& Trapp, 2002) and as such, taking this theoretical orientation will uncover how News \& Blog acts discursively to create organizational knowledge, reveal power relationships, and guide overall structures of literacy conceptualization. Applying Foucault's ideas regarding power/knowledge to the study of literacy 
holds the potential to improve literacy center efforts to connect with and provide services to atneed populations.

While Foucault is the driving theoretical orientation for this thesis and its purposes, I want to acknowledge a similar theoretical framework that, while not the focus of this thesis, is a complementary viewpoint to the Foucauldian concepts presented. Constitutive communication recognizes phenomena "as socially constructed and contested, including its relationship to identity, power, and fairness" (Rickard, 2019, p. 6). While this theoretical framework is certainly a corresponding viewpoint to Foucault's concepts I have outlined, I argue that taking a constitutive approach would lead to an entirely different project, because it would focus on the social construction of literacy as opposed to the discursive construction. A constitutive communication methodology would not fit with the rhetorical analysis approach used here. Given that my goal is to illustrate how literacy is conceptualized and evaluate effectiveness of News \& Blog, I find that Foucault's concepts of discursive formations and power/knowledge are better suited to accomplish this task. In addition, the inclusion of public relations as viewed through a Foucauldian lens further directs the focus of this thesis away from constitutive communication.

\section{Case Example}

This thesis utilizes a case example approach, in which one organization is the focal point of the study to generate new insights for the field of public relations and literacy centers. A case example is different from a case study approach because the latter uses multiple methods of analysis to arrive at specific findings. In their book examining how public relations is inextricably tied to power, Courtright and Smudde (2007) note that the use of specific cases “explore[s] how public relations' power is obtained, used, and misused to create and recreate 
worldviews for good or ill" (p. 3). Further, the case example type used is descriptive, in which "to describe an intervention or phenomenon and the real-life context in which it occurred" (Yin, 2003, as cited by Baxter \& Jack, 2008, p. 548). As the description portion of the analysis will take into account the context this organization and texts exist, I argue that I am using a descriptive case example with the purpose of describing a phenomenon (in this instance, adult literacy center communication) and its context. This study uses a case example methodology that focuses on one literacy center organization to yield insights about literacy conceptualization and the role of power/knowledge in public relations about literacy and literacy centers. In this way, then, this thesis's deep examination of a case example adds to the body of research on public relations and power, and particularly so for literacy centers that rely on discursive action with their various audiences.

\section{Literacy Center of West Michigan}

As explained in the literature review, literacy centers and programs encompass a broad array of adult education services that take unique shape and form. The LCWM opened in 1986 in Grand Rapids, Michigan and produces education services for adults (LCWM, n.d.). On its "About Us" page, the LCWM asserts that it is "deeply grounded in the belief that West Michigan will thrive only when we can access the assets of all of our community members" (n.d., para. 1). Its clientele includes “adults who read below a 9th grade level and/or who don't speak English as their first language" (LCWM, n.d., para. 3). The organization maintains 25 employees, benefits from 300 volunteers, and has educated 764 learners in the previous year. Over 40 employers and organizations utilize the LCWM for its programs. One in eight adults within the community face literacy difficulties (LCWM, n.d.). The LCWM offers one-on-one adult tutoring, English classes, family literacy services in partnerships with local schools, business and workplace services, and 
other events and programs to promote literacy. The LCWM is a 501(c)(3) nonprofit organization that is classified as an "Adult, Continuing Education" organization (ProPublica, n.d.). This organization is representative of a typical literacy nonprofit organization that provides varied services for adult clientele.

\section{Texts}

A notable reason for this specific center to be studied is the extensive News \& Blog section of its website. Many literacy program websites in Michigan I accessed are rudimentary, with basic details on services provided, need for volunteers, and contact information. The LCWM is unique in its extensive cataloguing of the organization through the last five and a half years in articles on the News \& Blog section of its website. These articles cover five categories of perspectives that reflect on literacy and the center: learners, tutors, donors, community members, and miscellaneous. In this center, as in others, the center itself represents literacy and demonstrates its role in learners' acquisition of literacy skills that matter in learners' lives. As these articles cover multiple viewpoints, research about the four categories will yield a comprehensive understanding of the discursive factors in LCWM's representation of itself and literacy. Due to the specific categories directed at varied audiences, the News \& Blog is worthy of study as emblematic of the public relations materials for literacy centers overall.

As the LCWM is continually publishing new articles, I set January 29, 2021, as the cutoff date for new materials. The first article was published online June 8, 2015. Between June 8, 2015 and January 29, 2021, 163 articles were published and categorized. There are five categories for articles: Learner Stories, Advocate Spotlights, Tutors, Community, and Uncategorized (i.e., the topics of the articles vary greatly and do not fit into the other categories). Table 3.1 provides a breakdown of the number of articles for each category. 
The topic-drive categories have been generated from each article's content. In fact, it is important to note that the first four categories are defined by LCWM. Importantly, articles can address multiple and interrelated subjects. So, primary, secondary, and, in some instances, tertiary topics, have been identified from each article. The allocation of a topic as primary, secondary, or tertiary pertains to how prominent a particular topic is to the overall article, with primary topics being used to place an article into one category while noting the supporting topics. Detail about how each topic was generated and the distribution of primary, secondary, and tertiary topics will be covered in the description portion of the rhetorical criticism of the News \& Blog articles and LCWM.

\section{$\underline{\text { Table } 1}$}

Number of Articles in News \& Blog

\begin{tabular}{|c|c|}
\hline Category & Number of articles \\
\hline Learner Stories & 51 \\
\hline Advocate Spotlight & 35 \\
\hline Tutors & 45 \\
\hline Community & 29 \\
\hline Uncategorized & 3 \\
\hline
\end{tabular}




\section{Methodological Unity}

Given these three components of rhetorical criticism, Foucault's approach to discourse, and public relations, there must be a singular approach to using them. The fundamental aspects of any rhetorical criticism are description, interpretation, and evaluation. These three elements will guide the overall structure of the analysis chapter to follow. The interpretation and evaluation sections will utilize components of effective literacy communication, Foucauldian analysis, and public relations. The fundamental aspects of a Foucauldian analysis are identifying the cultural codes that determine language structures and generate knowledge production and power relations (S. Foss, K. Foss, \& Trapp, 2002). Fundamentals for effective and ethical public relations, especially Foucauldian public relations, are clear and relevant message source, and that content is appropriate for the specific audience it is targeting. For this project, I will focus on uncovering how and why the LCWM does what it does. The process is as follows:

1. Draw out from the literature the salient principles about effective literacy communication and Foucauldian public relations to (a) guide the interpretation of the case and, in turn, (b) be used as criteria to evaluate the case, its texts, and the method of Foucauldian rhetorical criticism of a public relations case about literacy centers.

2. Identify primary, secondary, and, if relevant, tertiary topics in articles. Organize articles based on topics to illustrate patterns.

3. Select examples of the Center's News $\&$ Blog content that span a five-and-a-half year period. That span of time is reasonable because it covers the length of News \& Blog from its beginning in 2015 to now in 2021. 
4. Describe the artifacts from News \& Blog according to its organization context that includes the historical, discursive, and interpersonal features that pertain to literacy construction.

5. Interpret the artifacts according to (a) Foucault's principles for discursive formations and power/knowledge, (b) institutional principles for effective literacy center communication, and (c) field-oriented principles for effective public relations, especially those born out in Foucauldian analyses of PR.

6. Evaluate the artifacts against a single set of criteria for effectiveness that blend Foucault, literacy centers, and public relations.

\section{Conclusion}

This chapter presented the methodology to be utilized in this thesis. This approach combines literacy communication, Foucault, and public relations research into one cohesive approach for using rhetorical criticism as the means of applying these three elements in a specific case example. This methodological approach is unique in that these three areas have not before been combined in a rhetorical criticism, which should prove to be useful to other literacy organizations like the one featured in this project's case example. Using this particular methodology will accomplish my goal of evaluating the effectiveness of the literacy center's public relations materials, which will, in turn, provide literacy centers with greater insights into communicating effectively with their publics. This goal is important, as illiteracy is a serious problem in the U.S. that greatly inhibits the ability to function successfully in society. Improving literacy center communication offers centers the opportunity to better communicate with their publics and provide adults struggling with literacy a means of reclaiming their education. 


\section{CHAPTER IV: ANALYSIS OF THE CASE}

Case examples offer a means of focusing on one organization to provide insights for a particular field at large. This case example centers around the Literacy Center of West Michigan (LCWM), as it is representative of adult literacy centers and examining its discourse sheds light on literacy representation as a whole. In this section, I present the results of this case example through rhetorical analysis of the LCWM's News \& Blog. News \& Blog offers a space for individuals who struggle with literacy to share their stories. It is also representative of literacy discourse. There are three main parts to this section: description, interpretation, and evaluation. In the description portion, I present background information about the organization to provide context for the principle texts (i.e., articles in News \& Blog) it produces. The interpretation section takes a deeper look at these articles, particularly in how the Foucauldian notion of power/knowledge is revealed through discourse pertaining to literacy and public relations action from the organization. In the evaluation, I will present my judgement on the rhetorical validity of the articles, with particular attention to how these articles connect with varied audiences, represent literacy, and demonstrate Foucault's concept of power/knowledge.

\section{Description}

Before providing an interpretation and evaluation of the LCWM's News \& Blog content, it is necessary to first give context to the organization and where the News \& Blog fits into its organizational discourse. There are two parts to the description section: providing an overview of the case and the organization at its core, and supplying the collection of texts that form the basis of the subsequent interpretation and evaluation. The overview of the case will examine the organization's history and relevant historical events to demonstrate how the LCWM and its 
discursive action are contextually situated. The second part of this description pertains to the collection of News \& Blog texts and resulting topic selection and organization.

\section{Overview of the Case}

The LCWM began in 1986, preceding the first large scale survey in the U.S. of adult literacy rates in 1992. The Economic Opportunity Act of 1964 was the first major move of federal involvement in adult basic education, signed by President Johnson as a means of eradicating poverty (Department of Education, 2013; Eyre, 2013; Matthews, 2014; Levitan, 1969 as cited by Bailey \& Duquette, 2014). President Johnson noted how adult education can be a means of offering opportunity and reducing poverty, and federal funding of adult education programs signaled the importance of the issue. The LWCM asserts that 1 in 8 adults in the local area struggle with literacy, and the organization has a sizable immigrant clientele seeking to develop their English language skills. The LCWM's mission statement is "to bring about a just and vibrant West Michigan through the power of literacy. This will only be possible when literacy levels are high, thus unleashing the full potential of all members of our community" (n.d.). It is important to note that the organization's mission statement, in addition to providing its goals, also justifies the reason for its existence.

Program Assistant Nancy VanIngen details that when she joined the organization in 1990, the center was called the Kent County Literacy Council (VanIngen \& Payne, 2015). The organization then shifted to become the Literacy Center of West Michigan, discursively widening its geographic range. News \& Blog does not appear to be the organization's first attempt to catalogue the experiences of the organization through articles, but it is the identifiably longest and most prominent. Some News \& Blog articles mention The Reader, an email newsletter, and some articles even have links to PDF versions of this newsletter. However, 
mention to The Reader is sporadic, and the organization lacks a clear repository of these newsletters. Website visitors can offer basic information and their email address to sign up for a newsletter, but it is unclear whether this newsletter is the same as The Reader, which, given the lack of recent mention, may be an outdated communication form. News \& Blog supplies audiences with 165 articles for free that require no obstacle to access, such as submitting a name and email address, thus it is the most comprehensive system of message dissemination on its website.

News \& Blog is part of the LCWM's sophisticated and up-to-date online communication. The organization has a comprehensive website explaining the services offered, with a sleek design, photos, and consistent color palette. The organization regularly updates its social media platforms including Facebook, Instagram, Twitter, YouTube, and LinkedIn. The LCWM has a permanent physical location in Grand Rapids as a site for learning, although events and services may be utilized at different local spaces. The COVID-19 pandemic that resulted in a shift to remote working options since March 2020 also affected the LCWM. In-person services and tutor orientations transitioned into online formats. Some articles include photographs of Zoom meetings, which emerged as a popular synchronous online meeting format since the start of the COVID-19 pandemic. In its 35 years, the LCWM has stayed up-to-date with technological and communicative changes, utilizing frequently updated social media channels, News \& Blog, and the website itself, pivoting to online instructional formats necessitated by the pandemic.

\section{Collection of the Case's Texts}

The set of 165 texts for this case, summarized in the Appendix and referred to in Chapter 3, are the focus of this rhetorical criticism of LCWM and its discursive action. Patterns that exist among the texts must be described to provide an accurate overview of the texts to be interpreted 
and evaluated later in this chapter. Those patterns play into the specific interpretive and evaluative portions of rhetorical criticism of the case. This part addresses the pattern present within each of the four categories of texts: Learner Stories, Advocate Spotlights, Community, and Additional Stories.

\section{Learner Stories}

This category is for articles pertaining to learners of the LCWM and their experiences. Articles in this category were published between May 10, 2016 and December 23, 2020. There are a total of 51 articles under this category, constituting $39.19 \%$ of total News \& Blog articles. Considering that literacy centers as a whole exist to provide clientele with education services, I find it crucial to devote a substantial portion of this description area to providing information on this category. The majority of Learner Stories feature immigrant subjects who utilize the center as a place to develop English language skills. These articles center on immigrant experience, particularly in describing cultural and language assimilation, and the desire to improve English language skills to better integrate into society and obtain or improve at a job.

\section{Immigrant}

Thirty-seven articles have a primary topic of "immigrant," representing $73 \%$ of all Learner Stories. Articles that included description of a learner moving from another country to the U.S. were determined to have a topic of "immigrant," given that English-language acquisition was a strong motivating factor for the learner, and thus, an important part of the learner's overall experiences at the center. For example, an article published December 23, 2020 titled From Learning to Volunteering: Sonia's Story begins, "Sonia moved to West Michigan from her native Mexico in 2019 and found the Literacy Center soon thereafter" (Roper, 2020). Given that this article establishes Sonia as an immigrant from Mexico and follows her efforts to 
learn English and integrate into the community, I determined that the "immigrant" topic was the primary topic.

The first Learner Stories article, which I labeled as “immigrant,” was published May 10, 2016 and was written from the perspective of learner Alejandra. In the Right Place: Alejandra, Learner details Alejandra's work ethic as a crew trainer at McDonald's, motivated to improve her English to make her job smoother. Written entirely in first person, this article establishes Alejandra as a 38-year old wife and mother, who dabbled in different English classes before arriving at the LCWM and finding it a perfect fit. Through her improved English, Alejandra is better able to perform her job, received a raise, and is more "helpful" in supporting her children's schoolwork (Alejandra, 2016, para. 5).

When two topics are present, such as an article about an immigrant improving their English through the organization's services (the two topics being "immigrant" and "English language learning"), I select "immigrant" as the primary topic. This is due to my argument that the need to learn English in the U.S. is dependent upon being an immigrant speaking another language. The identity of a person as an immigrant creates a unique set of circumstances that necessitate learning English, thus I argue that the topic of "immigrant" is primary to the article contents. In instances where an article mentioned an individual learning English but did not specify coming to the U.S. from another country, I identified alternative primary topics, as to not make larger assumptions as to their backgrounds if not provided. There are different secondary topics and a few tertiary topics generated in articles that have a primary topic of "immigrant": English language learning, work opportunity, and family work \& education opportunity. These secondary topics were created to further specify the substance of each article. 


\section{Adult Education}

Adult education is the next most prominent primary topic present in Learner Stories. I found seven articles that fall under this overall topic. This topic was selected at the mention of education services utilized at the center, with either specificity as to learners being from the U.S. or the absence of information related to their background. In the case of the latter, "adult education" was selected as a primary topic if there was no reference to using English language classes. The articles I identify as "adult education" are representative of Learner Stories focusing on individuals learning in adulthood.

\section{Additional Categories}

There were additional topics identified that did not constitute great frequency in the Learner Stories category but are still necessary to note in order to provide a complete depiction of this section of News \& Blog articles. The other primary topics I identified were: English language learning, citizenship acquisition, virtual learning, work opportunity, work, and gardening. Some of these topics were also secondary or tertiary topics. "English language learning" was a topic I identified in the majority of "immigrant" stories, and as a primary topic on its own in some cases where immigrant background was not established. Eighteen articles that had "immigrant" as a primary topic also used "English language learning" as a secondary topic, indicating that Learner Stories predominantly focuses on the English language learning efforts of immigrants in the U.S. through the LWCM's services.

\section{Advocate Spotlights}

This category makes up 35 News \& Blog articles ranging from March 10, 2016 to January 11, 2021. These articles emphasize the various roles supporters of adult literacy education have taken within the organization. 


\section{Staff Profile}

"Staff profiles" were the primary topic of 16 Advocate Spotlight articles. I identified this as a primary topic in the articles if a staff member was interviewed, and/or the articles explored their professional background, hobbies, professional responsibilities and duties, or in some easily recognizable way communicated that the overall purpose of the article was to provide a description of a staff member.

\section{Staff Reflections}

"Staff reflections" made up 6 Advocate Spotlight articles. While these articles also concerned staff members and their role within the organization, I identified this topic as separate from the previously identified "staff profile" topic for one main reason: these articles emphasized the day-to-day or the lived experience of working at the organization. These articles did not so much emphasize the professional background or responsibilities of the staff member, but rather, cultivated a sense of what performing the job actually is like.

\section{Additional Topics}

I identified additional primary topics in the remaining Advocate Spotlight articles. These topics appeared in either four or less articles, so I will not devote a separate section to these topics but provide them here. "Volunteer profile" appeared in 4 articles, while 2 articles are "board member profiles." "Learner and Staff" was the primary topic in another 2 articles. These primary topics only appeared in one article each: volunteer reflection, profile, teaching materials, in memory, and advocate.

\section{Tutors}

There are a total of 45 articles under the Tutors category, published between January 4 , 2018 and April 17, 2020. No articles have been published under the Tutors category since April 
2020, and the next oldest article was published in June 12, 2019. Thirty-four of the total 45 articles were published in 2018. News \& Blog launched in June 2015, while the Tutors category did not come into fruition until January 2018. The creation of this category in 2018 is important to note, because an early article details the purpose of this category:

In these articles, we will be talking about textbooks, reference books and supplementary materials in our Tutor Library, tutors' stories, and other relevant information. Our intention is to introduce materials that could be interesting and useful for you, our tutors. Also, we wish to create a space for you to share your experiences, challenges, and accomplishments as tutors at the Literacy Center of West Michigan. (LCWM, 2018, para. 2-3)

Articles posted under the Advocate Spotlights category prior to the creation of the Tutors category in 2018 and after described the work of LCWM staff members and volunteers.

\section{Teaching Materials}

I identified "teaching materials" as the primary topic of 25 articles, comprising the majority of articles under the Tutors category. These articles featured suggestions for books, instructional index cards, and similar materials that tutors could utilize. For example, a September 15, 2018 article titled Accessible and Relatable Grammar Instruction, September's AZ Textbook | Focus on Grammar written by Literacy Coordinator Katherine Payne highlights the easily digestible information provided by this particular grammar textbook series.

A key difference between Focus on Grammar and other grammar resources is the amount of contextualized instruction built into each unit. Each unit builds upon the previous one, utilizing reading comprehension exercises with pre- and post-reading activities and detailed explanations of each grammar subject. 
Additionally, each unit utilizes sample photos, maps, articles, and emails to connect grammar skills to necessary life skills. From listening and conversation skills, to creating unique writing pieces, each unit allows learners to build grammar skills in all areas of instruction. (Payne, 2018, para. 4-5)

\section{Tutor Profile}

"Tutor profiles" accounted for 18 articles, or 42\%, of articles in this category. I selected this primary topic if an article featured an interview with a tutor, described or profiled a tutor, or discussed the experiences and interactions between a specific tutor and learner, as the emphasis of these articles was on the tutor experience. These articles explored the professional backgrounds of tutors, motivations of both staff and volunteers, personal moments between tutors and learners, and overall reflections of the experience.

\section{Community}

There are 29 articles under the Community category, with publication dates ranging from March 29, 2016 to January 13, 2021. This category combines a multitude of topics pertaining to the LCWM. The primary topic with greatest frequency in this category was "event," with articles promoting upcoming events, summarizing previous events, or providing information pertinent to literacy-related events.

\section{Event}

I identified articles as having a primary topic of "event" if the article's contents made any mention of belonging to a larger event. For example, the August 16, 2017 article Reading by Third Grade: Our Shared Opportunity, Our Shared Responsibility highlighted issues of childhood literacy: 
As many of us have heard by now, third grade reading is the most important predictor of high school graduation and career success. According to The Campaign for Grade Level Reading, approximately $67 \%$ of children nationwide are not proficient readers by the end of third grade. It jumps to $80 \%$ for children from families with low incomes. Locally, half of all students in Kent County are not reading proficiently by third grade. For students of color, that number rises to $74 \%$. (Nassar, 2017, para. 2)

The article then transitions into describing the then-upcoming 2018 Community Literacy Summit as an opportunity to discuss this issue: "The Summit will create a dynamic space for sharing our understandings and exploring opportunities for optimizing reading success for children in West Michigan" (Nassar, 2017, para. 5). A September 11, 2020 article, The Impact of Partnerships, presented the positive impacts of previous in-person events, like Storytime in the Park, and reflected on adapting to the events during the COVID-19 pandemic, which prevents large in-person events (Wahlstrom, 2020). While the article discussed how such events originally came about and numerous professional partnerships in the community, the overall point is the success of events; thus, I identified "event" as the primary topic, given that the specific contents are dependent upon that idea. I identified five articles out of twenty-nine, or $17.24 \%$ of Community articles, as having a primary topic of "event."

\section{New staff member}

Four articles utilized a primary topic of "new staff member." These profiles introduced the new staff member, occasionally previous professional experience, and other get-to-know-you pieces of information. For instance, an article published on November 2, 2020, Dr. Yilin Wendland-Liu Hired as Adult Tutoring Program Director, introduces the new staff member and provides a description of the duties and responsibilities they are taking on. The article then 
discusses Dr. Wendland-Liu's professional background, including teaching experience relevant to the position (Literacy Center of West Michigan, 2020a). Dr. Wendland-Liu provides quotes establishing her motivation to work at the LCWM and what she hopes to gain from the position (Literacy Center of West Michigan, 2020a).

\section{Award Recipient}

Four articles feature "award recipient" as their dominant topic. These articles typically profile people who have supported literacy programming in some way and are now receiving an award based on their efforts. One of these articles pertains to the LCWM itself receiving the Governor's Service Award, given "by Governor Whitmer and the Michigan Community Service Commission at a ceremony on Thursday, September 5 at the Detroit Opera House" (Literacy Center of West Michigan, 2019b, para. 1).

\section{Additional Topics}

The topics discussed here appeared in either one or two articles, which I assert does not constitute enough of a pattern to devote separate sections for, but which are important to note when describing this category of articles. Two articles contain a primary topic of "keynote speaker announcement" and each of these articles provides information on event keynote speakers recently acquired, their qualifications, and what insights they will bring to the event. Two articles feature a primary topic of "pandemic," in which the center specifically addresses the organization's response to COVID-19, and necessary rules and adjustments. Other primary topics identified include: project proposal, work opportunity, issues in literacy, obituary, event venue, conference, staff, immigrant, immigrant experience, and grant recipient. Some secondary topics were identified, which were determined to be secondary in that the article contents are less reliant on it and more dependent upon the nature of the primary topic. Several articles share both 
primary and secondary topics, which can be viewed in the Appendix. Secondary topics identified in the Community category are: work opportunity, partnership, award recipient, issues in literacy, partnership success, childhood literacy, family literacy program, professional background, and English language learning.

\section{Description Summary}

This description presented relevant information pertaining to the case and the texts. First, I charted the history of the organization from its inception in 1986 to the present day in 2021, while additionally demonstrating where the organization fits in relation to notable historical moments. The LCWM predates the first national survey on adult literacy skills in 1992, and had undergone different changes, such as being renamed from Kent County Literacy Center to its current title - the Literacy Center of West Michigan. Technological advancement in the past decades have transformed the ways organizations interact with their publics. The LCWM utilizes its website to host a blog, News \& Blog, with 165 articles of relevant, engaging, and insightful information about the organization. Now that these elements have been laid out, I will now introduce the interpretive principles to guide further exploration of the texts.

\section{Interpretation}

Public relations discourse provides valuable insights into the characteristics of the LCWM and its participation in the discourse community of adult literacy. The LCWM's News \& Blog reveals key features about the organization. In the broadest sense, between the dates of June 8, 2015 and January 29, 2021, the LCWM published 165 articles in News \& Blog. Over those years, the publication features nine webpages of articles. These include article titles, category (Learner Stories, Advocate Spotlights, Tutor, Community), date, and a short description or excerpt. 
Within the context of the organization and where News \& Blog fits into its overall public relations efforts, an interpretation of the case will focus on the discursive features of News \& Blog and on LCWM as a function of the discourse communities in which it participates. The process for interpretation of the case and its text will follow a simple and direct series of steps for analyzing the texts. My interpretation uses the three theoretical perspectives discussed in the previous chapter-Foucault, literacy, and Foucauldian public relations — as a guiding framework for the overall structure of this section. I will provide the principles I will use to guide my interpretation for each of the three theoretical perspectives and apply them to the four principal article categories: Learner Stories, Advocate Spotlights, Tutors, and Community.

\section{Foucauldian Power/Knowledge}

Michel Foucault was a critical scholar who evaluated the relationship between discourse and the construction of knowledge within discourse communities. From his ideas regarding power/knowledge and discursive formations, I composed a list of principles to apply to the interpretation of News \& Blog. News \& Blog is emblematic of the overall episteme of literacy center discourse and the discourse community in which the LCWM operates. By discourse community, I am referring to "a group of individuals bound by a common interest who communicate through approved channels and whose discourse is regulated" (Porter, 1986, p. 3839). News \& Blog is an example of an approved channel, as it is published by the organization, and regulated, in that the organization needs to approve content before it becomes available through this channel. Essential to taking a Foucauldian perspective in interpreting the texts, discourse governs everything. For Foucault, anything "that can be spoken about in a particular discourse community is knowledge" (S. Foss, K. Foss, \& Trapp, 2002, p. 347). Knowledge within a discipline is controlled by the discourse that exists in that discipline; "there is no 
knowledge without a particular discursive practice" (Foucault, 1972, p. 183). Knowledge is "both a creator of power and a creation of power" (p. 265), resulting in the inseparability of these terms (Motion \& Leitch, 2007). As S. Hall (2001) details, Foucault's notion of power is "the regulation of social conduct" (p. 75). However, this exists in the complex, varied, interwoven relationships between organizations, audiences, and other invested parties (Foucault, 1982; S. Hall, 2001). From these concepts, I derive the following principles:

1. Organizational discourse can be used as a means of examining the episteme

2. Discourse creates knowledge particular to the discourse community it is situated in

3. Power and knowledge reinforce one another through discourse

Key to the identification of discursive formations and relevant elements of News \& Blog is S.

Foss, K. Foss, and Trapp's (2002) observation to locate "a grouping of statements that suggests a consistent pattern, an order, or a regularity in how those statements function as constituents of a system of knowledge" (p. 348). While I have already presented topic patterns in each of the four categories, there are other examples of systematic regularity. A Foucauldian interpretation of the case, using these principles, will be applied at both the micro and macro levels in each category of stories in News \& Blog. The microlevel focuses on the texts and the macrolevel focuses on the organization.

\section{Learner Stories}

It is through the Learner Stories articles that the organization discursively maintains its success by assuring potential learners of the benefits of its programs, while also ensuring continued support from donors and volunteers who view the organization as a success. As Foucauldian principle 2 establishes, knowledge is created through discourse, and it is through an organization's discourse that knowledge within that specific discourse community is revealed. 
Learner Stories created for News \& Blog demonstrate audience segmentation by the organization. The intentional division of articles into categories reveals audiences and relevant parties to the adult literacy community as seen from the perspective of the organization. This is an example of discourse creating knowledge. Applying Foucauldian principle 3, it is through discourse that the relationship between knowledge and power is reinforced. By developing a specific category for learners, the organization is acknowledging the importance of this population to the episteme.

The majority of Learner Stories share immigrant stories. Given that the organization needs to commission these articles, so to speak, and identify participants to either provide their story in first-person or to have a staff member interview, or write an article about the learner, organizational oversight is present in these texts. Foucault stresses that who is given permission to speak can reveal governing rules used by the organization to maintain power in controlling what is considered organizational knowledge (S. Foss, K. Foss, \& Trapp, 2002; Foucault 1972 as cited by S. Foss, K. Foss, \& Trapp, 2002). The discourse community of the adult literacy center necessitates the existence of a clientele of adult learners seeking out adult education programs. The community, and thus the organization, would not exist without this population. Their centrality in News \& Blog indicates their importance to the episteme. The LCWM would not, in fact, be the organization it is today without these individuals.

While Learner Stories offer a space for individuals who struggle with literacy to share their story and experiences, this category also functions to control the role the LCWM plays. This demonstrates Foucauldian principle 3 in which power and knowledge reinforce one another through discourse. It is through News \& Blog that the LCWM exerts its power in the subject matter of Learner Stories. The absence of failure, learners dropping out, or not succeeding within 
the program suggests that the LCWM guarantees success. The theme of success arrived at through the LCWM creates a discursive formation in which the organization is responsible for the goals achieved by learners. However, this likely is not always the case-within other educational institutions, like kindergarten through high school grades, or colleges and universities, despite the best efforts of dedicated educational professionals some students do not end up succeeding. These students may end up being held back, transferring to other schools, performing well enough to obtain a high school diploma (like in the case of Charla Peterson, who earned a high school diploma through homeschooling, but was unable to read well), or drop out completely and quit education. It is a reasonable claim, then, that some learners enroll in courses at the LCWM and do not succeed. In the first Learner Stories article published, learner Alejandra details how she enrolled in similar programs in the community, before landing on the LCWM. Arguably, other learners could enroll in the LCWM, find its programs unfulfilling or not working, before seeking out alternative adult education services in the area. The absence of any reference to failure or not improving at reading it is not altogether surprising, given that organizations seek to use written material to attract clientele, donors, volunteers. Therefore, while Learner Stories provides knowledge about the clientele of the LCWM, it also demonstrates the complexity of power in the existing relationships between learners. The LCWM needs to both maintain strong relationships with its clientele and discursively reinforce organizational success through its learners.

\section{Advocate Spotlights}

The creation of this category by the LCWM reveals that the organization has other parties invested in the success of the organization and of the success of adult literacy programs, outside of learners. Foucauldian principle 1 ascertains that organizational discourse can be used as a 
means of examining the episteme. I find that the Advocate Spotlights category uncovers characteristics relevant to the episteme of adult literacy work. As discussed in previous chapters, the LCWM is a nonprofit organization, and as such the organization is heavily reliant on donors, volunteers, and community advocates to help the organization's mission succeed. How then, does the adult literacy center episteme, the entirety of all related parties to programs and centers dedicated to improving literacy, characterize itself? What are its defining elements that distinguish it from the larger nonprofit community? Notably, one early article describes the overall episteme of literacy center communications, and thus providing a look at how this discourse operates. VanIngen details how the organization constitutes a type of nonprofit organization separate from other forms of essential nonprofit work, like providing food and housing. In her description, VanIngen concisely justifies the existence of adult literacy work. We've had a lot of fun through the years, and we've always had a really great staff, too. I think the people that work for non-profits are kind of special. They have servant hearts, and they're here because they want to help people. They probably know that they could be making a lot more money in the for-profit sector, but there's just something very special about helping people find that tool that's going to help them. Many times, tutors share with me when they come in for interviews that they really just want to see that "light" go on for other people. I understand that it's important for people to have food, shelter, and clothing, but if we can give them literacy skills, we're giving them a tool to provide those other things for themselves and for their families. And that's why we're here. (VanIngen \& Payne, 2015, para. 7)

This article is the earliest in the Advocate Spotlights category, indicating that the purpose of this category is to highlight the importance of adult literacy programs and showcasing 
individuals who do so. There are other noticeable ways that the LCWM is emblematic of adult literacy discourse, as opposed to being grouped in with nonprofit discourse. In that early article, VanIngen justifies adult literacy work, while also foreshadowing that the following articles provided in News \& Blog are for this specific discourse.

\section{Tutors}

As Foucauldian principle 2 states, knowledge and power reinforce each other through discourse. As discussed earlier, learners are a crucial part of the adult literacy center episteme; it doesn't exist without them. Similarly, adult literacy work also needs a group of qualified individuals to provide the actual instruction to learners. In the Tutors category, tutor profiles and teaching materials were the two most commonly identified patterns I identified in topics, demonstrating important relationships between knowledge construction about the tutors, while indicating their power in that they are an essential population to the organization's survival. Having a space for tutors to share their stories and insights into working with learners discursively indicates that they are important to the center, and that their voices, their experiences, are just as important to the organization as the journeys of learners. The prevalence of articles referring to teaching materials also reinforces this; these articles are instructional guides for tutors, and the repository of articles is meant to be used by tutors in their work, which signals that the organization prioritizes their interests and work. Additionally, the existence of teaching material articles reveals how adult literacy discourse diverges from overall nonprofit discourse and shapes a separate episteme. This demonstrates Foucauldian Principle 1, in which organizational discourse can be used as a means of examining the overall episteme. Such articles would not be needed in the discourse of nonprofit organizations centered around providing housing, food, or legal reform. 


\section{Community}

Foucauldian principle 1 underscores that the discourse of an organization can be used to understand the larger episteme. This is demonstrated in the Community category of News \& Blog. Any organization does not exist in isolation to its surroundings, be they geographical or social. Central to the notion of literacy acquisition is how literacy functions in people's lives; their ability to connect, engage, and interact with the community at large. The existence of the Community category reveals that the LCWM finds the at-large community a literacy program is placed crucial to the episteme, further revealing what the organization prioritizes. Given that the LCWM establishes that literacy is deeply embedded in the local community (included in its mission statement), this category connects the organization to the larger environment in which it is located. Rather than literacy work being something that is done at a formal setting with relevant parties scattering afterward to their homes, leaving the work they've done behind them, this category reinforces the organization's belief that literacy is part of the community. The article Mark Peters: The Hidden Issue of Low Literacy in the Community category was written by Butterball Farms, Inc. CEO and the Chair of the Literacy Center's Donor Development committee Mark Peters. In the article, Peters notes the necessity of literacy skills in the employees of his company. Indeed, "if the people coming to work in my organization cannot understand work and safety instructions, the costs could be huge" (2018, para. 3). Peters (2018) also discusses how widespread the issue of illiteracy is in the community, forcing readers to consider that they have likely had interactions with people who struggled to read, but didn't realize it. The Community category similarly serves to underscore the necessity of adult literacy work, while connecting the organization to the community it is situated in. 


\section{Summary}

Using Foucault as a critical-theoretical framework reveals ways that the LCWM creates knowledge about the adult literacy community. An episteme is "a certain structure of thought that the men of a particular period cannot escape - a great body of legislation written once and for all by some anonymous hand" (Foucault, 1972, p. 191). Positioning adult literacy as an episteme, the LCWM is a prime example for investigating how its extensive News \& Blog creates knowledge. Additionally, given the close relationship between power and knowledge, News \& Blog reveals how power relationships are conducted in its discourse. While each of the four categories exhibits characteristics about different audiences, Learner Stories especially shows how adult literacy discourse needs to elevate the voice of learners, a traditionally voiceless population. As has been expanded upon in the literature review chapter, those who struggle with literacy often feel shame, and are unable to take part in many important areas of society that need reading skills. Particularly in offering a space to share their stories, either in first-person or through a staff member, Learner Stories creates knowledge about this population, while giving them the power to tell their own story. However, power is not so simply demonstrated in Learner Stories in that the organization selflessly provides this to learners. In creating a designated space for Learner Stories, the LCWM has control over what learners share, and this space is positioned to convey organizational success. Applying a Foucauldian perspective to News \& Blog allows us to explore these relationships, and how the LCWM is emblematic of the overall episteme of adult literacy community.

\section{Literacy Communication}

In being the main public relations vehicle for the LCWM, News \& Blog is uniquely positioned to shape our understanding of literacy representation and conceptualization. Literacy 
is central to the organization's mission. A loaded term in itself with many available definitions identified in literacy research, literacy is key to the LCWM's discourse. The Organisation for Economic Co-operation and Development (OECD) offers a succinct, but comprehensive definition of what literacy is:

Literacy is defined as the ability to understand, evaluate, use and engage with written texts to participate in society, to achieve one's goals, and to develop one's knowledge and potential. Literacy encompasses a range of skills from the decoding of written words and sentences to the comprehension, interpretation, and evaluation of complex texts. (OECD, 2013, p. 59)

From this definition, I generated the following principles to guide my interpretation of literacy representation by the LCWM. Using the OECD's (2013) definition of literacy, a complete representation of literacy should include how comprehension or use of written texts result in:

1. Societal participation and integration with the community

2. Achieving personally defined goals

3. Fostering knowledge and potential on a personal level

These principles will guide my interpretation of how literacy is represented and conceptualized throughout the four News \& Blog categories. For literacy to be effectively represented in News \& Blog, the organization needs to provide examples of how literacy or the acquisition and improvement of literacy skills allow learners to: engage, participate, and interact with the community they live in, accomplish fulfilling personally-defined goals, and advance knowledge and potential of the self. I will identify examples in News \& Blog that indicate how literacy is being used or what literacy acquisition can provide in a person's life. One single article need not 
demonstrate all three principles, but they should be appropriately represented throughout the 165 articles in order to truly reveal what literacy is and how it is situated in the lives of learners. Using these principles for effective literacy representation, my interpretation will examine each of the four article categories.

\section{Learner Stories}

These articles function to demonstrate the role literacy plays in their lives and, thus, is important to conceptualizing literacy (literacy principle 1). First, there are minor grammatical errors kept in the article, including run-on sentences and lack of capitalization in Mexico City. This raw authenticity lends itself to discursively experiencing the world as Alejandra interacts with it. This simplicity also aids in the contents of the message being understood by readers of varying levels. Alejandra (2016) first attempted taking other English classes but found them "too easy” (para. 2). She subsequently “tried many other places as well but in many they said I didn't have the requirements needed to take the classes" (2016, para. 2). With an opposing binary established of classes too easy and classes with too strict requirements, the LCWM fits neatly in the center as the "right place" (2016). Alejandra is given power as a learner, as only she is able to authentically convey the experience of a learner, particularly as an immigrant seeking to improve her English. Alejandra describes the class; "we learned about medical health, we learned how government works, the difference among everyone's cultures and my own. I also learned new vocabulary that helped me be more confident in the way I express myself in my job" (2016, para. 4). Alejandra notes that "now I am able to train new employees and be more helpful to my managers" (2016, para. 5). This section asserts improvements that result from her English skills, and the "now" at the beginning of the sentence suggests transition, of using the LCWM as a "tool", as VanIngen describes later, to better perform her job, provide for her family, and interact 
with the community. Articles similar to Alejandra's describe the motivations of immigrants to improve their English and use it as a means of integrating into American society.

The LCWM Learner Stories also detail how English speakers who struggle with reading join the center, in addition to revealing reasons as to why the issue remains prevalent. In the article, In My Own Words: Charla Peterson, Learner: My Past Does Not Define the Future, Peterson (2016) explores how long-term homeschooling left her behind academically, which translated into difficulty reading as an adult. Darkened by shame, Peterson (2016) only revealed her struggles to her husband after they were married. It is reasonable to wonder why, in the present day in American society with education requirements for children and teenagers, there are adults in the U.S. who struggle to read. Peterson's experience is representative of students who slip through the cracks in the education system in being homeschooled without regular supervision from education professionals who can ensure that her at-home program can keep up with the standards deemed necessary in public education. Peterson earned her high school diploma, but feels she did not earn it, and holds it in name only. Peterson spotlights the issue of children and teenagers who may officially have proceeded to the next grade level or obtained a high school diploma, but without the necessary skills to function in society. Rather than focus this article on how the center transformed her life, this article interrogates the preconceived assumptions that high school diploma equates reading at the level of a high schooler. Other articles presented by the LCWM establish how other learners have used its services and acquired reading, writing, and English skills to better integrate into society and to perform better professionally. This article, however, presents the reader with another problem-that of literacy in their backyard. The literacy struggles of neighbors, coworkers. This article creates a space to explore how illiterate adults in the U.S. function, hiding the issue in shame. 
The organization is needed not only to assist immigrants in learning English, but needed because there are people that slip through U.S. education standards without it being realized until too late and the child has left the system. Then, shame forces the now-adult individual into hiding the problem. This article convinces people like her, U.S. adults who were not afforded the opportunity of an equal education, to step forward and confront the problem head-on. An editor's note at the bottom updates readers on Peterson's progress, noting that "Like Charla, many native speakers of English struggle to admit that they need help with literacy." (2016). This addition to the article supplies organizational reinforcement to Peterson's story.

\section{Advocate Spotlights}

Literacy principle 3 ascertains that fostering knowledge and potential on a personal level is necessary. Here, I want to bring up the LCWM's mission statement, that was included earlier in this chapter. The LCWM ascertains that they want to use literacy as a means of "unleashing the full potential of all members of our community" (n.d., para. 2). Potential is mentioned both in the OECD's (2013) definition that I used to develop literacy-specific principles. I argue that this notion of potential is one used throughout the adult literacy episteme, in which literacy skills are connected to potential. Additionally, the 1964 Economic Opportunity Act, while using different verbiage, also conveys this point, in that low-literate individuals "whose inability to read and write the English language constitutes a substantial impairment of their ability to get or retain employment commensurate with their real ability" (Economic Opportunity Act, 1964, p. 520).

Given that the Learner Stories described above include subsequent and specific improvements to their lives as a result of literacy, News \& Blog is reinforcing the idea that these individuals are inherently capable of succeeding, when provided with sufficient skills to read and communicate. However, given the prominence of this theme in adult literacy discourse, learners could also be 
influenced by this existing discourse and shape their experiences to fit this narrative. As the LCWM's mission statement is readily accessible on their "About Us" page on the very same website that houses News \& Blog, learners could be influenced by these terms as they enroll and go through programs to make sense of their own experiences. Additionally, given that articles are either written by staff members or go through a review process before being published, the organization could also be framing article contents to align with particular concepts familiar within the episteme. Nonetheless, it is evidence that fulfilling one's potential is an important concept to adult literacy.

In order for this to be achieved, the organization where this takes place needs to adequately position itself as a site of personal growth through its discourse. The first News \& Blog article published establishes the LCWM as a compassionate place by giving the organization a face. The article, 25 Years of the Literacy Center: An Interview with Nancy, covers the necessities expected of a public relations piece commemorating an employee's 25 th anniversary with an organization, in covering major organizational changes witnessed while at the organization: change in name, size of the organization, growth in the number of programs (VanIngen \& Payne, 2015). However, there are key elements in this article that humanize the organization and make it seem less like an institution of education.

The first is that the employee, Nancy VanIngen, is referred to exclusively as Nancy, with the exception of an introductory sentence spelling out her whole name-25 Years of the Literacy Center: An Interview with Nancy (VanIngen \& Payne, 2015). The title of the piece itself only uses her first name. This makes the organization feel like a real person that prospective learners can be on first-name basis with, encouraging prospective learners, particularly immigrants with little experience interacting with U.S. agencies, to approach this educational institution. When 
VanIngen describes having her "fingers in a lot of different pieces of the pie" (2015, para. 5) when detailing her role and responsibilities within the organization early on, this discourse forgoes institutional jargon in favor of humanizing colloquialisms. Given that VanIngen describes at-length the responsibilities and realities of tutoring, prospective tutors, be they volunteer or paid staff, are prioritized in this article. Prospective tutors could resonate with VanIngen's story of her career and feel inspired to create a similar career. However, at the same time, the humanizing characteristics of the article also appeal to prospective learners, who may be hesitant to enroll in adult education for a number of reasons, like the stigma of adult illiteracy (C. Doak, L. Doak, \& Root, 1996). While reluctant learners may hesitate to approach Ms. VanIngen, Program Assistant, they may be more willing to seek out Nancy, longtime resident and reading enthusiast. Given that this was the first article published in News \& Blog, it is rhetorically positioned to offer a humanizing image of the organization to audiences.

VanIngen's message, and the Advocate Spotlights category as a whole, produce an entirely separate division of nonprofit work: adult literacy service. VanIngen (VanIngen \& Payne, 2015) distinguishes nonprofit staff from for-profit staff in that they give up the opportunity for higher income to provide a social service for individuals in need. However, VanIngen carves out a space exclusively for literacy nonprofit work. This is ascertained by two elements: the first, that VanIngen notes how literacy is a means of providing for oneself, much like "food, shelter, and clothing" (VanIngen \& Payne, 2015) and that the LCWM is a "tool" to make that happen. This discourse establishes a foundation for News \& Blog in justifying the importance of the organization and the work it does. While literacy may not be as immediate a short-term need as food or a having a warm place to sleep, literacy is a means of obtaining those essential services long-term through sustained employment made possible by basic adult skills. 


\section{Tutors}

Literacy principles 1 and 2 emphasize how literacy functions in a person's life. Literacy enables individuals to participate in society and the community they live in. It also allows individuals a means of accomplishing their goals. The Tutors category chronicles the work of LCWM tutors and their experiences with learners, revealing how literacy instruction shapes learners. Phil Wittry, a tutor at the LCWM, wrote and published An Increase in Confidence in 2018. This article describes Wittry's background, motivations for tutoring, and experiences working with learners. A large portion of this article details Wittry's work with learner Addison, who "grew up in Grand Rapids and dropped out of high school after a couple of years" (para. 2). Addison's goals revolve around potentially obtaining a GED and reading the Bible. While Addison's overall reading ability increased, "the most significant change, in my opinion, has been the increase in his confidence" (Wittry, 2018, para. 3). Wittry (2018) describes his enthusiasm for Addison to test out of the program. This article clearly describes the goals of the learner, what he has achieved both personally and academically, and provides an end to Addison's need to be in the program — achieving high enough test scores to proceed with his education elsewhere.

\section{Community}

Literacy principle 2 emphasizes the connection between literacy and accomplishing goals. However, this principle is not restricted to only learners at adult literacy centers and programs. Learning at the TESOL Conference (2018), under the Community category, conveys how staff members utilize a conference as a means of furthering their skills to provide such services. This article describes that they "were able to meet and learn from other English teaching professionals from around the world" suggesting that the tool that is literacy in the 
larger machine of the organization was sharpened by this professional convention, receiving even more specialized knowledge with which to improve teaching practices (Summers, 2018, para. 1). Summers and her colleagues learned "best practices in working with refugees, aligning curriculum with standards, creating meaningful professional development, naturalization, and consumer literacy" (2018, para. 2). Summers notes that as a result of the convention the staff is "back with fresh ideas, encouragement, and tools, and are excited to continue serving in our community" (Summers, 2018, para. 3). This rhetorically serves to position the convention as something that benefits the local Grand Rapids community by bettering the employees teaching practices and providing inspiration and fresh motivation to continue with their work.

\section{Summary}

Using the principles for effective literacy representation based on the OECD's (2013) definition of literacy to guide my interpretation of News \& Blog offers a means of exploring how the organization conceptualizes literacy. Literacy itself is central to the organization, as it is its mission, purpose, and reason for existence. Further, it's important to understand exactly why adult literacy is such a necessary research area. Literacy allows people to more fully participate in their own lives by expanding potential opportunities. Learner Stories emphasizes the positive role improved literacy plays, while Advocate Spotlights demonstrates motivations for people to volunteer or work at the center-enabling this type of progress for learners. The Tutors category provides information for potential tutors to understand the role tutors play. These articles detail the relationships between tutors and learners, and further reinforces the positive outcomes of learners improving literacy skills. Additionally, the Community category expands the role of literacy beyond that of the organization to how it affects the overall locale. 


\section{Foucauldian Public Relations}

Public relation is the "strategic communication process that builds mutually beneficial relationships between organizations and their publics" (PRSA, n.d., para. 4). Public relations acts as "an instrument of power" (p. vii) in that its discourse is meant to "inspire intended audiences to behave in desired ways" (Epley, 2007, p. vii). Public relations as viewed through a Foucauldian perspective reveals how public relations materials are influencing the society in which we live. Foucauldian public relations is an existing, but not expansive, area of research

that addresses this. Foucault's critical perspective works well when applied to public relations, as Foucault's principles look at "some of the deeply problematic, contradictory and even questionable aspects of this complex profession by placing meaning production, power effects, truth claims and knowledge systems at the centre of our thinking and investigations" (Motion \& Leitch, 2007, p. 263). Foucauldian public relations, then, "means that human discourse creates and recreates human reality, including that for organizations, not the other way around" (Smudde, 2007, p. 207). The key component of Foucauldian public relations is that "public relations, with its purview covering communication activities for a diverse range of internal and external audiences, can be seen as the key discursive actor between organizations and their publics" (Smudde, 2007, p. 207).

Part of effective public relations involves clearly defining target audiences and constructing appropriate materials for that audience. For instance, the specifics of messages promoting literacy programs to learners will differ greatly from messages soliciting donations from community members. Jae (2014) found that the "one-size-fits-all" (p. 52) approach utilized by the READ Center was ineffective. One noteworthy reason for this conclusion was that there was a lot of written content "that participants were demotivated from trying to read" (Jae, 2014, 
p. 53). Focus group participants, who were learners at this center, concluded that its promotional materials seemed geared for prospective donors and tutors. They did not feel that the center's promotional materials were targeting them (Jae, 2014). In their instruction of creating patient materials for low-literate audiences within a healthcare setting, C. Doak, L. Doak, and Root (1996) find that excessive written content dissuades low-literate audiences from reading. Additionally, written materials that have more information on them than necessary hides the most important information for patients (C. Doak, L. Doak, \& Root, 1996). Given the paradoxical nature of using written materials to appeal to low-literate audiences, effective literacy communication needs to market itself differently to its unique audiences. Providing headers, putting the most important content first, and providing contextual information first are ways to improve the readability of text (C. Doak, L. Doak, \& Root, 1996). As Kelleher (2018) describes, "the best writers have a good sense of who their readers are" (p. 222).

Rhetorically, audiences are multifaceted and the speaker composes a message desiring "something from the audience: their attention, their patience, their openness, a change of mind, a change of action" (Keith \& Lundberg, 2008, p. 19). Goals drive speakers to craft specific messages (Keith \& Lundberg, 2008). In the case of literacy center communication, centers use written messages as a means of convincing low-literate audiences to utilize their services. Kelleher (2018) provides a public relations perspective when considering target audiences, or a "group of people strategically identified for their propensity to consume an organization's products, services or ideas" (p. 75). Many individuals are interested or involved in an organization that do not have a financial stake. These publics are important to the organization and the organization must seek to maintain those relationships (Kelleher, 2018). For example, centers rely on volunteers, may host free events, or simply be a resource about literacy in the 
community. There is a great variety in how content for the Learner Stories category is presented. Some articles are written in first-person from the perspective of the learner. These articles serve to forge a deep connection between potential learners who may possess sufficient reading skills to understand the article, and become inspired by these stories of success.

Message design must consider how words, visuals, and forms work together (Pettersson, 2012). Additionally, consistency among communication materials is necessary to ensure that News \& Blog functions overall as a uniform piece of public relations. Technology journalist Erica Swallow emphasizes the importance of developing both editorial guidelines and a content theme when working on an organizational blog (as cited by Kelleher, 2018). This concept works well alongside Foucault's idea in which "one describes the conceptual network on the basis of the intrinsic regularities of discourse" (Foucault, 1972, p. 62). Elements of message design are relevant to the construction of effective public relations materials but are also indicative of discursive formations that reveal power/knowledge relationships. Thus, "the rules of formation operate not only in the mind or consciousness of individuals, but in discourse itself; they operate therefore, according to a sort of uniform anonymity, on all individuals who undertake to speak in this discursive field" (Foucault, 1972, p. 63).

Public relations discourse shapes the episteme, which in turn shapes the ways people read, write, and discuss the adult literacy center episteme. These ideas can be distilled into the following principles for Foucauldian public relations that guide the interpretation of the LCWM case:

1. Messages have a clear target audience in mind 
2. Messages are produced for this audience to develop or maintain a relationship between this audience and the organization, revealing insights into how messages demonstrate power/knowledge relationships

3. Clear guidelines are evident in the use of the four categories and in the overall content and structure of articles. These guidelines or rules for formation of discourse also reveal characteristics of the episteme of adult literacy center communication.

One means of identifying intended audience, relationship formation and maintenance, and guidelines is to notice where inconsistencies exist. Taking a Foucauldian public relations perspective merges elements of message design with Foucauldian principles. Noticing "points of incompatibility" (Foucault, 1972, p. 65) within News \& Blog articles can reveal structural patterns in the texts. The four News \& Blog categories also indicate audience segmentation by the organization, and assessing the topics present in each category can guide the interpretation of intended audiences. While the Foucault and literacy parts of this interpretation have assessed the four categories - Learner Stories, Advocate Spotlights, Tutors, and Community —in that order and devoting a separate subsection to each, I will combine the Advocate Spotlights and Tutors into one subsection. As I will detail further, the Advocate Spotlight and Tutor categories are intrinsically connected in that they have a similar intended audience and overlap in subject matter.

\section{Learner Stories}

Applying Foucauldian public relations principle 1, in which messages need to articulate an intended audience, the Learner Stories category presents a clear audience. Given that the majority of Learner Stories present in articles are immigrant learners seeking to utilize the center's services to improve their English language skills, current and prospective learners are a 
clear intended audience for this category of articles. As detailed in the Foucault section of this interpretation, learners are a crucial element of the episteme of adult literacy. Without learners, there is no organization. Thus, for the organization to succeed, it needs to attract learners. Learner Stories function to draw in prospective learners in two main ways. One way is for potential learners to read articles, resonate with their experience, and decide to enroll in programming. The other is for community members to read these articles to become convinced of the center's effectiveness, and then persuade friends, family members, coworkers, or other people they know to utilize the center's services.

Foucauldian public relations principle 2 ascertains that these messages, in seeking to develop a relationship between this group of individuals and the organization, demonstrate how power/knowledge relations function in this episteme. Learner Stories, while constructing knowledge relevant to the episteme, signify the power learners hold in relation to the organization; the LCWM would not exist without learners. The 2017 article In her own words: Doroty Delli Ficorelli uses first-person narration to describe Doroty's move with her family from Italy to the U.S. and her use of the LCWM to improve her English language skills (Ficorelli, 2017). Many other Learner Stories articles are also in first-person, such as the 2019 article Now I Can Help my Children with Homework: Gonzalo's Story (Gonzalez, 2019). The use of first-person indicates the organization's efforts to authentically represent the experiences of learners, so that potential learners will feel that the success current learners experience will be their experience at the center. From a Foucauldian perspective, Learner Stories seemingly ensures prospective learners that the path to personal or professional success is through the center's services. 


\section{Advocate Spotlights \& Tutors}

Foucauldian public relations principle 3 indicates that the guidelines or rules present for the formation of discourse reveal features of the episteme of adult literacy communication. The Advocate Spotlights and Tutors categories have been merged here, as I argue that this is a "point of diffraction" (Foucault, 1972, p. 65), in which the organization attempts to use either category as a means of providing information on staff and volunteers. However, the organization does not clearly define the distinction between these categories, which will be discussed here. Many Tutors articles profile LCWM tutors in an interview style, with the article specifying who is facilitating the interview and who the piece is profiling. Beneath the questions are the respondent's answers, written in first person. This format is easy-to-follow and ensures that tutors' raw testimony about their experiences stays as unchanged as possible. However, within the Tutors category, there are noticeable deviations to this pattern.

For example, Learning Together: Paul and Livingstone specifies that an interview was conducted by Literacy Coordinator Thomas Rodgers. A brief third-person biography introduces tutor Paul Conlon and his learner Livingstone (Rodgers, 2018). The article then contains subheadings of topics, such as "Favorite Lesson: The Airport" or "Advice for Potential Tutors." However, rather than have Paul or Livingstone's first-person answers provided, the content beneath these subheadings are paragraphs written in the third-person. This approach makes it unclear to the reader who the actual author of the overall content is. If Literacy Coordinator Thomas Rodgers wrote the article, rather than including a line "Interviewed by Thomas Rodgers," a byline specifying the author would be sufficient. There is also a lack of consistency in the use of quotation marks around interview responses. Some interview-style articles, such as Tutor Spotlight | Legacy of Tutoring, include paragraph first-person answers from the tutor being 
interviewed, with no quotation marks around answers (Buys, 2019). This is understandable, as the reader can recognize that answers following the questions are the responses of the person being interviewed. However, other articles like July's Featured Tutor Spotlight, Limerick Lessons with Steve and Maria, include quotation marks around the respondent's answers, while all other formatting remains consistent (Loar \& Payne, 2018). This suggests a lack of an organization style guide to ensure consistency and professionalism throughout all written information.

While the Tutors category overall clearly outlines its intended audience, current and potential tutors, the frequency of use calls into question its functionality. The first article was published in this category in January 2018 and the majority of articles were published in 2018 . The Tutors category took a decline in 2019 , with only ten of the total 45 articles published then. The most recent use of the category was in April 2020. Given the emergence of the COVID-19 pandemic in the U.S. in March 2020, the organization could have shifted priorities away from utilizing this category. However, considering its decline in usage since 2018, I argue that the organization was already shying away from using this category. Few articles were published under the Advocate Spotlights category in 2018 and no articles used this category in 2019. However, 14 of the 35 articles using this category were published in 2020, indicating an uptick in use of the Advocate Spotlights category. The LCWM pulled away from using the Advocates Spotlight category at the height of the Tutors category use, and then subsequently went back to utilizing the Advocate Spotlights category as the primary means of communicating about organization staff and volunteers. The Tutors category is restricted in that the individuals profiled are tutors for the center. Some are volunteer tutors, while others tutor as part of their job, or are employees for the organization in another capacity who volunteer as a tutor. However, the 
Advocate Spotlights category is not so restricting in that it can profile staff members who are not exclusively or partially tutors, but provide other services for the organization.

\section{Community}

Foucauldian public relations principle 1 details that messages need to have a clear target audience in mind. There are numerous topics of articles within the Community category, indicating that rather than having one targeted audience, like the Learner Stories or Tutors category, this category is meant to provide information for an overall community, a larger catchall category for anyone connected to the center. For instance, I identified events as a topic in seven of the 29 Community articles. Events can involve numerous audiences relevant to the center, from community members, donors, and current staff to learners.

There are even some direct references to the concept of community within this category. The 2017 article Building Community at the Literacy Center provides insights into the organizational climate to allow community members the opportunity to better understand the organization. Patton (2017) notes that "developing a strong community within a classroom is one of the keys to educational success" (para. 1), while pointing out that learners, particularly new immigrants, experience feelings of isolation. Thus, "we strive to create a sense of community in order to lessen some of that isolation and 'otherness' that our learners might experience outside the Literacy Center" (para. 1). While the experiences inside the classroom are referred to in other article categories, this perspective is unique in that it represents the organization's goals. Rather than one specific audience benefiting from insights such as this, the Community category is for varied audiences. There are numerous topics and subjects for articles, signaling that this category is to capture the breadth of the organization, from award recipients to project proposals, new staff profiles to pandemic-specific information. 


\section{Summary}

Having used the outlined principles for effective public relations to structure my interpretation reveals the ways News \& Blog functions as a channel of public relations for the organization. The existing categories provided by the LCWM reveal the intended audiences of each category, and thus the different intended audiences, and relevant parties, of News \& Blog and the organization. Additionally, both existing patterns and inconsistencies in message design become apparent when examining discursive elements of the texts.

\section{Interpretation Summary}

Using interpretive principles based on Foucault, literacy, and Foucauldian public relations, I argue that the LCWM's News \& Blog is representative of the episteme of adult literacy center discourse. This discourse features demonstrating how literacy center work is different from the work of other nonprofit organizations while also still operating as a legitimate nonprofit organization. Structural elements of the News \& Blog reinforce this point as well as show how the organization is connected to the larger locale in which it is situated through stories in all four categories. This approach again reveals how News \& Blog generate discursive expectations relevant to the discourse community of the LCWM and the overall episteme of adult literacy center communication. Using the principles for effective literacy representation, News \& Blog features numerous examples displaying how improved literacy has played a positive role in learners' lives as they perform their jobs better, feel more confident, acquire citizenship, vote, or help out children with homework. News \& Blog is constructed for multiple audiences, the separation of each of the four categories serves to help readers find content that is best suited to their needs. 


\section{Evaluation}

News \& Blog is representative of the overall episteme of adult literacy center discourse. However, it also functions at the primary public relations channel for the LCWM, and needs to connect with audiences to effectively serve a multitude of purposes. Having provided context for the organization and texts, and interpreting News \& Blog articles according to the principles discussed, I will now evaluate how News \& Blog functions based on a criteria for effectiveness blending Foucault, literacy centers, and public relations. The 165 articles that make up News \& Blog are a repository of information that yield insights into how literacy is conceptualized and organizational discourse specific to literacy centers. To help visualize the ways that these three frameworks work together, Table 4.1 presents the principles I introduced in the interpretation part of this chapter adapted to function as evaluative criteria for assessing effectiveness. 


\section{Table 2}

\section{Criteria for Effectiveness}

\begin{tabular}{|c|c|c|}
\hline Foucault & Literacy & Foucauldian Public Relations \\
\hline $\begin{array}{l}\text { Power and knowledge } \\
\text { reinforce one another } \\
\text { through discourse }\end{array}$ & $\begin{array}{l}\text { Societal } \\
\text { participation and } \\
\text { integration with the } \\
\text { community is } \\
\text { presented }\end{array}$ & $\begin{array}{l}\text { Audience-centered messages are produced } \\
\text { that develop or maintain relationships } \\
\text { between target audiences and the } \\
\text { organization, revealing insights into how } \\
\text { messages demonstrate power/knowledge } \\
\text { relationships }\end{array}$ \\
\hline $\begin{array}{l}\text { Discourse creates } \\
\text { knowledge and affirms } \\
\text { power relationships }\end{array}$ & $\begin{array}{l}\text { Knowledge and } \\
\text { potential are } \\
\text { fostered on a } \\
\text { personal level }\end{array}$ & $\begin{array}{l}\text { Messages impart salient information } \\
\text { audiences want, need, and use }\end{array}$ \\
\hline $\begin{array}{l}\text { Organizational discourse } \\
\text { is used as a means to } \\
\text { examine the overall } \\
\text { episteme of the discourse } \\
\text { community }\end{array}$ & $\begin{array}{l}\text { Goal achievement } \\
\text { is stressed }\end{array}$ & $\begin{array}{l}\text { Clear message-centered guidelines are } \\
\text { evident in the content and structure of } \\
\text { articles about the four story categories and } \\
\text { the organization according to its mission } \\
\text { and vision }\end{array}$ \\
\hline
\end{tabular}

These principles are lined up to show similar or complementary ideas among these three theoretical frameworks. Overall, I argue that there are parts of News \& Blog that are effective at achieving its goal of providing public relations materials for diverse audiences while being 
representative of adult literacy center communication as a whole. However, there are also elements of News \& Blog that are not effective, as they do not match the criteria above. This evaluation will assess News \& Blog on both a macro level, in how the LCWM's discourse functions in the episteme of adult literacy center communication, and the micro level, judging the individual texts.

\section{Foucauldian Power/Knowledge}

Effective discourse necessitates clearly demonstrating how power and knowledge reinforce one another through discourse. The adult literacy episteme needs to allow discursive space for learners to present their stories and describe the role literacy acquisition plays in their lives. On a macro level, the episteme, and the organization in question, cannot exist without learners. They are an integral component to adult literacy centers, and the LCWM's emphasis on Learner Stories positions learners as central to the organization. Articles listed as Learner Stories are exclusively made up of actual learner stories. Articles under this category create a discursive formation with clear criteria - the subject of the message typically is a learner who has utilized the center's services and found success. The LCWM uses "Now I Can..." in many titles, such as Now I Can Dream in English (Summers, 2020a), Now I Can Vote in a Presidential Election: Maria's Story (Summers, 2020b), and Now I Can Help My Children with Homework: Gonzalo's Story (Gonzalez, 2019). "Now I Can" is used by the center to emphasize what learners are currently able to do as a result of improved literacy, ultimately positioning the center as a means of providing success. The depth of these articles provides insight into immigrant experience in the U.S., particularly in navigating speaking and learning another language. These articles vary greatly, as well, which adds to their overall strength, but are cohesive enough to have one unifying theme. Variance in articles can be seen in the different authors, from the learners 
themselves writing in first person to the more polished prose of literacy center staffers. News $\&$ Blog both generates knowledge about the lives of learners, while providing these individuals with the opportunity to share their story. This reinforces how knowledge and power are inextricably linked to News \& Blog. Given that the episteme of adult literacy pertains to providing education services for an adult clientele who struggle with reading, this is a notable feature of News \& Blog and the overall episteme; prioritizing the experiences and lives of learners.

Organizational discourse creates knowledge and affirms power relationships. The episteme of adult literacy necessitates particular consideration for these power/knowledge relationships given the many relevant publics. News \& Blog effectively charts these complex relationships. The Learner Stories articles provide insights into individuals who struggle with literacy and/or English language skills, while also discursively underscoring the organization's success by only presenting learner stories that are successes, so to speak. By avoiding including articles in which learners at the center do not find success, the LCWM is controlling the discourse, reinforcing its ultimate power in defining the episteme. Power between learners and the organization is not so simply conceptualized as one party either has it or doesn't. Rather, in taking a Foucauldian approach, the nuances in power conveyance can be revealed through the relationships between learners and the LCWM personnel, especially tutors. Articles in other categories highlight the efforts and work of volunteers, another crucial audience to the organization. The organization relies on volunteers, and providing articles on their work simultaneously reveals the role volunteers play in the episteme and underscoring the power they wield in the organization's long-term survival. Organizational terminology and its potential influence on learners and News \& Blog content has been touched on before, but I find it fitting to 
include in the context of discussing Foucault. The LCWM's mission statement references "potential," which is also the same word used in the OCED's (2013) definition of literacy and used in my literacy principles and criteria. As potential, confidence, and improvement are recurring throughout News \& Blog, existing organizational discourse could affect the way learners describe their respective stories. Adult literacy discourse could also be acting as an organizational restraint on staff members, who now view literacy in a particular way and are compelled to write about it in a particular way, thus perpetuating the existing structures and thought processes surrounding adult literacy. Ultimately, it becomes difficult to ascertain the exact flow of power within the episteme, but that particular relationships can be examined discursively.

The overall episteme of the discourse community can be examined by analyzing organizational discourse. Literacy center discourse is not a well-researched area in the communication discipline, but it is well-documented. News \& Blog spans a period of five-andhalf years, cataloguing the organization's discourse through the stories of learners, tutor profiles, events, program changes as a result of the COVID-19 pandemic, teaching materials, awards, and other relevant topics to the discourse community through 165 articles. This positions News \& Blog as an effective means of examining the overall episteme. News \& Blog acts as a repository of adult literacy center discourse.

\section{Literacy}

Texts that effectively represent literacy need to demonstrate how literacy enables societal participation and integration with the community. Maintaining employment is an important part of participating in society and obtaining financial security. News \& Blog articles note how improved literacy has allowed for different examples of societal participation. Ewing (2019) 
congratulates learner Pedro de Ingunza Aguilar for graduating from his adult literacy program. Pedro "can communicate better at work, pronounce words better, and understand what people say" (Ewing, 2019, para. 1). Summers (2020b) describes how learner Maria is able to vote for the first time in a U.S. presidential election. Maria's tutor "helped her prepare to become a citizen by explaining the Constitution, quizzing her on the 100 questions, and practicing for the interview with her" (Summers, 2020b, para. 1). Maria's tutoring experience was tailored to her particular needs in how she would use English language literacy skills to interact with the community. For example, given Maria's excitement to vote for the first time, "Maria and Denise looked over their ballots, reading through the proposals and looking at the various positions" (Summers, 2020b, para. 4). News \& Blog effectively demonstrates how literacy leads to societal involvement.

Although visual imagery is not the primary focus of this thesis, I find it relevant to include information about photos and images the LCWM provides on its website and in News \& Blog to reinforce the written messages produced. Given that many learners struggle to read, the LCWM needs to be intentional in design choices aside from written content. The LCWM's (n.d.) homepage features three rotating photos. Each photo stays for several moments before being replaced by the next image. The first image features two individuals. This is the dominant image that greets visitors to the website, and I argue is an intentional effort of the part of the organization to allow potential learners to identify with existing learners at the center. The homepage shows a tutoring session taking place, with a man in a baseball cap and a woman holding a piece of paper. We should infer, by the bookcases in the background and the one-onone nature of the interaction, that this is a tutoring session. This photo then transitions into an image of two adults and two children; presumably they are a family. Given that many learners 
are parents, this allows for visual identification on the part of current or prospective learners. The third image is of letter pieces lying on top of printed pages of text, visually displaying the literacy-focused mission of the organization. Many News \& Blog articles include photos relevant to the written content. I argue that the inclusion of photos is to both complement the written text and provide a means of conveying content to audiences who may not be able to read the accompanying articles.

The next criteria for evaluating effectiveness of literacy representation is that the texts need to show how knowledge and potential are fostered on a personal level. Learner Addison enrolled in literacy programming "to develop his reading comprehension and understanding of The Bible and possibly pursuing his GED” (Wittry, 2018, para. 2). Addison's tutor remarks that his confidence has drastically improved and is related to his improved literacy skills. Wittry (2018) notes that when Addison "advances in his level of reading, his overall confidence continues to increase. It is a wondrous, virtuous cycle" (para. 3). News \& Blog effectively explores nuances in literacy acquisition and the development of the self.

The final criteria for judging effectiveness of literacy representation is emphasizing goal achievement. News \& Blog does this in a variety of ways. First, Learner Stories provide examples of how improved literacy has helped obtain a goal of some kind. Istanbul immigrants Fatos and Apo used the English language skills acquired through the center to achieve their goal of opening up a restaurant in Grand Rapids (LCWM, 2019a). However, achievement pertaining to literacy is not restricted to learners. The 2019 article, The Literacy Center Honored with Governor's Service Award, presents the organization as worthy of particular attention (Literacy Center of West Michigan, 2019b). 


\section{Foucauldian Public Relations}

Foucauldian public relations establishes that public relations materials act discursively to shape societal reality about a phenomena. As the "key discursive actor between organizations and their publics" (Smudde, 2007, p. 207), communication produced by the organization can be examined from this particular perspective. The audience-centered messages produced by the organization need to develop or maintain relationships between target audiences and the organization to function effectively. These relationships, revealed through discourse, present information on how power and knowledge discursively reinforce each other. As a whole, News $\&$ Blog effectively considers audiences and the role messages play in the maintenance of the relationship between audience and organization. However, there are examples where the LCWM could more effectively structure its content to develop or maintain relationships between relevant parties and the organization. Given the set-up of the News \& Blog, in which audiences view a list of article titles with brief synopses, the full article is accessed through clicking on the article title. This requires that the title accurately and concisely inform the reader of the article contents, as the audience learns from the title of a piece if it is worth reading. Thus, article titles need to be constructed with the audience in mind. The LCWM fails to do this in some instances, weakening the overall effectiveness of its public relations materials. For example, a compelling message from LCWM Executive Director Dr. Wendy Falb about the necessity of immigrants to the U.S. and the importance of inclusion is hidden beneath the title Fiscal Year 2015 Annual Report Released (Falb \& Literacy Center of West Michigan, 2016). While a link is provided to this report at the top of the page, the overwhelmingly compelling message directly addressing and advocating for equality vanishes, as few people are likely to select such a bland title when searching for information on the center's views. Given the largely immigrant clientele of the 
center, the center should make more of an effort to push information validating immigrant experience to the forefront of its public relations. Especially given the majority of immigrant narratives in Learner Stories, the LCWM could consider creating a designated immigrant category. Given the power than learners hold in relation to the organization's existence, the LCWM needs to critically evaluate the needs of this population.

The next criteria for assessing effectiveness is that messages need to impart salient information audiences want, need, and use. The Tutors category, when it was frequently utilized, contained many articles pertaining to teaching materials, providing important and useful information for tutors on options for instructional materials to use in the classroom. However, the Tutors category has not been frequently used since 2019 (only one article was published in 2020), halting the regular production of messages for tutors. In order for News \& Blog to effectively provide useful messages for this audience, the organization needs to consider the needs of tutors. It is possible that the LCWM received feedback indicating that the teaching materials article were not of assistance. However, it does not appear to be replaced with alternative content designed to serve a similar purpose. It is worth pointing out that, aside from this example, News \& Blog features articles relevant to audience concerns. For instance, when the COVID-19 pandemic forced business shutdowns and working from home in March 2020, the organization replied with Literacy Center Response to COVID-19 published March 13, 2020 (Literacy Center of West Michigan, 2020b).

The final criteria for evaluating effectiveness from a public relations perspective is that content and structure of article categories clearly demonstrate message-centered guidelines, with consideration to the mission and vision of the organization. Learner Stories functions effectively as public relations in part because the category follows this criteria. The organization's mission 
statement (n.d.) is "to bring about a just and vibrant West Michigan through the power of literacy. This will only be possible when literacy levels are high, thus unleashing the full potential of all members of our community." Learner Stories clearly communicates implicit guidelines that structure its articles: they need to be learner-centered, detail usage of the center's services, and promote success. When it was used, the Tutors category reflected consistent patterns in content, indicating that there were clear parameters in creation of content for the category. However, there is a lot of overlap with the Advocate Spotlights, and to some extent the Community category. Staff profiles, tutor profiles, and new staff member articles all fall under the larger umbrella of reflecting the discourse of the organization from the perspective of the people who work or volunteer there. For example, the article Dr. Yilin Wendland-Liu Hired as Adult Tutoring Program Director is posted under the Community category (Literacy Center of West Michigan, 2020a). A subsequent article profiling Dr. Wendland-Liu, About Adult Tutoring Program Director Yilin Wendland-Liu was published under the Advocate Spotlights category (Literacy Center of West Michigan, 2021). The distinction between where information about staff should be published is not entirely clear, particularly with the sharp decline in use of the Tutors category. Given that the Community category seeks to connect with a broader audience, the hiring of employees might serve as an announcement for organizational changes, while the Advocate Spotlights category serves at the discursive space to explore the work and motivations of these individuals. Reflecting back on the inconsistent nature of formatting interviews discussed earlier, the organization would greatly benefit from constructing a style guide to ensure consistent formatting of interviews. 


\section{Evaluation Summary}

As a whole, News \& Blog demonstrates how the episteme of adult literacy discourse operates. As many adult literacy centers, like the LCWM, are nonprofit organizations, they belong to the broader nonprofit episteme. Nonprofit organizations function differently from forprofit companies, which means that there is an inherent distinction in their respective discourses relevant to their specific needs. For instance, nonprofit organizations are greatly reliant on the work of volunteers, and as such, nonprofit organizations need to constantly attract volunteers, while also providing a compelling reason for existing volunteers to continue to donate their time to the organization and its cause. Volunteers are an integral element to the success of nonprofit organizations and even the most rudimentary of nonprofit website will provide details on volunteer opportunities. However, there exists much variance within nonprofit organizations on the respectful cause they serve. I argue that these particular causes lead to the creation of separate, more specific epistemes, in which the discourse is especially relevant to that cause. For instance, the episteme of adult literacy centers represents a form of a social movement, begun at the beginnings of adult basic education programs in the U.S. Emerging governmental interest in the importance of adult literacy during President Johnson's presidency and subsequent national surveys on adult literacy rates in the 1990s and early 2000s, and even the current international research on adult literacy, demonstrates how adult literacy constitutes its own movement.

Adult literacy discourse is separate from the discourse of other nonprofit organizations, and News \& Blog reveals how this episteme operates. First, News \& Blog supplies information into what constitutes knowledge within this episteme. While each of the four categories provides insights into the episteme, the Learner Stories category is the most impactful in that it both discursively supports the organization's mission, reveals how literacy plays a role in the lives of 
learners, and elevates the voices of learners. Those struggling with literacy skills feel powerless and ashamed. There are few places where they are given the agency to share their story, thus providing information as to how to best provide services for this population and understand the issue. From a Foucauldian perspective, Learner Stories creates knowledge about the episteme of adult literacy communication, while also giving power to learners to share their stories. This is especially revealing of the relationship between knowledge construction and power; it is the learners themselves, individuals who struggle to read, that are creating knowledge in sharing their stories and providing insights into the issue of illiteracy and how literacy fits into their lives.

\section{Conclusion}

This chapter divided analysis of the case into three overarching sections: description, interpretation, and evaluation. The LCWM is representative of nonprofit adult education centers specializing in literacy instruction. Originally founded in 1986, the organization has kept up-todate with technological transitions and currently maintains active social media channels, online instruction in light of the COVID-19 pandemic, and a website with an exemplary News \& Blog that spans five-and-half years and features 165 articles. In addition to describing the context in which the organization exists, my description relays the collection of texts used, organizing them based on the four categories provided by the LCWM and topics I identified to reveal patterns in subject matter. The interpretation part of this chapter utilized principles from Foucault, literacy, and public relations to guide my examination of the texts. News \& Blog is representative of the episteme of adult literacy center discourse, which balances multiple audiences and interests. For example, the Tutors category allows tutors at the center a space to share their experiences working with learners, as well as a place to access information about teaching materials to 
provide support in their work. Learner Stories are indicative of knowledge being created about literacy by learners themselves, supplying power to a group that is traditionally seen as powerless. Learner Stories also demonstrate effectively the role that literacy plays in society. Improved literacy skills allow for a myriad of positive changes that help learners function more easily. The Advocate Spotlights and Community categories provide information on various parties, including employees, but also widen the interests of the organization beyond the center to the work and activities in the greater Grand Rapids community, such as events.

Analysis of the articles reveals patterns in topics that shed insights into the episteme, such as the majority of Learner Stories detailing the narratives of immigrants seeking to improve their English and literacy capabilities.

Discursively, News \& Blog creates knowledge about the episteme of adult literacy center communication, while reinforcing power relations of the respective audiences related to the episteme. Multiple audiences are necessary for the success of the organization and thus are crucial to the episteme. The LCWM cannot exist without a clientele of adult learners. By providing a designated Learner Stories category for learners to share their stories, News \& Blog is providing agency, and thus power, to a traditionally powerless group of individuals. These articles, charting the lives of learners, also provide insights into literacy as a whole, particularly in the positive impacts literacy acquisition has. The evaluation section of this chapter draws on the principles used in the interpretation to develop a criteria for assessment based on Foucault, literacy, and public relations. There are elements of News \& Blog that are effective at communicating with their audiences as a public relations device when considering elements of message design. However some categories require more thought on the part of the organization as to critically consider the intended audience to create more cohesive categories that function as 
clear discursive formations representative of the organization and its goals. Given the many audiences that the organization is balancing, from current and prospective learners to tutors, employees, community members, and donors, News \& Blog is ambitious in trying to provide a space for them all. There is overlap in some of the categories that indicate the organization needs to instate a more uniform set of criteria when it comes to allocating categories to articles, to create an even more effective News \& Blog that engagingly connects to all relevant audiences. Utilizing Foucault, literacy, and public relations as theoretical perspectives generates insights essential to understanding the episteme of adult literacy center communication. 


\section{CHAPTER V: CONCLUSION}

This thesis is predicated on the notion that the ability to read well in English is a necessary part of leading a fulfilling life in the U.S. This belief underpins the entirety of this work. The goal driving this research is that it may be used by literacy organizations as they construct public relations materials in order to best connect with their respective audiences, and ensure such organization's survival to continue providing an important service to the community. Little research exists assessing the communicative materials of these centers and program, which is surprising given the obvious paradox of using written materials to attract an audience lacking sufficient literacy skills. The Literacy Center of West Michigan (LCWM) provides literacy services for the Grand Rapids area and offers a variety of services and programs. The LCWM is particularly unique in its thorough and expansive online blog spanning five-and-half years. Examining these articles allows for deeper understanding of adult literacy centers and programs.

\section{Overview and Key Findings}

The introduction and literature review provided an overview of existing research relevant to literacy. Recent research from 2012, 2014, and 2017 establishes that 52 million adults in the U.S. have low literacy skills (National Center for Education Statistics, n.d.). This indicates that a sizable population in the U.S. are unable to complete necessary tasks that require reading, and this hinders their ability to fully engage with society. While there have been many iterations of adult education programs in the U.S., President Johnson signing the 1964 Economic Opportunity Act "provided impetus for the Federal Government to work with states to expand adult education

opportunities" (Eyre, 2013, p. iv; Department of Education, 2013). Literacy centers and programs contribute an important service to their respective communities. 
In order to assess the LCWM News \& Blog, I identified the theoretical frameworks I used in the methodology chapter. Rhetorical criticism was the overarching method used in this thesis, while Foucault's ideas provided the theoretical orientation, and a case example approach was utilized. Kuypers' (2016b) system of breaking down the rhetorical criticism into description, interpretation, and evaluation formed the basis for this analysis. Central to Foucault's work is the idea of power and knowledge and being mutually reinforced through discourse (S. Foss, K. Foss, \& Trapp, 2002; Motion \& Leitch, 2007). These concepts can be applied to public relations to form a different theoretical orientation; Foucauldian public relations, in which public relations "can be seen as the key discursive actor between organizations and their publics" that, in turn, “creates and recreates human reality" (Smudde, 2007, p. 207).

In the description portion of my analysis, I examined the organization's history to detail the context in which it and News \& Blog exists. Then, I described the collection of texts, or the 165 News \& Blog articles used in the analysis. To do this, I created charts first dividing articles by the four categories the LCWM use in News \& Blog to organize articles: Learner Stories, Advocate Spotlights, Tutors, Community. I also created a fifth category, Uncategorized, for the three lone articles that the LCWM did not provide a category for, although given its limited size in relation to the other categories, I did not use Uncategorized articles in the analysis.

Additionally, two of the Uncategorized articles are vehicles for videos, a medium that I have not focused on for this thesis. Uncategorized articles are more difficult to find and access compared to articles that have been tagged to include one of the four main categories. Since I found these articles to be irrelevant compared to the other articles, I did not devote analysis to them, although they are included in Appendix E. 
Combining principles of Foucault, literacy, and Foucauldian public relations into criteria with which to evaluate News \& Blog shows the strengths and weaknesses of the material. Learner Stories is particularly effective in providing power to a traditionally powerless group individuals who struggle with literacy. Learner Stories functions as a discursive space for these individuals to share their stories, providing deeper insight into this population and their needs. Immigrant stories take the forefront of Learner Stories, which details what unique circumstances brought these individuals to the U.S. and to the LCWM. Learner Banza Mukalay fled war in Congo to a refugee camp in Tanzania (Patton, 2018). Banza stayed at the refugee camp for fifteen years and held a variety of positions: World Vision security guard, International Rescue Committee social worker, and United Methodist Church pastor. Once arriving in the U.S., Banza sought to improve his English (Patton, 2018). From a Foucauldian perspective, this generates knowledge about the clientele of the LCWM.

The 2019 article Now I Can Give Back to My Community: Charles' Story describes learner Charles, what lead for him to enroll at the LCWM, and his subsequent success. Despite the fact that "Charles always had a hard time with school" (para. 2) due to reading difficulties, he completed high school (Nieto, 2019). Through classes at the LCWM, Charles learned about syllables; "it was like a light bulb went on, and he quickly understood the importance syllables played in his reading, writing and spelling. As a result of his discovery, Charles' literacy improved significantly" (Nieto, 2019, para. 4). Charles represents a community of people who still achieved an education milestone in finishing high school, but who struggle to read as adults. This signifies that completing a certain level of education does not necessarily mean that individuals can read at that level, which can be important for literacy organizations to recognize when communication with potential learners. Further, Learners Stories demonstrates how 
improved literacy functions in the lives of learners, reinforcing that literacy, as defined by the OECD (2013) and utilized in the literacy principles I developed, is deeply embedded in the individual's personal and professional life, and how they engage with society. Learner Charles found that confidence grew and aims to become a literacy tutor (Nieto, 2019).

The Tutors category similarly provides a space for staff and volunteer tutors to share their perspective. When it was frequently used, the Tutors category was easily recognized as for tutors in that instructional articles were regularly published supplying information on textbooks that could be used and how they could benefit learners. Additionally, in describing classroom interactions and the work of tutors, more information is supplied about learners in a different context. This reinforces that learners are central to the organization's success and the episteme: without learners, there is no adult literacy center sphere. The Tutors category was frequently used in 2018 and declined in usage in 2019, stalling to one published article in 2020. The Community category is both a miscellaneous section for additional topics that don't quite fit into the aforementioned three categories and a means of expressing how the organization represents its own community and is embedded in the local region it is situated in. For example, the 2018 article Mark Peters: The Hidden Issue of Low Literacy is written by the CEO of Butterball Farms, Inc. and Chair of the Literacy Center's Donor Development Committee. While Mark Peters certainly would qualify as an advocate of literacy, positioning his work to be published under Advocate Spotlights, the contents of the article emphasizes how deeply intertwined literacy struggles are with the surrounding community. The Community category includes information about events, award recipients, and new staff hires. 


\section{Suggestions}

Having reviewed key findings from my analysis of News \& Blog, I now offer suggestions that the LCWM and similar organizations can use when constructing public relations materials. While News \& Blog provides extensive documentation of the LCWM's past and present endeavors and has effective elements, there are steps the organization can take to improve this online repository of literacy information.

First, the LCWM must critically examine and evaluate the purpose of three of the four categories: Advocate Spotlights, Tutors, and Community. The Tutors category featured a sharp decline in use since 2018, and only one article utilized this category in 2020. Advocate Spotlights and the Tutors category features some overlap in material that makes the distinction between categories, and indeed their purposes, unclear. I recommend that instead, the LCWM use the following categories: Learner Stories, Staff, Volunteers, and Community. The Learner Stories category would continue to function as is, utilizing first-person narratives written by learners and third-person accounts written by staff members. However, the Staff category would cohesively unite all articles pertaining to paid organization staff: new staff profiles, existing staff profiles, staff reflections, staff changes. The Staff category could also include instructional material, similar to the teaching materials included in the existing Tutors category, relevant to the staff members working in various positions at the organization. The Volunteer category would exclusively focus on organizational members and tutors who donate their time and unite all articles relating to volunteers: volunteer profiles, volunteer reflections, volunteer tutors. This distinction would make it easier for staff and volunteer audiences to identify information relevant to their needs. The Community category would then largely function as it currently does, a section for miscellaneous information related to the organization, or connecting to the 
organization to the greater Grand Rapids community. However, existing Community articles related to staff members would now be allocated to the designated Staff category. Additionally, the three articles without a category should be included in the category they are more suited to, to make it easier to locate them. I argue that the LCWM should adopt these four categories as its main categories: Learner Stories, Staff, Volunteers, and Community.

Second, I recommend that the LCWM develop a style guide, or a manual, to guide future communication materials to ensure cohesiveness throughout all public relations channels. For example, I pointed out inconsistencies in the presentation of interviews in the analysis chapter. These inconsistencies in presentation detract from the overall content. The LCWM would benefit from considering what guidelines they want to follow in structuring content and use these guidelines going forward.

\section{Limitations}

There are limitations in the research presented here. Namely, the LCWM features many up-to-date online channels of information, from its website to social media mediums. As such,

there are other methods the LCWM uses to connect with audiences. For example, the LCWM has a YouTube channel going back 7 years and featuring 55 videos. The LCWM also has a respectable following on social media: its Facebook page has approximately 2,800 likes. A similar rhetorical analysis to the one conducted in this thesis could be done to LCWM Facebook posts. Additionally, there are limitations particular to the methodology employed in this thesis: rhetorical analysis. While I am able to assess News \& Blog from a Foucauldian perspective, I am unable to ascertain how the intended audiences judge the material. I have mentioned the paradox in using written material to communicate with a clientele struggling with literacy, but without actually interviewing learners at the literacy centers, I am unable to speak for this population. 
Another limitation is in clearly distinguishing literacy from literacy in the English language. Literacy centers like the LCWM typically include some form of English language classes to serve a clientele seeking to improve their English. I emphasize that for the purposes of this thesis, by literacy, I mean literate in the English language, given the context of my research is the U.S. This neglects to take into account individuals who are literate in their native-language, but utilize literacy centers as a means of improving their English. Thus, they are not illiterate in the sense that they struggle to read as a whole, but are unable to read the English language. The National Center for Education Statistics (n.d.) offers this explanation for measuring participants literacy only in English for the PIACC, the international assessment of literacy that provides more up-to-date data on adult literacy rates in the U.S. than the exclusively U.S.-based 1992 and 2003 surveys:

PIAAC assesses adults in the official language or languages of each participating country. Based on a 1988 congressional mandate and the 1991 National Literacy Act, the U.S. Department of Education is required to evaluate the status and progress of adults' literacy in English. However, in order to obtain background information from a wide range of respondents in the United States, the PIAAC Background Questionnaire was administered in both English and Spanish. (National Center for Education Statistics, n.d., para. 6)

However, I argue that the above limitations to my own study suggests future research endeavors in adult literacy communication. A greater understanding of immigrants who utilize such services could aid in developing communication materials. Additionally, more research on immigrant literacy rates in the U.S. could provide essential information for organizations 
creating these programs, in distinguishing learners who need to primarily learn English, learn how to read as a whole, or both.

\section{Future Research}

There are many potential avenues for future research in this area. The LCWM has other communication channels and platforms on which a rhetorical analysis could be performed. Additionally, the LCWM is just one such organization seeking to supply the community with a necessary resource and there are many similar organizations and programs around the nation that could serve as a case example for future study.

Using different methodologies could also yield insights relevant for increasing knowledge and understanding of these organizations, adult literacy, and the communities they serve. I have extensively referenced Jae (2014), as an example of available research on adult literacy center communication. Jae (2014) utilized a focus group approach of learners to judge and evaluate their center's promotional materials. This study found that using one flyer to appeal to all relevant audiences was ineffective and learners did not find the materials considered them. Consider all the relevant audiences to a literacy center and their respective motivations. Volunteers are seeking to contribute their time and efforts to a worthy cause. Donors are considering where to invest their money. Individuals seeking a job are looking to ascertain positions available, the duties and responsibilities required of them, and pay. Learners are searching for programs and classes relevant to their particular needs. Jae (2014) underscores that these diverse audiences need separate communication materials salient to their own interests. Future research in this area should continue to prioritize the needs of learners. While I can offer a rhetorical criticism of News \& Blog, I cannot provide insights into how learners in Michigan use, access, or judge its contents. It would be incredibly valuable to continue with Jae's (2014) 
research, using focus groups of people from these organizations to understand how these materials are constructed, disseminated, and used. It would have doubtlessly been both fascinating and instructional to have an in-person focus group with learners at the LCWM and go through News \& Blog with them, asking them questions and hearing them discuss their thoughts and impressions of its contents. Learner-based focus groups would also allow for organizations to pinpoint where to invest greater money and effort in their public relations. Are these webbased platforms effective? Do they discover these programs through word-of-mouth recommendation? Do they come across these programs through other places in the community such as schools their children attend, libraries, or community centers? Adult literacy communication is a research area with many possible future research opportunities.

\section{Importance}

This thesis seeks to contribute to the field of literacy communication, a research area with great potential and utility, but little current research. Literacy skills are an important factor in leading a fulfilling life and 52 million adults in the U.S. (National Center for Education Statistics, n.d.). Many forms of adult basic education programs exist in the U.S., and literacybased programs provide this population with an important service. Therefore, it is crucial to understand how these organizations communicate with audiences, to ensure effective maintenance of relationships between audiences and the organizations. This thesis emphasizes the importance of discourse, specifically public relations, in shaping societal perceptions of the particular issue of literacy. The main takeaway that literacy centers should gain from this overall research is a recognition of the necessity for thoughtful, planned-out communicative materials. The LCWM has stayed up to date on communication advancements and transitioned into a digital age with a polished website. While there are elements of News \& Blog that can be 
improved, it can also serve as an example for other literacy centers and programs in how to balance and connect with multiple audiences. The division of News \& Blog into categories allows for audiences to more readily access content salient to them. In prioritizing audience's varied needs by providing separate discursive spaces, the LCWM is ultimately demonstrating the importance of these audiences to their overall success.

It is easy to underestimate the magnitude and severity of this problem, however it affects the entire community. Given the shame and stigma associated with illiteracy, those who struggle to read have find ways to hide this inability (C. Doak, L. Doak, \& Root, 1996).

To close, I will share a poignant message from the Chair of the Literacy Center's Donor Development Committee and CEO of Butterball Farms, Inc.:

Literacy. Why is it important? Well, if you are reading this, you may actually take your literacy for granted. But imagine for a moment that reading this was a matter of life and death. Maybe your own, or maybe that of a loved one. Imagine that this paragraph was the dosage instructions for one of your parent's heart medicines, and you could not read it. The reality is that $10-15 \%$ of the adult population in West Michigan would not be able understand this paragraph. (Peters, 2018, para. 1) 


\section{REFERENCES}

Aldridge, M. D. (2004). Writing and designing readable patient education materials. Nephrology Nursing Journal, 31(4).

Alejandra. (2016). In the right place: Alejandra, learner. Literacy Center of West Michigan. https://iteracycenterwm.org/news-blog/learner-stories/108-in-the-right-place-alejandralearner.

Bailey, M. J., \& Duquette, N. J. (2014). How Johnson fought the war on poverty: The economics and politics funding at the office of economic opportunity. Journal of Economic History, 74(2), 351-388.

Barbour, J. B., Jacocks, C. W., \& Wesner, K. J. (2013). The message design logics of organizational change. Communication Monographs, 80(3), 354-378. http://dx.doi.org/10.1080/03637751.2013.788251.

Bastable, S. B. (2011). Literacy in the adult client population. In S. B. Bastable, P. Gramet, K. Jacobs, \& D. L. Sopczyk (Eds.), Health professional as educator: Principles of teaching and learning. Jones \& Bartlett Learning, LLC.

Baxter, P., \& Jack, S. (2008). Qualitative case study methodology: Study design and implementation for novice researchers. The Qualitative Report, 13(4).

Berger, B. K. (2005). Power over, power with, and power to relations: Critical reflections. Journal of Public Relations Research, 17(1), 5-28. doi: 10.1207/s1532754xjprr1701_3.

Brooks, M. D., \& Frankel, K. K. (2018). Why the "struggling reader" label is harmful (and what educators can do about it). Journal of Adolescent \& Adult Literacy, 62(1), 111-114. doi 10.1002/jaal.758. 
Brummett, B. (2019). Techniques of close reading (2nd ed.). Thousand Oaks, CA: SAGE Publications Inc.

Buys, J. (2019). Tutor spotlight | Legacy of tutoring. Literacy Center of West Michigan. https://literacycenterwm.org/news-blog/tutors/228-tutor-spotlight-legacy-of-tutoring.

Castro-Caldas, A., Reis, A., \& Guerreiro, M. (1997). Neuropsychological aspects of illiteracy. Neuropsychological Rehabilitation, 7(4), 327-338.

Cho, J., Chun, J. W., \& Lee, M. J. (2018). Impacts of message framing and social distance in health campaign for promoting regular physical exercise. Journal of Health Communication, 23(9), 824-835. doi: 10.1080/10810730.2018.1527872.

Courtright, J. L., \& Smudde, P. M. (2007). "Problems" of power in public relations theory and practice. In J. Courtright and P. Smudde (Eds.), Power and Public Relations (pp. 1-7). Cresskill, New Jersey: Hampton Press Inc.

Courtright, J. L., \& Smudde, P. M. (2009) A genre perspective on public relations message design. International Public Relations Research Conference, 146-159.

Curtis, L., Edwards, C., Fraser, K. L., Gudelsky, S., Holmquist, J., Thornton, K., \& Sweetser, K. D. (2010). Adoption of social media for public relations by nonprofit organizations. Public Relations Review, 36(1). doi: 10.1016/j.pubrev.2009.10.003.

Department of Education. (2005). National Assessment of Adult Literacy (NAAL): A first look at the literacy of America's adults in the 21st century. National Center for Education Statistics.

Department of Education. (2013). An American heritage, federal adult education, a legislative history, 1964-2013. U.S. Department of Education: Office of Vocational and Adult Education. 
Department of Labor and Economic Opportunity. (n.d.). Learn more, earn more! Michigan.gov. https://www.michigan.gov/leo/0,5863,7-336-94422_95539_64362-395180—,00.html.

Doak, C. C., Doak, L. G., \& Root, J. H. (1996). Teaching patients with low literacy skills (2nd ed.). J.B. Lippincott Company.

Dodd, M. D., \& Collins, S. J. (2017). Public relations message strategies and public diplomacy 2.0: An empirical analysis using Central-Eastern European and Western Embassy Twitter accounts. Public Relations Review, 43(2), 417-425. doi: 10.1016/j.pubrev.2017.02.004.

Durnan, D. \& Boughton B. (2018). Making it stick. The post literacy phase of the Literacy for Life Foundation Aboriginal adult literacy campaign. Fine Print, 41(3), 11-15.

Dyer, S., Buell, T., Harrison, M., \& Weber, S. (2002). Managing public relations in nonprofit organizations. Public Relations Quarterly, 47(4).

Economic Opportunity Act, Pub. L. 88-452, 78 Stat. 508. (1964). https://www.govinfo.gov/content/pkg/STATUTE-78/pdf/STATUTE-78-Pg508.pdf.

Epley, J. S. (2007). Foreword. In J. Courtright and P. Smudde (Eds.), Power and Public Relations (pp. vii - x). Cresskill, New Jersey:Hampton Press, Inc.

Ewing, R. (2019). Now I can communicate better at work. Literacy Center of West Michigan. https://literacycenterwm.org/news-blog/learner-stories/245-now-i-can-communicatebetter-at-work.

Eyre, G. A. (2013). Preface in the U.S. Department of Education's An American heritage, federal adult education, a legislative history, 1964-2013.

Falb, W., \& Literacy Center of West Michigan. (2016). Fiscal year 2015 annual report released. Literacy Center of West Michigan. https://literacycenterwm.org/newsblog/community/97-fiscal-year-2015-annual-report-released. 
Ficorelli, D. D. (2017). In her own words: Doroty Delli Ficorelli. Literacy Center of West Michigan. https://literacycenterwm.org/news-blog/learner-stories/157-in-her-own-wordsdoroty-delli-ficorelli.

Foss, S. K., Foss, K. A., \& Trapp, R. (2002). Michel Foucault. In Contemporary Perspectives on Rhetoric (3rd ed.). Prospect Heights, Illinois: Waveland Press Inc.

Foucault, M. (1972). The Archaeology of Knowledge \& The Discourse on Language. Tavistock. Foucault, M. (1982). The subject and power. Critical Inquiry, 8(4), pp. 777-795.

Frumkin, P. (2002). On being nonprofit: A conceptual and policy primer. Cambridge, Massachusetts: Harvard University Press.

Fussell Sisco, H., Collins, E.L., \& Zoch, L.M. (2010). Through the looking glass: A decade of Red Cross crisis response and situational crisis communication theory. Public Relations Review, 36(36), 21-27. doi: 10.1016/j.pubrev.2009.08.018.

Gee, J. P. (2001). A sociocultural perspective on early literacy development. In S. B. Neuman and D. K. Dickinson (Eds.), Handbook of early literacy research. New York: The Guilford Press.

Gee, J. P. (2015). The new literacy studies. In J. Roswell and K. Pahl (Eds.), The Routledge handbook of literacy studies. London: Routledge.

Gonzalez, G. (2019). Now I can help my children with homework: Gonzalo's story. Literacy Center of West Michigan. https://literacycenterwm.org/news-blog/learner-stories/249now-i-can-help-my-children-with-homework-gonzalo-s-story.

Goodwyn, L. F. (2019). Rates of African American studies in a Texas adult education and literacy program. Journal of Research \& Practice for Adult Literacy, Secondary \& Basic Education, Special Issue, 33-47. 
Gregory, A. (2000). Planning and managing public relations campaigns (2nd ed.). London: Kogan Page Limited.

Hall, L. A. (2012). Rewriting identities: Creating spaces for students and teachers to challenge the norms of what it means to be a reader in school. Journal of Adolescent \& Adult Literacy, 55(5), 368-373. doi: 10.1002/JAAL.00045.

Hall, S. (2001). Foucault: Power, knowledge and discourse. In M. Wetherell, S. Taylor, and S. J. Yates (Eds.), Discourse Theory and Practice: A Reader. SAGE Publications, Ltd.

Henry, L. A. (2013). Literacy content knowledge expertise among adult education providers in Kentucky. Journal of Research \& Practice for Adult Literacy, Secondary \& Basic Education, 2(1), 35-48.

Higgins, L. (2010). Community literacy center website, Colorado State University. Book and New Media Reviews, 199-201.

Higgins, L., Long, E., \& Flower, L. (2006). Community literacy: A rhetorical model for personal and public inquiry. Community Literacy Journal, 1(1).

Holland, D., Krause, A., Provencher, J., \& Seltzer, T. (2018). Transparency tested: The influence of message features on public perceptions of organizational transparency. Public Relations Review, 44(2), 256-264. doi: 10.1016/j.pubrev.2017.12.002.

Jae, H. (2014). Developing promotional materials for adult literacy programs. Journal of Research and Practice for Adult Literacy, Secondary, and Basic Education, 3(3).

Jerome, A. M., Moffitt, M. A., \& Knudsen, J. W. (2007). Understanding how Martha Stewart harmed her image restoration through a "micropolitics" of power. In J. Courtright and P. Smudde (Eds.), Power and Public Relations (pp. 207-237). Cresskill, New Jersey: Hampton Press Inc. 
Johnson, L. B. (1964). First State of the Union Address.

https://www.americanrhetoric.com/speeches/lbj1964stateoftheunion.htm.

Keith, W. M., \& Lundberg, C. O. (2008). The Essential Guide to Rhetoric. Boston, MA: Bedford/St. Martin's.

Kelleher, T. (2018). Public relations. New York, NY: Oxford University Press.

Kirsch, I., Jungeblut, A., Jenkins, L., \& Kolstad, A. (2002). Adult literacy in America: A first look at the findings of the National Adult Literacy Survey (3rd ed.). National Center for Education Statistics. https://nces.ed.gov/pubs93/93275.pdf.

Kutner, M., Greenberg, E., Jin, Y., Boyle, B., Hsu, Y., \& Dunleavy, E. (2007). Literacy in everyday life: Results from the 2003 National Assessment of Adult Literacy. National Center for Education Statistics. Retrieved from https://nces.ed.gov/Pubs2007/2007480.pdf.

Kuypers, J. A. (2016a). Elements of rhetorical criticism: The big picture. In J. A. Kuypers (Ed.), Rhetorical Criticism: Perspectives in Action. Lanham, MD: Lexington.

Kuypers, J. A. (2016b). Rhetorical criticism as art. In J. A. Kuypers (Ed.) Rhetorical Criticism: Perspectives in Action (2nd ed), pp. 21-39. Lanham, Maryland: Rowman \& Littlefield.

Kuypers, J. A., \& King, A. (2016). What is rhetoric? In J. A. Kuypers (Ed.), Rhetorical Criticism: Perspectives in Action. Lanham, MD: Lexington.

Lee, R., \& Blood, A. (2016). Ideographic criticism. In J. A. Kuypers (Ed.) Rhetorical Criticism: Perspectives in Action (2nd ed), pp. 215-236. Lanham, MD: Lexington.

Lewis, C., \& del Valle, A. (2008). Literacy and identity: Implications for research and practice. In L. Christenbury, R. Bomer, \& P. Smagorinsky (Eds.), Handbook of adolescent literacy research (pp. 307-322). New York: Guilford Press. 
Literacy Center of West Michigan. (n.d.). About Us. https://literacycenterwm.org/about-us.

Literacy Center of West Michigan. (n.d.) About Us: People. https://literacycenterwm.org/aboutus/people.

Literacy Center of West Michigan. (n.d.). Homepage. https://iteracycenterwm.org/.

Literacy Center of West Michigan. (n.d.). Learn. https://literacycenterwm.org/learn

Literacy Center of West Michigan. (n.d.). News \& Blog. https://literacycenterwm.org/news-blog

Literacy Center of West Michigan. (2018). New content! https://iteracycenterwm.org/newsblog/tutors/162-new-content.

Literacy Center of West Michigan. (2019a). Now I can open a restaurant: Fatos \& Apo's story. Literacy Center of West Michigan. https://literacycenterwm.org/news-blog/learnerstories/240-now-i-can-open-a-restaurant-fatos-apo-s-story.

Literacy Center of West Michigan. (2019b). The literacy center honored with Governor's Service Award. https://literacycenterwm.org/news-blog/community/242-the-literacy-centerhonored-with-governor-s-service-award.

Literacy Center of West Michigan. (2020a). Dr. Yilin Wendland-Liu hired as adult tutoring program director. https://iteracycenterwm.org/news-blog/community/279-dr-yilinwendland-liu-hired-as-adult-tutoring-program-director.

Literacy Center of West Michigan. (2020b). Literacy center response to COVID-19. https://literacycenterwm.org/news-blog/community/253-literacy-center-response-tocovid-19.

Literacy Center of West Michigan. (2021). About adult tutoring program director Yilin Wendland-Liu. Literacy Center of West Michigan. https://literacycenterwm.org/newsblog/advocate-spotlights/288-about-adult-tutoring-program-director-yilin-wendland-liu. 
Loar, S., \& Payne, K. (2018). July's featured tutor spotlight. Limerick lessons with Steve and Maria. Literacy Center of West Michigan. https://literacycenterwm.org/newsblog/tutors/208-july-s-featured-tutor-spotlight.

Malicky, G. V., \& Norman, C. A. (1995). Perceptions of literacy and adult literacy programs. The Alberta Journal of Educational Research, 41(1), 63-83.

Matthews, D. (2014). Everything you need to know about the war on poverty. The Washington Post. https:/www.washingtonpost.com/news/wonk/wp/2014/01/08/everything-you-needto-know-about-the-war-on-poverty/.

McGeough, R. E., \& King, A. (2016). Dramatism and Kenneth Burke's pentadic criticism. In J. A. Kuypers (Ed.) Rhetorical Criticism: Perspectives in Action (2nd ed.), pp. 147-165. Lanham, Maryland: Rowman \& Littlefield.

McHardy, J., \& Chapman, E. (2019). The teaching focus of adult-reading teachers when developing word reading skills. Literacy, 53(3), 125-133. doi: 10.1111/lit.12168.

McKerrow, R. E. (2011). Foucault's relationship to rhetoric. The Review of Communication, 11(4), 253-271, doi: 10.1080/15358593.2011.602103.

Merriam, S. B., \& Brockett, R. G. (2007). The profession and practice of adult education: An introduction (1st ed.). John Wiley \& Sons, Inc.

Mezirow, J., Darkenwald, G. G., \& Knox, A. B. (1975). Last gamble on education: Dynamics of adult basic education. Adult Education Association of the U.S.A.

Montero, M. K. (2018). Standing \#withrefugees: A review of supporting refugee children: Strategies for educators. Journal of Adolescent \& Adult Literacy, 62(1), 123-125. doi: 10.1002/jaal.866. 
Motion, J., \& Leitch, S. (2007). A toolbox for public relations: The oeuvre of Michel Foucault. Public Relations Review, 33, 263-268. doi:10.1016/j.pubrev.2007.05.004.

Nassar, M. (2017). Reading by third grade: our shared opportunity, our shared responsibility. Literacy Center of West Michigan. https://literacycenterwm.org/newsblog/community/150-reading-by-third-grade-our-shared-opportunity-our-sharedresponsibility.

National Center for Education Statistics. (n.d.). Frequently asked questions. Program for the International Assessment of Adult Competencies. https://nces.ed.gov/surveys/piaac/faq.asp\#6001.

National Center for Education Statistics. (n.d.). What is NAAL? National Assessment of Adult Literacy. https://nces.ed.gov/naal/.

National Center for Education Statistics. (n.d.). What is PIAAC? Program for the International Assessment of Adult Competencies (PIAAC). https://nces.ed.gov/surveys/piaac/.

National Center for Education Statistics. (2003). State \& county estimates of low literacy. National Center for Education Statistics. https://nces.ed.gov/naal/estimates/StateEstimates.aspx.

Neuman, S. B., Caperelli, B. J., \& Kee, C. (1998). Literacy learning, a family matter. The Reading Teacher, 52(3).

Nieto, E. (2019). Now I can give back to my community: Charles' story. Literacy Center of West Michigan. https://iteracycenterwm.org/news-blog/learner-stories/241-now-i-can-giveback-to-my-community-charles-story. 
Patton, C. (2017). Building community at the literacy center. Literacy Center of West Michigan. https://literacycenterwm.org/news-blog/community/145-building-community-at-theliteracy-center.

Patton, C. (2018). Banza's story. Literacy Center of West Michigan. https://literacycenterwm.org/news-blog/learner-stories/175-banza-s-story.

Payne, K. (2018). Accessible and relatable grammar instruction, September's A-Z textbook | Focus on grammar. Literacy Center of West Michigan. https://iteracycenterwm.org/news-blog/tutors/212-grammar-focus-with-context.

Peters, M. (2018). Mark Peters: The hidden issue of low literacy. Literacy Center of West Michigan. https://iteracycenterwm.org/news-blog/community/180-mark-peters-thehidden-issue-of-low-literacy.

Peterson, C. (2016). In my own words: Charla Peterson, learner. Literacy Center of West Michigan. https://literacycenterwm.org/news-blog/learner-stories/37-in-my-own-wordscharla-peterson-learner.

Pettersson, R. (2012). Introduction to message design. Journal of Visual Literacy, 31(2), 93-104.

Porter, J. E. (1986). Intertextuality and the discourse community. Rhetoric Review, 5(1), 34-47.

ProPublica. (n.d.) Literacy Center of West Michigan.

https://projects.propublica.org/nonprofits/organizations/382725232.

Public Relations Society of America. (n.d.). About public relations. PRSA. Retrieved from https://www.prsa.org/about/all-about-pr.

O'Keefe, B. J. (1988). The logic of message design: Individual differences in reasoning about communication. Communication Monographs, 55, 80 - 103. doi:

$10.1080 / 03637758809376159$. 
Organisation for Economic Co-operation and Development. (2009). PIAAC literacy: A conceptual framework. OECD Education Working Papers, No. 3. doi: $10.1787 / 220348414075$

Organisation for Economic Co-operation and Development. (2013). OECD skills outlook 2013: First results from the survey of adult skills. OECD Publishing. http://dx.doi.org/10.1787/9789264204256-en.

Rickard, L. N. (2019). Pragmatic and (or) constitutive. On the foundations of contemporary risk communication research. Risk Analysis, 41(1). doi: 10.1111/risa.13415.

Rodgers, T. (2018). Learning together: Paul and Livingstone. Literacy Center of West Michigan. https://literacycenterwm.org/news-blog/tutors/214-paul-and-livingstone.

Roh, S. (2017). Examining the paracrisis online: The effects of message source, response strategies and social vigilantism on public responses. Public Relations Review, 43(3), 587-596. doi: 10.1016/j.pubrev.2017.03.004.

Roper, C. (2020). From learning to volunteering: Sonia's story. Literacy Center of West Michigan. https://literacycenterwm.org/news-blog/learner-stories/286-from-learning-tovolunteering-sonia-s-story.

Rose, A. D. (1992). The adult education act. SAGE Journals. doi/10.1177/104515959200300409.

Saunders, C. M. (2006). Insuring the uninsured: Reducing the barriers to public insurance. The Qualitative Report, 11(3), 499-515.

Smith, B. (1996). Marketing your adult literacy program: A "how to" manual. Hudson River Center for Program Development.

Smudde, P. (2001). Issue or crisis: A rose by any other name....Public Relations Quarterly, 46(4), 34-36. 
Smudde, P. (2004). Implications on the practice and study of Kenneth Burke's idea of a "public relations counsel with a heart”. Communication Quarterly, 52(4). doi: $10.1080 / 01463370409370210$.

Smudde, P. (2007). Public relations' power, as based on knowledge, discourse, and ethics. In J.L. Courtright \& P.M. Smudde (Eds.) Power and Public Relations, pp. 207-237. Cresskill, New Jersey: Hampton Press, Inc.

Smudde, P. M., \& Courtright, J. L. (2012). Inspiring cooperation \& celebrating organizations: Genres, message design \& strategy in public relations. New York: Hampton Press.

Stanić, M. K. (2019). Transparency in public relations: Evidence from associations' ethics codes. Interdisciplinary Description of Complex Systems, 17(2-B). doi: 10.7906/indecs. 17.2.15.

Summers, J. (2018). Learning at the TESOL Conference. Literacy Center of West Michigan. https://iteracycenterwm.org/news-blog/community/182-learning-at-the-tesol-conference.

Summers, J. (2020a). Now I can dream in English: Eliana's story. Literacy Center of West Michigan. https://literacycenterwm.org/news-blog/learner-stories/257-now-i-can-dreamin-english-eliana-s-story/.

Summers, J. (2020b). Now I can vote in a presidential election: Maria’s story. Literacy Center of West Michigan. https://literacycenterwm.org/news-blog/learner-stories/274-now-i-canvote-in-a-presidential-election-maria-s-story.

Terry, M. (2006). The importance of interpersonal relations in adult literacy programs. Education Research Quarterly, 30(2), 30-43.

Thomas, A. (1989). Definitions and evolution of the concept. In M. C. Taylor, \& J. A. Draper (Eds.) Adult Literacy Perspectives, pp. 3-14. 
Townley, B. (1993). Foucault, power/knowledge, and its relevance for human resource management. Academy of Management Review, 18(3), 518-545.

VanIgen, N., \& Payne, K. (2015). 25 years of the literacy center: An interview with Nancy. Literacy Center of West Michigan. https://literacycenterwm.org/news-blog/advocatespotlights/99-25-years-of-the-literacy-center-an-interview-with-nancy.

Wahlstrom, L. (2020). The impact of partnerships. Literacy Center of West Michigan. https://iteracycenterwm.org/news-blog/community/271-the-impact-of-partnerships.

Warkineh, T. Z., Rogers, A., \& Danki, T. N. (2018). Profiling adult literacy facilitators in development contexts: An ethnographic study in Ethiopia. International Review of Education, 64(1), 9-30. doi: 10.1007/s11159-017-9686-6.

Wittry, P. (2018). An increase in confidence. Literacy Center of West Michigan. https://literacycenterwm.org/news-blog/tutors/177-an-increase-in-confidence.

Wolf, A., \& Jenkins, A. (2014). Do 'learners' always learn? The impact of workplace adult literacy courses on participants’ literacy skills. British Education Research Journal, 40(4), 585-609. doi: 10.1002/berj.3110.

Yildiz, A. (2011). Could one become literate in literacy courses? Educational Sciences: Theory \& Practice, 1(1), 415-421. 


\section{APPENDIX A: LEARNER STORIES}

\section{$N E W S \& B L O G$}

\begin{tabular}{|c|c|c|c|c|c|}
\hline Learner Stories & Date Published & Primary Topic & Secondary Topic & Tertiary Topic & Author \\
\hline $\begin{array}{l}\text { From Learning to Volunteering: } \\
\text { Sonia's Story }\end{array}$ & $\begin{array}{r}\text { December } 23, \\
2020\end{array}$ & Immigrant & $\begin{array}{l}\text { English language } \\
\text { learning }\end{array}$ & & Carrie Roper, IET Coordinator \\
\hline $\begin{array}{l}\text { Now I Can Dream in English: Eliana's } \\
\text { Story }\end{array}$ & April 13, 2020 & Immigrant & $\begin{array}{l}\text { English language } \\
\text { learning }\end{array}$ & & Jennifer Summers, Program Coordinator \\
\hline $\begin{array}{l}\text { Now I Can Serve My Community: } \\
\text { Maria's Story }\end{array}$ & March 30, 2020 & Immigrant & $\begin{array}{l}\text { English language } \\
\text { learning }\end{array}$ & & Jennifer Summers, Program Coordinator \\
\hline $\begin{array}{l}\text { Larry and Coromoto: New Language, } \\
\text { New City }\end{array}$ & August 7, 2019 & Immigrant & $\begin{array}{l}\text { English language } \\
\text { learning }\end{array}$ & & Jennifer Summers, Program Coordinator \\
\hline $\begin{array}{l}\text { Learning English for her Family: } \\
\text { Monika's Story }\end{array}$ & March 20, 2019 & Immigrant & $\begin{array}{l}\text { English language } \\
\text { learning }\end{array}$ & & Carrie Roper, Literacy Coordinator \\
\hline Hearing the Sounds of English & July 11,2016 & Immigrant & $\begin{array}{l}\text { English language } \\
\text { learning }\end{array}$ & & Unspecified \\
\hline $\begin{array}{l}\text { Learner Profile: The de Leon-Lopez } \\
\text { Family }\end{array}$ & July 17,2016 & Immigrant & $\begin{array}{l}\text { English language } \\
\text { learning }\end{array}$ & & Unspecified \\
\hline Staying "Alert": Ludi Trevino, Learner & October 11,2016 & Immigrant & $\begin{array}{l}\text { English language } \\
\text { learning }\end{array}$ & & Unspecified \\
\hline $\begin{array}{l}\text { In her own words: Doroty Delli } \\
\text { Ficorelli }\end{array}$ & $\begin{array}{r}\text { December } 12, \\
2017\end{array}$ & Immigrant & $\begin{array}{l}\text { English language } \\
\text { learning }\end{array}$ & & Doroty Delli Ficorelli, Learner \\
\hline Life in Michigan & June 14, 2017 & Immigrant & $\begin{array}{l}\text { English language } \\
\text { learning }\end{array}$ & & Jisun Lee, Learner \\
\hline $\begin{array}{l}\text { Now I Can Help My Children with } \\
\text { homework: Gonzalo's Story }\end{array}$ & $\begin{array}{r}\text { December 19, } \\
2019\end{array}$ & Immigrant & $\begin{array}{l}\text { English language } \\
\text { learning }\end{array}$ & & Gonzalo Gonzalez, Learner \\
\hline $\begin{array}{l}\text { In her own words: Yuwiska Alcantara- } \\
\text { Tagliati }\end{array}$ & $\begin{array}{r}\text { November } 28, \\
2017\end{array}$ & Immigrant & $\begin{array}{l}\text { English language } \\
\text { learning }\end{array}$ & & $\begin{array}{l}\text { Yuwiska Alcantara-Tagliati, Learner turned } \\
\text { staff }\end{array}$ \\
\hline In the Right Place: Alejandra, Learner & May 10, 2016 & Immigrant & $\begin{array}{l}\text { English language } \\
\text { learning }\end{array}$ & & Alejandra, Learner \\
\hline $\begin{array}{l}\text { In My Own Words: Rebekah, May } \\
2014\end{array}$ & July 17,2016 & Immigrant & $\begin{array}{l}\text { English language } \\
\text { learning }\end{array}$ & & Rebekah, Learner \\
\hline
\end{tabular}




\begin{tabular}{|c|c|c|c|c|c|}
\hline $\begin{array}{l}\text { In My Own Words: Veronica } \\
\text { Gonzalez, Learner }\end{array}$ & July 17,2016 & Immigrant & $\begin{array}{l}\text { English language } \\
\text { learning }\end{array}$ & & Veronica Gonzalez, Learner \\
\hline In My Own Words: Norielit & July 17, 2016 & Immigrant & $\begin{array}{l}\text { English language } \\
\text { learning }\end{array}$ & & Norielit, Learner \\
\hline $\begin{array}{l}\text { Minh's Story: Accent Modification for } \\
\text { Career Success }\end{array}$ & June 17, 2018 & Immigrant & $\begin{array}{l}\text { English language } \\
\text { learning }\end{array}$ & $\begin{array}{l}\text { Work } \\
\text { Opportunity }\end{array}$ & $\begin{array}{l}\text { Chad Patton, Director of the Customized } \\
\text { Workplace English Program }\end{array}$ \\
\hline $\begin{array}{l}\text { Anna's Story: Don't Be Afraid to Ask } \\
\text { Questions }\end{array}$ & June 29, 2018 & Immigrant & $\begin{array}{l}\text { English language } \\
\text { learning }\end{array}$ & $\begin{array}{l}\text { Work } \\
\text { Opportunity }\end{array}$ & $\begin{array}{l}\text { Jennifer Summers, Customized Workplace } \\
\text { English Coordinator }\end{array}$ \\
\hline $\begin{array}{l}\text { Shola's Story: Finding Opportunities } \\
\text { for Further Education }\end{array}$ & July 29,2020 & Immigrant & $\begin{array}{l}\text { Work \& Education } \\
\text { Opportunity }\end{array}$ & & Carrie Roper, IET Coordinator \\
\hline $\begin{array}{l}\text { Well-Prepared: Ahmed's Story } \\
\text { [Continued] }\end{array}$ & $\begin{array}{r}\text { December } 18, \\
2019\end{array}$ & Immigrant & Work Opportunity & & Jennifer Summers, Program Coordinator \\
\hline $\begin{array}{l}\text { Now I Can Communicate Better at } \\
\text { Work }\end{array}$ & $\begin{array}{r}\text { November 22, } \\
2019\end{array}$ & Immigrant & Work Opportunity & & Rebekah Ewing, Literacy Coordinator \\
\hline A New Opportunity: Olivia's Story & June 9, 2020 & Immigrant & Work Opportunity & & $\begin{array}{l}\text { Chad Patton, Customized Workplace } \\
\text { English Director }\end{array}$ \\
\hline A True Handyman: Antonio's Story & May 21, 2020 & Immigrant & Work Opportunity & & $\begin{array}{l}\text { Chad Patton, Customized Workplace } \\
\text { English Director }\end{array}$ \\
\hline $\begin{array}{l}\text { Lili and Omary: Literacy Is A Family } \\
\text { Affair }\end{array}$ & $\begin{array}{r}\text { December } 17, \\
2018\end{array}$ & Immigrant & Work Opportunity & & Unspecified \\
\hline A Second Chance at a Dream & October 12,2018 & Immigrant & Work Opportunity & & Carrie Roper, Literacy Coordinator \\
\hline $\begin{array}{l}\text { Now I Can Open a Restaurant: Fatos \& } \\
\text { Apo's Story }\end{array}$ & August 12, 2019 & Immigrant & Work Opportunity & $\begin{array}{l}\text { English } \\
\text { language } \\
\text { learning }\end{array}$ & Unspecified \\
\hline The Reader: My Name is Franciel & July 18,2018 & Immigrant & Family & & Franciel Palencia, Learner \\
\hline Learner Writing: My Three Wishes & July 17, 2019 & Immigrant & & & Salvador Geron, Learner \\
\hline Returning Home & October 2, 2017 & Immigrant & & & Unspecified \\
\hline $\begin{array}{l}\text { The Reader: The Green Belt } \\
\text { Movement }\end{array}$ & $\begin{array}{r}\text { December 21, } \\
2017\end{array}$ & Immigrant & & & Rebecca Thak, Learner \\
\hline $\begin{array}{l}\text { In My Own Words: Sandra Martinez- } \\
\text { Cruz, Learner }\end{array}$ & July 17,2016 & Immigrant & & & Sandra Martinez-Cruz, Learner \\
\hline $\begin{array}{l}\text { My Achievements and My Goals in the } \\
\text { USA }\end{array}$ & February 27, 2018 & Immigrant & & & Maria Bacerra, Learner \\
\hline
\end{tabular}




\begin{tabular}{|c|c|c|c|c|}
\hline $\begin{array}{l}\text { Three Major Goals: Silva Guzman, } \\
\text { Learner }\end{array}$ & May 17, 2016 & Immigrant & & Silva Guzman, Learner \\
\hline Banza's Story & March 14, 2018 & Immigrant & & $\begin{array}{l}\text { Chad Patton, Director of Customized } \\
\text { Workplace English }\end{array}$ \\
\hline Chandra's Story & June 30,2017 & Immigrant & Refugee & $\begin{array}{l}\text { Jamie Lesman, AmeriCorps Family } \\
\text { Literacy Tutor }\end{array}$ \\
\hline $\begin{array}{l}\text { Zina's Story: A journey from Iraq to } \\
\text { Sweden to Grand Rapids }\end{array}$ & February 6, 2017 & Immigrant & Refugee & $\begin{array}{l}\text { Chad Patton, Director of the Customized } \\
\text { Workplace English Program }\end{array}$ \\
\hline $\begin{array}{l}\text { Ahmed: Being As Prepared As } \\
\text { Possible }\end{array}$ & January 20, 2017 & Immigrant & Refugee & Katherine Payne, a Literacy Coordinator \\
\hline Now I Can: Access More Resources & $\begin{array}{r}\text { November } 21, \\
2019\end{array}$ & $\begin{array}{l}\text { English } \\
\text { language } \\
\text { learning }\end{array}$ & Work Opportunity & Carrie Roper, IET Coordinator \\
\hline $\begin{array}{l}\text { Baldo's Story: Learning English at } 5 \\
\text { AM }\end{array}$ & May 23, 2018 & $\begin{array}{l}\text { English } \\
\text { language } \\
\text { learning }\end{array}$ & & $\begin{array}{l}\text { Carrie Roper, Literacy Coordinator and } \\
\text { Kent Companies' Instructor }\end{array}$ \\
\hline $\begin{array}{l}\text { Now I Can Vote in a Presidential } \\
\text { Election: Maria's Story }\end{array}$ & October 6, 2020 & $\begin{array}{l}\text { Citizenship } \\
\text { Acquisition }\end{array}$ & Civic Engagement & Jennifer Summers, Program Coordinator \\
\hline $\begin{array}{l}\text { Preparing for Citizenship during a } \\
\text { Pandemic }\end{array}$ & July 29,2020 & $\begin{array}{l}\text { Virtual } \\
\text { Learning }\end{array}$ & & Carrie Roper, IET Coordinator \\
\hline $\begin{array}{l}\text { Now I Can Practice Phlebotomy: Zina's } \\
\text { Story [Continued] }\end{array}$ & November 4, 2019 & $\begin{array}{l}\text { Work } \\
\text { Opportunity }\end{array}$ & & $\begin{array}{l}\text { Chad Patton, Customized Workplace } \\
\text { English Director }\end{array}$ \\
\hline $\begin{array}{l}\text { Reading Robin Hood: Mario Vinson, } \\
\text { Learner }\end{array}$ & October 11,2016 & $\begin{array}{l}\text { Adult } \\
\text { education }\end{array}$ & Learning disability & Unspecified \\
\hline $\begin{array}{l}\text { Improving Our Family's Legacy } \\
\text { Debra's Story }\end{array}$ & March 24, 2020 & $\begin{array}{l}\text { Adult } \\
\text { education }\end{array}$ & Family & $\begin{array}{l}\text { Chad Patton, Customized Workplace } \\
\text { English Director }\end{array}$ \\
\hline Learner Profile: Jerry, November 2014 & July 17,2016 & $\begin{array}{l}\text { Adult } \\
\text { education }\end{array}$ & & Chris, Literacy Coordinator \\
\hline Beacon Street & June 2, 2016 & $\begin{array}{l}\text { Adult } \\
\text { education }\end{array}$ & & Christy Dam, class instructor \\
\hline $\begin{array}{l}\text { Now I Can Give Back to My } \\
\text { Community: Charles's Story }\end{array}$ & September 6, 2019 & $\begin{array}{l}\text { Adult } \\
\text { education }\end{array}$ & & $\begin{array}{l}\text { Emilio Nieto, Recruitment and Retention } \\
\text { Specialist and Class Instructor }\end{array}$ \\
\hline $\begin{array}{l}\text { In My Own Words: Charla Peterson, } \\
\text { Learner }\end{array}$ & July 17,2016 & $\begin{array}{l}\text { Adult } \\
\text { education }\end{array}$ & & Charla Peterson, Learner \\
\hline
\end{tabular}


Gaining Confidence Through the

Literacy Center of West Michigan

Learner Writing: The Garden

The Reader: Vacation
Adult

January 11, 2017 education April 25, 2019 Gardening

December 21 2017 Work
Quatina Michael, Learner

Olivia Montero, Learner 
APPENDIX B: ADVOCATE SPOTLIGHTS

NEWS \& BLOG

\begin{tabular}{|c|c|c|c|c|c|}
\hline Advocate Spotlights & Date & Primary Topic & $\begin{array}{l}\text { Secondary } \\
\text { Topic }\end{array}$ & $\begin{array}{l}\text { Tertiary } \\
\text { Topic }\end{array}$ & Author \\
\hline $\begin{array}{l}\text { About Adult Tutoring Program Director } \\
\text { Yilin Wendland-Liu }\end{array}$ & $\begin{array}{r}\text { January } 11, \\
2021\end{array}$ & Staff profile & & & Unspecified \\
\hline $\begin{array}{l}\text { About Finance Director Laurie Zarzecki } \\
\text { Emelander }\end{array}$ & $\begin{array}{r}\text { January 4, } \\
2021\end{array}$ & Staff profile & & & Unspecified \\
\hline $\begin{array}{l}\text { About Community Literacy Initiative } \\
\text { Director Mike Nassar }\end{array}$ & $\begin{array}{r}\text { December } \\
21,2020\end{array}$ & Staff profile & & & Mike Nassar \\
\hline $\begin{array}{l}\text { About Development Director Libby } \\
\text { Wahlstrom }\end{array}$ & $\begin{array}{r}\text { December } 7, \\
2020\end{array}$ & Staff profile & & & Unspecified \\
\hline $\begin{array}{l}\text { About Executive Assistant \& Office } \\
\text { Manager Dierdre Deering }\end{array}$ & $\begin{array}{r}\text { November } \\
23,2020\end{array}$ & Staff profile & & & Unspecified \\
\hline $\begin{array}{l}\text { About Family Literacy Instructor Megan } \\
\text { Bowers }\end{array}$ & $\begin{array}{r}\text { November } \\
16,2020\end{array}$ & Staff profile & & & Megan Bowers \\
\hline $\begin{array}{l}\text { About Customized Workplace English } \\
\text { program Coordinator Jennifer Summers }\end{array}$ & $\begin{array}{r}\text { November } 9, \\
2020\end{array}$ & Staff profile & & & Unspecified \\
\hline $\begin{array}{l}\text { About Integrated Education \& Training } \\
\text { Coordinator/English Instructor Carrie } \\
\text { Roper }\end{array}$ & $\begin{array}{r}\text { November } 2 \text {, } \\
2020\end{array}$ & Staff profile & & & Carrie Roper \\
\hline $\begin{array}{l}\text { About Customized Workplace English } \\
\text { Instructor Maureen Birnie }\end{array}$ & $\begin{array}{r}\text { October 26, } \\
2020\end{array}$ & Staff profile & & & Maureen Birnie \\
\hline $\begin{array}{l}\text { About Family Literacy Instructor Bree } \\
\text { Straayer }\end{array}$ & $\begin{array}{r}\text { October 19, } \\
2020\end{array}$ & Staff profile & & & Bree Staayer \\
\hline $\begin{array}{l}\text { About Customized Workplace English } \\
\text { Program Director Chad Patton }\end{array}$ & $\begin{array}{r}\text { October } 12, \\
2020\end{array}$ & Staff profile & & & Unspecified \\
\hline About English Instructor Alyssa Nora & $\begin{array}{r}\text { October } 5, \\
2020\end{array}$ & Staff profile & & & Alyssa Nora \\
\hline $\begin{array}{l}\text { Q \& A with AmeriCorps Instructor Kari } \\
\text { Sovereign }\end{array}$ & $\begin{array}{r}\text { August 20, } \\
2018\end{array}$ & Staff profile & & & Kari Sovereign interviewed by Libby Wahlstrom \\
\hline
\end{tabular}




\begin{tabular}{|c|c|c|c|}
\hline $\begin{array}{l}\text { Q \& A with AmeriCorps Learner Support } \\
\text { Advocate }\end{array}$ & July 13,2017 & Staff profile & Interview with Anna Linder, AmeriCorps member \\
\hline $\begin{array}{l}\text { Q \& A with AmeriCorps Member Leandra } \\
\text { Pogson }\end{array}$ & July 17,2018 & Staff profile & Leandra Pogson Interviewed by Libby Wahlstrom \\
\hline $\begin{array}{l}25 \text { Years of the Literacy Center: An } \\
\text { Interview with Nancy }\end{array}$ & June 8,2015 & Staff profile & $\begin{array}{l}\text { Program Assistant Nancy VanIngen interviewed } \\
\text { by Katy Payne }\end{array}$ \\
\hline $\begin{array}{l}\text { Anna's Story: Big Improvements in Small } \\
\text { Conversations }\end{array}$ & $\begin{array}{r}\text { March 8, } \\
2020\end{array}$ & Staff reflections & AmeriCorps team member Anna Leo \\
\hline A Lesson in Traditions & June 4, 2018 & Staff reflections & Kari Sovereign, AmeriCorps member \\
\hline Making a Lasting Impact & $\begin{array}{r}\text { March 15, } \\
2018\end{array}$ & Staff reflections & Navi Gill, AmeriCorps member \\
\hline Kiri's Story: Building Trust & $\begin{array}{r}\text { February } 10, \\
2017\end{array}$ & Staff reflections & Kiri DeYoung, AmeriCorps member \\
\hline Preston's Story & $\begin{array}{r}\text { January } 18, \\
2017\end{array}$ & Staff reflections & Preston Wyckoff, AmeriCorps member \\
\hline More than Mole Sauce & July 18, 2016 & Staff reflections & Paloma Deerfield, AmeriCorps member \\
\hline A Place Where Everyone is Welcomed & $\begin{array}{r}\text { June } 23, \\
2020\end{array}$ & Volunteer profile & Interview w/ Johanna Schulte \\
\hline Champion of Literacy: Loy Adamy & $\begin{array}{r}\text { March 27, } \\
2017\end{array}$ & Volunteer profile & Unspecified \\
\hline Investing in Her Community & $\begin{array}{r}\text { April 28, } \\
2017\end{array}$ & Volunteer profile & Claira Freeman, AmeriCorps member \\
\hline Volunteer of the Year: Denise Joseph & $\begin{array}{r}\text { April 25, } \\
2017\end{array}$ & Volunteer profile & Unspecified \\
\hline $\begin{array}{l}\text { Putting Kids Out of the Interpretation } \\
\text { Business }\end{array}$ & $\begin{array}{r}\text { March 27, } \\
2020\end{array}$ & $\begin{array}{l}\text { Board member } \\
\text { profile }\end{array}$ & $\begin{array}{l}\text { Omar Cuevas, Vice President for Sales and } \\
\text { Marketing at the Grand Rapids Chamber and } \\
\text { Literacy Center Board Member }\end{array}$ \\
\hline Micki Benz, Compelled by the Mission & $\begin{array}{r}\text { November } \\
12,2020\end{array}$ & $\begin{array}{l}\text { Board member } \\
\text { profile }\end{array}$ & Unspecified \\
\hline A Friendship Story: Erica and Laurie & June 9, 2017 & Learner and Staff & $\begin{array}{l}\text { Erica Gonzalez, Learner \& Laurie Zaraecki } \\
\text { Emelander, Tutor }\end{array}$ \\
\hline
\end{tabular}




\begin{tabular}{|c|c|c|}
\hline GED Prep Among Coworkers & $\begin{array}{l}\text { April 24, } \\
2017 \text { Learner and Staff }\end{array}$ & Unspecified \\
\hline Tutor Highlight: Alice Apol & $\begin{aligned} & \text { November } \text { Volunteer } \\
& 20,2015 \text { reflections }\end{aligned}$ & Unspecified \& Alice Apol Excerpts \\
\hline Far Beyond Workbooks & $\begin{array}{r}\text { April 27, } \\
2017 \text { Profile }\end{array}$ & Unspecified \\
\hline Tutor Resources: The Activist Series & \begin{tabular}{r|r} 
March 14, Teaching \\
2017 & Materials
\end{tabular} & Brad Hieftje, AmeriCorps member \\
\hline Linda Alkire & $\begin{array}{r}\text { January 17, } \\
2017 \text { In Memory }\end{array}$ & Unspecified \\
\hline $\begin{array}{l}\text { Mr. John C. Kennedy to be honored as the } \\
\text { Fifth Third Bank Champion of Literacy }\end{array}$ & $\begin{array}{r}\text { March 10, } \\
2016 \text { Advocate }\end{array}$ & Unspecified \\
\hline
\end{tabular}




\section{APPENDIX C: TUTORS}

\section{$N E W S \& B L O G$}

\begin{tabular}{|c|c|c|c|c|c|}
\hline Tutors & Date & Primary Topic & $\begin{array}{l}\text { Secondary } \\
\text { Topic }\end{array}$ & $\begin{array}{l}\text { Tertiary } \\
\text { Topic }\end{array}$ & Author \\
\hline An Easy Decision & April 17, 2020 & Tutor Profile & & & Interview with Lorenzo Gutierrez, tutor \\
\hline Tutor Spotlight: Marielena Huerta & June 12, 2019 & Tutor Profile & & & $\begin{array}{l}\text { Marielena Huerta, Interviewed by Carrie Roper, } \\
\text { Literacy Coordinator }\end{array}$ \\
\hline $\begin{array}{l}\text { Tutor Spotlight: Emmalee } \\
\text { Anderson }\end{array}$ & May 16, 2019 & Tutor Profile & & & $\begin{array}{l}\text { Emmalee Anderson Interviewed by Thomas Rodgers, } \\
\text { Family Literacy Coordinator }\end{array}$ \\
\hline $\begin{array}{l}\text { Staff Tutor Spotlight: Laurie } \\
\text { Celebrates } 25 \text { Years }\end{array}$ & April 16, 2019 & Tutor Profile & & & $\begin{array}{l}\text { Laurie Zarzecki Emelander, Interviewed by Katherine } \\
\text { Payne, Literacy Coordinator }\end{array}$ \\
\hline $\begin{array}{l}\text { Tutor Spotlight: Connecting on a } \\
\text { Personal Level }\end{array}$ & March 28, 2019 & Tutor Profile & & & $\begin{array}{l}\text { Amanda VanLente, Interviewed by Family Literacy } \\
\text { Coordinator Thomas Rodgers }\end{array}$ \\
\hline $\begin{array}{l}\text { Tutor Spotlight } \mid \text { Legacy of } \\
\text { Tutoring }\end{array}$ & March 1, 2019 & Tutor Profile & & & Jean Buys, Interviewed by Queyonna Hunt \\
\hline $\begin{array}{l}\text { Meaningful Exchange: Christopher } \\
\text { and Saw }\end{array}$ & January 18, 2019 & Tutor profile & & & Carrie Roper, Literacy Coordinator \\
\hline $\begin{array}{l}\text { Tutor Spotlight } \mid \text { Tale of } \\
\text { Perseverance }\end{array}$ & December 18, 2018 & Tutor profile & & & Anthony Hanline, Interviewed by Katherine Payne \\
\hline $\begin{array}{l}\text { Making Connections: Diedre and } \\
\text { Malvin }\end{array}$ & October 30,2018 & Tutor profile & & & Diedre Deering, Interviewed by Queyonna Hunt \\
\hline $\begin{array}{l}\text { Resourceful and Persistent: Justin } \\
\text { \& Kalista }\end{array}$ & August 29, 2018 & Tutor profile & & & Kalista Castine, Interviewed by Carrie Roper \\
\hline $\begin{array}{l}\text { Learning Together: Paul and } \\
\text { Livingstone }\end{array}$ & September 25,2018 & Tutor profile & & & Thomas Rodgers \\
\hline July's Featured Tutor Spotlight & July 19,2018 & Tutor profile & & & Steve Loar, Interviewed by Katherine Payne \\
\hline May's Featured Tutor Spotlight & May 22, 2018 & Tutor profile & & & Ariel DuVal Zinn, Interviewed by Queyonna Hunt \\
\hline An Increase in Confidence & March 16, 2018 & Tutor profile & & & Phil Wittry, Tutor \\
\hline
\end{tabular}




\begin{tabular}{|c|c|c|c|c|}
\hline April's Featured Tutor Spotlight & April 19, 2018 & Tutor profile & & $\begin{array}{l}\text { Intro by Katherine Payne, Literacy Coordinator. Kelly } \\
\text { Perutelli Tutor }\end{array}$ \\
\hline $\begin{array}{l}\text { My Experience as an AmeriCorps } \\
\text { Tutor }\end{array}$ & January 29, 2018 & Tutor profile & & Miranda Buckwald \\
\hline My Experience as a Tutor & February 19, 2018 & Tutor profile & & Anna Roseboro, Tutor \\
\hline $\begin{array}{l}\text { Cheri Stanard, Volunteer of the } \\
\text { Year Recipient }\end{array}$ & April 20, 2018 & Tutor profile & $\begin{array}{l}\text { Award } \\
\text { recipient }\end{array}$ & Unspecified \\
\hline $\begin{array}{l}\text { Strategies for Adult Literacy and } \\
\text { ESL Tutors }\end{array}$ & February 15, 2019 & Teaching materials & & Carrie Roper, Literacy Coordinator \\
\hline $\begin{array}{l}\text { Supplementary Material: It's a } \\
\text { Matter of Fact }\end{array}$ & April 12, 2019 & Teaching materials & & Queyonna Hunt, Literacy Coordinator \\
\hline $\begin{array}{l}\text { A-Z Textbook Series: VENTURE } \\
\text { into Learning! }\end{array}$ & March 8, 2019 & Teaching materials & & $\begin{array}{l}\text { Thomas Rodgers (Family Literacy Coordinator) and } \\
\text { Queyonna Hunt (Literacy Coordinator) }\end{array}$ \\
\hline $\begin{array}{l}\text { Listening Literacy: Using Classic } \\
\text { Short Stories }\end{array}$ & January 8, 2019 & Teaching materials & & Katherine Payne, Literacy Coordinator \\
\hline $\begin{array}{l}\text { A-Z Textbook Series: Listen \& } \\
\text { Level Up }\end{array}$ & December 5, 2018 & Teaching materials & & Queyonna Hunt, Literacy Coordinator \\
\hline $\begin{array}{l}\text { Weaving It Together: A Reference } \\
\text { Material Spotlight }\end{array}$ & November 27, 2018 & Teaching materials & & Thomas Rogers \\
\hline $\begin{array}{l}\text { October's Featured Material: A } \\
\text { Phrasal Verb Affair }\end{array}$ & October 25,2018 & Teaching materials & & Carrie Roper, Literacy Coordinator \\
\hline $\begin{array}{l}\text { Accessible and Relatable Grammar } \\
\text { Instruction }\end{array}$ & September 12, 2018 & Teaching materials & & Katherine Payne, Literacy Coordinator \\
\hline $\begin{array}{l}\text { August's Reference Material } \\
\text { Spotlight }\end{array}$ & August 6, 2018 & Teaching materials & & Queyonna Hunt, Literacy Coordinator \\
\hline $\begin{array}{l}\text { July's Featured Supplementary } \\
\text { Material }\end{array}$ & July 10,2018 & Teaching materials & & Thomas Rodgers \\
\hline $\begin{array}{l}\text { June's Featured A-Z Textbook } \\
\text { Grammar Wise }\end{array}$ & June 22, 2018 & Teaching materials & & Miranda Buckwald, AmeriCorps Family Literacy Tutor \\
\hline June's Supplemental Material & June 11, 2018 & Teaching materials & & Carrie Roper \\
\hline May's A-Z Textbook Series & May 31, 2018 & Teaching materials & & Katherine Payne \\
\hline
\end{tabular}




\begin{tabular}{|c|c|c|c|c|}
\hline May's Reference Material & May 10, 2018 & Teaching materials & & Miranda Buckwald \\
\hline $\begin{array}{l}\text { Supplementary for May | From } \\
\text { Home to School }\end{array}$ & May 7, 2018 & Teaching materials & & Thomas Rodgers \\
\hline Featured A-Z Textbook for April & April 27, 2018 & Teaching materials & & Carrie Roper \\
\hline $\begin{array}{l}\text { Featured Tutor Reference Material } \\
\text { for April }\end{array}$ & April 6, 2018 & Teaching materials & & Queyonna Hunt \\
\hline $\begin{array}{l}\text { Featured Supplementary Reading } \\
\text { for April }\end{array}$ & March 30, 2018 & Teaching materials & & Miranda Buckwald \\
\hline Featured A-Z Textbook for March & March 29, 2018 & Teaching materials & & Tom Rodgers \\
\hline $\begin{array}{l}\text { Featured Reference Material for } \\
\text { March }\end{array}$ & March 9, 2018 & Teaching materials & & Katherine Payne \\
\hline Featured Textbook for March & March 2, 2018 & Teaching materials & Citizenship & Miranda Buckwald \\
\hline $\begin{array}{l}\text { Featured Supplementary Reading } \\
\text { for February }\end{array}$ & February 27,2018 & Teaching materials & & Queyonna Hunt \\
\hline $\begin{array}{l}\text { Featured Reference Material for } \\
\text { February }\end{array}$ & February 12,2018 & Teaching materials & & Carrie Roper \\
\hline $\begin{array}{l}\text { Featured Supplementary Reading } \\
\text { for January }\end{array}$ & February 6, 2018 & Teaching materials & & Katherine Payne \\
\hline Tutor Library Update! & January 23, 2018 & Teaching materials & & Unspecified \\
\hline New content! & January 15,2018 & $\begin{array}{l}\text { Content } \\
\text { announcement }\end{array}$ & & Unspecified \\
\hline January 18 Tutor News & January 4, 2018 & Events & & Unspecified \\
\hline
\end{tabular}




\section{APPENDIX D: COMMUNITY}

\section{$N E W S \& B L O G$}

\begin{tabular}{|c|c|c|c|c|c|}
\hline Community & Date & $\begin{array}{l}\text { Primary } \\
\text { Topic }\end{array}$ & $\begin{array}{l}\text { Secondary } \\
\text { Topic }\end{array}$ & $\begin{array}{l}\text { Tertiary } \\
\text { Topic }\end{array}$ & Author \\
\hline Summit 2020 Breakout Sessions & February 4, 2020 & Event & Issues in literacy & & Unspecified \\
\hline Summit 2018 Breakout Sessions & January 4, 2018 & Event & Issues in literacy & & Unspecified \\
\hline The Impact of Partnerships & September 11, 2020 & Event & $\begin{array}{l}\text { Partnership } \\
\text { Success }\end{array}$ & & $\begin{array}{l}\text { Libby Wahlstrom, Development Director \& } \\
\text { Cynthia Salinas, Communication Coordinator \& } \\
\text { FLP Instructor }\end{array}$ \\
\hline $\begin{array}{l}\text { Reading by third grade: our shared } \\
\text { opportunity, our shared responsibility }\end{array}$ & August 16, 2017 & Event & $\begin{array}{l}\text { Childhood } \\
\text { literacy }\end{array}$ & & $\begin{array}{l}\text { Mike Nassar, Director of Community Literacy } \\
\text { Initiative }\end{array}$ \\
\hline $\begin{array}{l}\text { Deadline Extended for Summit } \\
\text { Proposals }\end{array}$ & October 3, 2017 & Event & $\begin{array}{l}\text { Childhood } \\
\text { literacy }\end{array}$ & & $\begin{array}{l}\text { Mike Nassar, Director of Community Literacy } \\
\text { Initiative }\end{array}$ \\
\hline Spellebration 2016 & May 13, 2016 & Event & & & Unspecified \\
\hline $\begin{array}{l}\text { Literacy Celebration Promotes } \\
\text { Literacy at Home for ESL Parents }\end{array}$ & March 21, 2017 & Event & & & Unspecified \\
\hline $\begin{array}{l}\text { The Literacy Center Honored with } \\
\text { Governor's Service Award }\end{array}$ & September 6, 2019 & $\begin{array}{l}\text { Award } \\
\text { Recipient }\end{array}$ & $\begin{array}{l}\text { Family Literacy } \\
\text { Program }\end{array}$ & & Unspecified \\
\hline $\begin{array}{l}\text { John Helmholdt: Ledy Award for } \\
\text { Community Engagement Recipient }\end{array}$ & April 29, 2018 & $\begin{array}{l}\text { Award } \\
\text { Recipient }\end{array}$ & & & Unspecified \\
\hline $\begin{array}{l}\text { Champions of Literacy: Rick and Loy } \\
\text { Adamy }\end{array}$ & April 26, 2017 & $\begin{array}{l}\text { Award } \\
\text { Recipient }\end{array}$ & & & Unspecified \\
\hline $\begin{array}{l}\text { Award for Community Engagement: } \\
\text { Christina Arnold }\end{array}$ & April 20, 2017 & $\begin{array}{l}\text { Award } \\
\text { Recipient }\end{array}$ & & & Unspecified \\
\hline $\begin{array}{l}\text { Literacy Center names new Family } \\
\text { Literacy Program director }\end{array}$ & October 8, 2018 & $\begin{array}{l}\text { New staff } \\
\text { member }\end{array}$ & $\begin{array}{l}\text { Family Literacy } \\
\text { Program }\end{array}$ & & Unspecified \\
\hline $\begin{array}{l}\text { Dr. Yilin Wendland-Liu Hired as } \\
\text { Adult Tutoring Program Director }\end{array}$ & November 2, 2020 & $\begin{array}{l}\text { New staff } \\
\text { member }\end{array}$ & $\begin{array}{l}\text { Professional } \\
\text { background }\end{array}$ & & Unspecified \\
\hline Queyonna Hunt, An Introduction & February 27, 2018 & $\begin{array}{l}\text { New staff } \\
\text { member }\end{array}$ & $\begin{array}{l}\text { Professional } \\
\text { background }\end{array}$ & & $\begin{array}{l}\text { Queyonna Hunt, Literacy Coordinator of the } \\
\text { Adult Tutoring Program }\end{array}$ \\
\hline
\end{tabular}




\begin{tabular}{|c|c|c|c|c|}
\hline $\begin{array}{l}\text { Miguelina Quinones Hired as New } \\
\text { Family Literacy Program Director }\end{array}$ & August 4, 2017 & $\begin{array}{l}\text { New staff } \\
\text { member }\end{array}$ & $\begin{array}{l}\text { Professional } \\
\text { background }\end{array}$ & Unspecified \\
\hline $\begin{array}{l}\text { Early Childhood Literacy Expert } \\
\text { Provides Summit } 2020 \text { Keynote }\end{array}$ & December 9, 2019 & $\begin{array}{l}\text { Keynote } \\
\text { speaker } \\
\text { announcement }\end{array}$ & $\begin{array}{l}\text { Childhood } \\
\text { literacy }\end{array}$ & Unspecified \\
\hline $\begin{array}{l}\text { NPR's Claudio Sanchez Provides } \\
\text { Summit Keynote }\end{array}$ & December 1, 2017 & $\begin{array}{l}\text { Keynote } \\
\text { speaker } \\
\text { announcement }\end{array}$ & $\begin{array}{l}\text { Childhood } \\
\text { literacy }\end{array}$ & Unspecified \\
\hline Starting Our New Program Year & September 11,2020 & Pandemic & & Wendy Falb, Executive Director \\
\hline $\begin{array}{l}\text { Literacy Center Response to COVID- } \\
19\end{array}$ & March 13, 2020 & Pandemic & & Unspecified \\
\hline $\begin{array}{l}\text { Literacy Center Named a Finalist in } \\
\text { U.S. Department of Education } \\
\text { Challenge }\end{array}$ & January 13,2021 & $\begin{array}{l}\text { Project } \\
\text { Proposal }\end{array}$ & $\begin{array}{l}\text { Work } \\
\text { Opportunity }\end{array}$ & Unspecified \\
\hline $\begin{array}{l}\text { Irwin Seating Company: Creative } \\
\text { Solutions in a Tight Labor Market }\end{array}$ & April 30, 2018 & $\begin{array}{l}\text { Work } \\
\text { Opportunity }\end{array}$ & Partnership & Unspecified \\
\hline $\begin{array}{l}\text { Mark Peters: The Hidden Issue of } \\
\text { Low Literacy }\end{array}$ & April 4, 2018 & $\begin{array}{l}\text { Issues in } \\
\text { literacy }\end{array}$ & & $\begin{array}{l}\text { Mark Peters, CEO Butterball Farms, Inc., Chair of } \\
\text { the Literacy Center's Donor Development } \\
\text { committee }\end{array}$ \\
\hline $\begin{array}{l}\text { A Remembrance of Tony Campbell, } \\
\text { Champion of Literacy Award } \\
\text { Recipient }\end{array}$ & April 19, 2018 & Obituary & Award Recipient & Fritz Crabb, Colleague of Campbell \\
\hline $\begin{array}{l}\text { A Brief History of Wine \& Words } \\
\text { Venue }\end{array}$ & October 17, 2017 & Event Venue & & Unspecified \\
\hline Learning at the TESOL Conference & April 13, 2018 & Conference & & $\begin{array}{l}\text { Jennifer Summers, Customized Workplace } \\
\text { English Program Coordinator }\end{array}$ \\
\hline $\begin{array}{l}\text { Lifelong Learning: The Latino Talent } \\
\text { Initiative }\end{array}$ & June 14, 2016 & Staff & $\begin{array}{l}\text { Professional } \\
\text { background }\end{array}$ & $\begin{array}{l}\text { Kaylee Moreno, Director of the Community } \\
\text { Literacy Initiative }\end{array}$ \\
\hline $\begin{array}{l}\text { Fiscal Year } 2015 \text { Annual Report } \\
\text { Released }\end{array}$ & March 29, 2016 & Immigrant & & Wendy Falb, Executive Director \\
\hline $\begin{array}{l}\text { Building Community at the Literacy } \\
\text { Center }\end{array}$ & June 28, 2017 & $\begin{array}{l}\text { Immigrant } \\
\text { Experience }\end{array}$ & $\begin{array}{l}\text { English language } \\
\text { learning }\end{array}$ & $\begin{array}{l}\text { Chad Patton, Director of Cutomized Workplace } \\
\text { English }\end{array}$ \\
\hline $\begin{array}{l}\text { Literacy Center Receives Grant from } \\
\text { Michigan Office of New Americans }\end{array}$ & December 6, 2016 & $\begin{array}{l}\text { Grant } \\
\text { Recipient }\end{array}$ & $\begin{array}{l}\text { Work } \\
\text { Opportunity }\end{array}$ & Unspecified \\
\hline
\end{tabular}


APPENDIX E: UNCATEGORIZED

$N E W S \& B L O G$

\begin{tabular}{|l|l|l|l|l|}
\hline Uncategorized & Date & Primary Topic & Secondary Topic & Author \\
\hline Watch Now: 2019 Tribute Video & April 23, 2019 Tribute video & Unspecified \\
\hline Watch Now: 2017 Honoree Tribute & May 24, 2017 & Tribute video & Unspecified \\
\hline Celebrating with Three Generations & July 11,2016 Graduation & AmeriCorps Volunteer Claira Freeman \\
\hline
\end{tabular}

